\title{
Cell-Type Specificity of Neuronal Excitability and Morphology in the Central Amygdala
}

\author{
Anisha P. Adke, Aleisha Khan," Hye-Sook Ahn," Jordan J. Becker, Torri D. Wilson, Spring Valdivia, \\ Yae K. Sugimura, Santiago Martinez Gonzalez, and Yarimar Carrasquillo
}

https://doi.org/10.1523/ENEURO.0402-20.2020

${ }^{1}$ National Center for Complementary and Integrative Health, National Institutes of Health, Bethesda, MD 20892

\begin{abstract}
Central amygdala $(\mathrm{CeA})$ neurons expressing protein kinase $\mathrm{C} \delta\left(\mathrm{PKC} \delta^{+}\right)$or somatostatin $\left(\mathrm{Som}^{+}\right)$differentially modulate diverse behaviors. The underlying features supporting cell-type-specific function in the CeA, however, remain unknown. Using whole-cell patch-clamp electrophysiology in acute mouse brain slices and biocytin-based neuronal reconstructions, we demonstrate that neuronal morphology and relative excitability are two distinguishing features between $\mathrm{Som}^{+}$and $\mathrm{PKC} \delta^{+}$neurons in the laterocapsular subdivision of the $\mathrm{CeA}$ (CeLC). Som ${ }^{+}$neurons, for example, are more excitable, compact, and with more complex dendritic arborizations than $\mathrm{PKC} \delta^{+}$neurons. Cell size, intrinsic membrane properties, and anatomic localization were further shown to correlate with cell-type-specific differences in excitability. Lastly, in the context of neuropathic pain, we show a shift in the excitability equilibrium between $\mathrm{PKC} \delta{ }^{+}$and $\mathrm{Som}^{+}$neurons, suggesting that imbalances in the relative output of these cells underlie maladaptive changes in behaviors. Together, our results identify fundamentally important distinguishing features of $\mathrm{PKC} \delta \delta^{+}$and $\mathrm{Som}^{+}$cells that support cell-type-specific function in the CeA.
\end{abstract}

Key words: central amygdala; intrinsic excitability; morphology; neuropathic pain; protein kinase $\mathrm{C} \delta$; somatostatin

\section{Significance Statement}

Genetically distinct neurons in the central nucleus of the amygdala $(\mathrm{CeA})$ are functionally opposed in the modulation of many behavioral outputs, including fear and pain-related behaviors. In this study, we use whole-cell patch-clamp electrophysiology in acute mouse brain slices in combination with molecular genetics and biocytin-based neuronal reconstructions to characterize protein kinase $\mathrm{C} \delta$-expressing (PKC $\left.\delta^{+}\right)$ and somatostatin-expressing $\left(\mathrm{Som}^{+}\right)$neurons in the $\mathrm{CeA}$. Our experiments revealed striking differences in both electrophysiological and morphologic properties of these two subpopulations of CeA neurons, Som ${ }^{+}$ neurons are more excitable, compact, and have more complex dendritic arborizations compared with $\mathrm{PKC} \delta{ }^{+}$neurons. These results support the notion that genetically distinct CeA neurons have differing functions and properties, advancing our understanding of the mechanisms underlying cellular and functional heterogeneity in the $\mathrm{CeA}$.

\section{Introduction}

The laterocapsular subdivision of the central nucleus $(\mathrm{CeA})$ of the amygdala (CeLC) has received increasing interest because of its widespread function in mediating innate, as well as learned, adaptive and maladaptive

Received September 18, 2020; accepted October 12, 2020; First published November 13, 2020.

The authors declare no competing financial interests. behaviors. Previous work has demonstrated, for example, that the CeLC is functionally diverse, modulating fear conditioning and aversion (Aggleton, 2000; Davis and Whalen, 2001), nociception (Zald, 2003; Neugebauer et al., 2004;

Author contributions: A.P.A. and Y.C. designed research; A.P.A., A.K., H.-S.A., J.J.B., T.D.W., S.V., Y.K.S., S.M.G., and Y.C. performed research; A.P.A., A.K., H.-S.A., J.J.B., T.D.W., S.V., Y.K.S., S.M.G., and Y.C. analyzed data; A.P.A. and Y.C. wrote the paper. 
Veinante et al., 2013), anxiety, and drug reward and relapse in rodent models (Gilpin et al., 2015; Venniro et al., 2017, 2018), to name a few. This diverse span of function is mirrored by the genetic, physiological and morphologic heterogeneity in CeA neuron subtypes (Martina et al., 1999; Schiess et al., 1999; Janak and Tye, 2015).

Two genetically identified cell types, protein kinase $\mathrm{C} \delta$ expressing $\left(\mathrm{PKC} \delta^{+}\right)$neurons and somatostatin-expressing $\left(\mathrm{Som}^{+}\right)$neurons, constitute most CeLC neurons and are largely non-overlapping ( $\mathrm{Li}$ et al., 2013; Kim et al., 2017; Wilson et al., 2019). PKC $\delta^{+}$and $\mathrm{Som}^{+}$neurons in the CeA undergo differential plasticity in the context of behavioral output and they both have critical, but distinct, functions in the modulation of CeA-dependent behaviors, including fear conditioning and pain-related behaviors. The activity of $\mathrm{PKC} \delta{ }^{+}$cells, for example, is reduced following exposure to a conditioned stimulus after fear conditioning (Haubensak et al., 2010) but increased following nerve injury (Wilson et al., 2019). In contrast, Som ${ }^{+}$cells respond to a threat stimulus by increasing their activity (Yu et al., 2016) but their excitability is decreased following nerve injury (Wilson et al., 2019). Consistent with these correlational changes in excitability, both $\mathrm{Som}^{+}$and $\mathrm{PKC} \delta{ }^{+}$ CeA neurons have been shown to differentially contribute to fear and pain-related behaviors (Haubensak et al., 2010; Li et al., 2013; Yu et al., 2016; Wilson et al., 2019). The underlying features that support cell-type-specific opposite functions of these genetically distinct $\mathrm{CeA}$ neurons, however, remain unclear.

Previous studies have demonstrated that the electrophysiological and morphologic properties of CeLC neurons are highly heterogeneous across different species (Schiess et al., 1999; Dumont et al., 2002; Chieng et al., 2006; Li and Sheets, 2018). Recent studies have further shown that CeLC neurons with different firing properties are topographically organized based on their projection targets (Li and Sheets, 2018), suggesting that heterogeneity of function within the CeLC might also be anatomically defined.

In the present study, we contributed to the growing body of knowledge about the CeLC by performing a characterization of the electrophysiological and morphologic properties of $\mathrm{PKC} \delta{ }^{+}$and $\mathrm{Som}^{+}$neurons. Our overarching hypothesis was that these two genetically distinct populations of CeLC neurons are electrophysiologically and

This work was supported by the National Center for Complementary and Integrative Health Intramural Research Program.

${ }^{*}$ A.K. and H.-S.A. contributed equally to this work.

Acknowledgements: We thank Dr. Hugo Tejeda, Dr. Mario Penzo, and Dr. Yavin Shaham for comments on this manuscript and Dr. Ted Usdin and the Systems Neuroscience Imaging Resource of the National Institute of Mental Health for making possible the morphological reconstruction and analysis of biocytin-filled cells. We also thank the National Institutes of Neurological Disorder Mouse Facility staff for their vital work in animal husbandry.

Correspondence should be addressed to Yarimar Carrasquillo at yarimar.carrasquillo@nih.gov.

https://doi.org/10.1523/ENEURO.0402-20.2020

Copyright @ 2021 Adke et al.

This is an open-access article distributed under the terms of the Creative Commons Attribution 4.0 International license, which permits unrestricted use, distribution and reproduction in any medium provided that the original work is properly attributed. morphologically different. We used whole-cell patchclamp electrophysiology in acute mouse brain slices in combination with biocytin-based morphologic reconstructions to characterize and compare the passive and active membrane properties, as well as the evoked repetitive firing responses, single action potential waveforms, and neuronal morphologies of these two subpopulations of neurons. We further evaluated whether membrane properties and excitability are dependent on the anatomic localization within the $\mathrm{CeA}$, both at the subnuclei and rostro-caudal levels.

Finally, using a mouse model of neuropathic pain, we tested whether perturbations known to alter CeLC-dependent behavioral outputs would result in a shift in the relative excitability of these two CeLC cell types. Using this cell-type-specific approach, we demonstrated that $\mathrm{PKC} \delta{ }^{+}$and $\mathrm{Som}^{+}$neurons have distinct electrophysiological and morphologic properties and that the differences in the excitability of these cells are occluded in the context of neuropathic pain. Our combined findings provide an essential foundation for understanding functional heterogeneity within the $\mathrm{CeA}$.

\section{Materials and Methods}

\section{Subjects}

All animal procedures were performed in accordance with the guidelines of the National Institutes of Health $(\mathrm{NIH})$ and were approved by the Animal Care and Use Committee of the National Institute of Neurologic Disorders and Stroke and the National Institute of Deafness and other Communication Disorders. Adult (9- to 17-week-old) male mice were used for all experiments. Prkcd-cre heterozygote male or female mice (GENSAT-founder line 011559-UCD) were obtained from the Mutant Mouse Resource and Research Center (MMRRC) at University of California at Davis, an $\mathrm{NIH}$-funded strain repository. This line was donated to the MMRRC by Dr. Nathaniel Heintz and Dr. Charles Gerfen (Gong et al., 2003, 2007). Sstcre heterozygote males (The Jackson Laboratory, founder line 018973) were obtained from The Jackson Laboratory and donated by Z. Josh Huang (Taniguchi et al., 2011; He et al., 2012). Prkcd-cre and Sst-cre mice were crossed with homozygous Ai9 (The Jackson Laboratory, founder line 007909) mice. The fidelity and penetrance of Cre in $\mathrm{PKC} \delta{ }^{+}$or Som ${ }^{+}$neurons in the CeA has been previously characterized in these mouse lines (Taniguchi et al., 2011; Wilson et al., 2019). Offspring mice were genotyped for the presence of cre-recombinase using DNA extracted from tail biopsies and PCR (Transnetyx) with the following primers: TTAATCCATATTGGCAGAACGA AAACG (forward) and CAGGCTAAGTGCCTTCTCTACA (reverse). Mice were housed in single cages or in pairs with littermates, separated by a perforated Plexiglas divider and kept in a reversed 12/12 h light/dark cycle, with lights on from 9 P.M. to 9 A.M. Food and water were provided ad libitum. Before all experiments, mice were handled as previously described for at least $5 \mathrm{~d}$ to minimize potential stress effects associated with handling (Hurst and West, 2010). While handling, mice were also administered $0.1-\mathrm{ml}$ saline intraperitoneally by the 
same experimenter that would be anesthetizing it for perfusion and acute slice preparation.

\section{Ex vivo electrophysiology}

\section{Acute slice preparation}

Mice were deeply anesthetized using 1.25\% Avertin ( $0.4 \mathrm{mg} / \mathrm{g}$ body weight) injected intraperitoneally and then transcardially perfused with ice-cold cutting solution composed of the following: $110 \mathrm{mM}$ choline chloride, 25 $\mathrm{mM} \mathrm{NaHCO}, 1.25 \mathrm{mM} \mathrm{NaH}_{2} \mathrm{PO}_{4}, 2.5 \mathrm{mM} \mathrm{KCl}, 0.5 \mathrm{mM}$ $\mathrm{CaCl}_{2}, 7.2 \mathrm{mM} \mathrm{MgCl}_{2}, 25 \mathrm{mM}$ D-glucose, $12.7 \mathrm{mM}$ L-ascorbic acid, and $3.1 \mathrm{mM}$ pyruvic acid, oxygenated with 95\%/ $5 \% \mathrm{O}_{2} / \mathrm{CO}_{2}$. The brains were rapidly extracted, placed in ice-cold cutting solution, and cut in coronal slices (250$300 \mu \mathrm{m})$ using a Leica VT1200 S vibrating blade microtome (Leica Microsystems Inc.). Slices containing the CeA were incubated at $33^{\circ} \mathrm{C}$ for 30 min in a holding chamber containing artificial CSF (ACSF) composed of the following: $125 \mathrm{mM} \mathrm{NaCl}, 2.5 \mathrm{mM} \mathrm{KCl}, 1.25 \mathrm{mM} \mathrm{NaH}_{2} \mathrm{PO}_{4}, 25 \mathrm{mM}$ $\mathrm{NaHCO}_{3}, 2 \mathrm{mM} \mathrm{CaCl}_{2}, 1 \mathrm{mM} \mathrm{MgCl}$, and $25 \mathrm{mM} \mathrm{D}$-glucose. The chambers containing the slices were then moved to room temperature, and slices recovered for at least $20 \mathrm{~min}$ before recording. During incubation and recovery, the chambers were continuously oxygenated with $95 \% / 5 \% \quad \mathrm{O}_{2} / \mathrm{CO}_{2}$. Experiments were replicated with 17 Prkcd-cre and 10 Sst-cre male mice.

\section{Whole-cell patch-clamp recordings}

The recording chamber was perfused continuously with ACSF oxygenated with $95 \% / 5 \% \quad \mathrm{O}_{2} / \mathrm{CO}_{2}(1 \mathrm{ml} / \mathrm{min})$ and all recordings were performed at $33 \pm 1^{\circ} \mathrm{C}$. A recording chamber heater and an in-line solution heater (Warner Instruments) were used to control and monitor the bath temperature throughout the experiment. Recording pipettes (3- to 5-M $\Omega$ resistance) were filled with internal solution composed of the following: $120 \mathrm{~mm}$ potassium methyl sulfate, $20 \mathrm{~mm} \mathrm{KCl,} 10 \mathrm{~mm}$ HEPES, $0.2 \mathrm{~mm}$ EGTA, $8 \mathrm{~mm}$ $\mathrm{NaCl}_{2}, 4 \mathrm{~mm}$ Mg-ATP, $0.3 \mathrm{~mm}$ Tris-GTP, and $14 \mathrm{~mm}$ phosphocreatine with $\mathrm{pH} 7.3$ using $5 \mathrm{M} \mathrm{KOH}$ and an osmolarity of $\sim 300 \mathrm{mosmol}^{-1}$. Biocytin $(3 \mathrm{mg} / \mathrm{ml})$ was added to the internal solution of some recordings and sonicated in icecold water for $20 \mathrm{~min}$. Whole-cell current-clamp recordings were obtained from tdTomato-expressing CeLC neurons in the right hemisphere. Cells were visually identified using an upright microscope (Nikon Eclipse FN1) equipped with differential interference contrast optics with infrared illumination and epifluorescence. Recording electrodes were visually positioned in the CeLC, guided by the distinctive fiber bundles and anatomic landmarks delineating its structure (Fig. 1B). Recordings were controlled using the Multiclamp 700B patch-clamp amplifier interfaced with a Digidata 1500 acquisition system and pCLAMP 10.7 software (Molecular Devices) on a Dell computer. Before forming a membrane-pipette seal, pipette tip potentials were zeroed and pipette capacitances and series resistances (not exceeding $20 \mathrm{M} \Omega$ ) were monitored throughout the recordings. Whole-cell capacitance was measured in voltage-clamp configuration, with the cell held at $-70 \mathrm{mV}$ then subjected to a $\pm 10-\mathrm{mV}$ current change of $25-\mathrm{ms}$ duration. Spontaneously active cells were recorded gap-free in current-clamp configuration for $10 \mathrm{~s}$. Brief $(5 \mathrm{~ms})$ and prolonged $(500 \mathrm{~ms})$ depolarizing current of various amplitudes were injected from resting membrane potential to cells that were silent at rest, to elicit single and repetitive action potential firing, respectively. Liquid junction potentials were not corrected during recordings. All recordings were acquired at $100 \mathrm{kHz}$ and filtered at $10 \mathrm{kHz}$.

\section{Data analysis}

The sample sizes used in each experiment were based on the standards set forth by the field. At least 10 mice were used as biological replicates for all electrophysiology experiments, rather than repeating identical tests on a single sample to generate technical replicates. Cells were allocated into experimental groups based on genotype $\left(\mathrm{PKC} \delta^{+}\right.$or $\left.\mathrm{Som}^{+}\right)$. Electrophysiological data were analyzed using ClampFit 10.7 (Molecular Devices), Microsoft Excel, Mini Analysis (v. 6.0.7, Synaptosoft), and Prism (version 8, GraphPad Software Inc.). Data obtained from naive animals and animals that received a sciatic nerve sham surgery were pooled and used to analyze baseline properties as no significant differences were seen between these conditions.

Single action potential properties were measured from the action potentials generated in response to a 5-ms depolarizing current injection. Current threshold for action potential generation $\left(I_{\text {threshold }}\right)$ was defined as the minimum current injection required to elicit an action potential. Voltage threshold $\left(\mathrm{V}_{\text {threshold }}\right)$ was calculated from the third derivative of the variation in membrane potential as a function of time during the rise of the action potential using the Mini Analysis software. Differentiated traces were digitally Gaussian filtered and smoothed by 30-100 points. Action potential duration (APD) was measured at $100 \%$ repolarization to $V_{\text {threshold. }}$ Rise time was defined as the time required for the membrane potential to reach peak voltage from $V_{\text {threshold }}$ and decay was defined as the time required for the membrane potential to repolarize from $90 \%$ of its peak to $V_{\text {threshold. }}$. Phase plots of single action potentials were generated by plotting the first derivative of the variation in membrane potential as a function of the membrane potential. Action potential afterhyperpolarization (AHP) was calculated from the phase plots of single action potentials and was defined as the voltage at which the first derivative of the variation in membrane potential during the repolarizing phase of the action potential reached zero or switched polarity.

Input resistance $\left(R_{\text {in }}\right)$ was calculated using the average change in membrane potential in response to a $\pm 20-p A$ current injection of 500-ms duration. Rheobase was defined as the minimum current required to induce an action potential in response to a 500-ms depolarizing current injection for both late-firing and regular-spiking neurons. Latency to fire for $\mathrm{PKC} \delta{ }^{+}$versus Som ${ }^{+}$cells comparisons was calculated at $2 \times$ rheobase and was defined as the time between current injection onset to action potential threshold. Voltage sag was calculated from the difference between the steady state and peak voltage responses to a 500-ms 500-pA hyperpolarizing current injection. Accommodation of interspike interval 
A

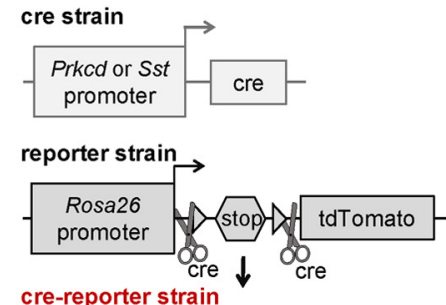

cre-reporter strain

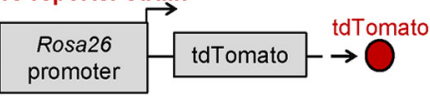

B
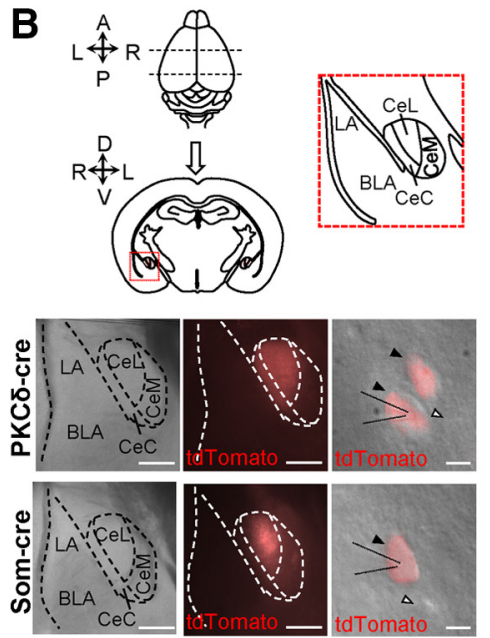

C
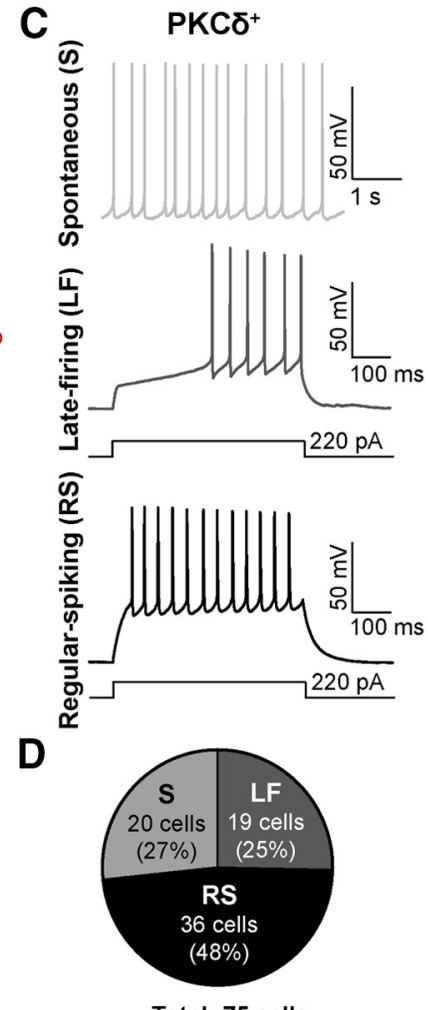

Total: 75 cells
Som $^{+}$
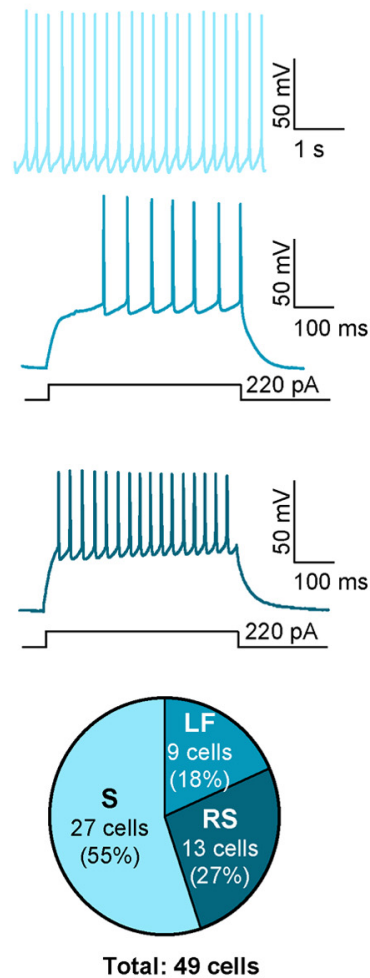

Figure 1. Firing phenotypes are heterogenous in $\mathrm{PKC} \delta^{+}$and Som ${ }^{+}$CeLC neurons. $\boldsymbol{A}$, Strategy for labeling genetically distinct subpopulations of neurons. Prkcd-Cre or Sst-Cre mice were crossed with Ai9 reporter mice to produce offspring that express tdTomato fluorescent protein in either $\mathrm{PKC} \delta \delta^{+}$or Som ${ }^{+}$cells. B. Acute amygdala slices for patch clamp electrophysiology. Whole brains were extracted and coronally sectioned. Bottom panels are low-magnification (left and middle) and high-magnification (right) images of CeA slices. The CeA was visually identified by the distinct fiber bundles outlining the nuclei using differential interference contrast (left). PKC $\delta^{+}$cells or Som ${ }^{+}$cells expressing tdTomato (red) were readily seen under fluorescent microscopy (middle and right). Right panels show high-magnification images of individual CeLC cells, with fluorescent images and differential interference contrast images overlaid. Black arrows denote fluorescently labeled cells, while white arrows denote unlabeled cells. Scale bars: $200 \mu \mathrm{m}$ (left and center panel) and $10 \mu \mathrm{m}$ (right panel). $\boldsymbol{C}$, Representative voltage recordings of spontaneously active (S) cells, late-firing (LF), and regular-spiking (RS) PKC $\delta^{+}$(left) or Som ${ }^{+}$(right) neurons. $\boldsymbol{D}$, Proportions of each firing phenotype within recorded $\mathrm{PKC} \delta^{+}$and $\mathrm{Som}^{+}$cell populations. The distribution of firing phenotypes is significantly $\left(p=0.0055, \chi^{2}\right.$ test) different between $\mathrm{PKC} \delta^{+}$and $\mathrm{Som}^{+}$cell populations. $\mathrm{BLA}=$ basolateral amygdala; $L A=$ lateral amygdala; CeL= lateral subdivision of central amygdala; $\mathrm{CeC}=$ capsular subdivision of central amygdala; $\mathrm{CeM}=$ medial subdivision of central amygdala.

(ISI), action potential amplitude, APD (calculated at 50\% repolarization relative to $\mathrm{V}_{\text {threshold }}$ ) and $\mathrm{AHP}$ amplitude were calculated from the ratio of the measurements obtained from the last and first action potential in response to a $500-m s$ depolarizing current injection at $2 \times$ rheobase. ISI accommodating cells were defined as cells with a ratio $\geq 1.5$, whereas ISI non-accommodating cells had a ratio of $<1.5$.

Latency to first spike was used to classify cells as latefiring or regular-spiking neurons. Cells with latencies shorter than $100 \mathrm{~ms}$ (at baseline) or $90 \mathrm{~ms}$ (pain conditions) were classified as regular-spiking. Conversely, cells with latencies higher than $100 \mathrm{~ms}$ (at baseline) or $90 \mathrm{~ms}$ (pain conditions) were classified as late-firing. Current amplitudes that elicited an average of 10 spikes (range of 5-19 spikes) were used to calculate latencies to first spike and, subsequently, to classify cells as late-firing or regular-spiking. In baseline (no pain) conditions, this current amplitude was $220 \mathrm{pA}$ for $\mathrm{Som}^{+}$cells and $280 \mathrm{pA}$ for $\mathrm{PKC} \delta^{+}$neurons. Current amplitudes of $220 \mathrm{pA}$ were used for both $\mathrm{Som}^{+}$and $\mathrm{PKC} \delta^{+}$neurons in pain conditions. Number of spikes in response to a 500-ms depolarizing current injection of 140-pA (regular-spiking cells) or 240pA (late-firing cells) amplitude was used to evaluate subnuclei and rostro-caudal differences in firing responses as well as firing responses as a function of whole-cell capacitance. Whole-cell membrane capacitance was calculated by integrating the capacitive transients elicited by a 25 ms voltage step $( \pm 10 \mathrm{mV}$ ) from $-70 \mathrm{mV}$.

Spontaneously active neurons were analyzed by selecting a 5-s segment of stable firing. Firing frequency was calculated as the number of action potentials fired divided by 5-s. IS potential was calculated as the average membrane potential between two spikes, when the membrane potential plateaus and is stable, after the AHP of one spike, and before $V_{\text {threshold }}$ of the next spike. Peak voltage was measured as the most depolarized potential reached during an action potential. Capacitance, $R_{\text {in }}, V_{\text {threshold, }}$ rise, decay, APD, and AHP of spontaneously active cells were calculated using the methods described above. Single action 
potential parameters (IS potential, peak voltage, $\mathrm{V}_{\text {threshold, }}$ rise, decay, APD, and AHP) were calculated for each action potential within the 5-s selected trace and averaged, for a single value per cell. Analysis was performed blind to cell genotype. Recording sites were constructed using the mouse brain atlas as a guide (Paxinos et al., 2001).

\section{Morphologic reconstruction of biocytin-filled cells \\ Preservation and staining of biocytin-filled neurons}

Following current-clamp recordings, we followed procedures previously described to remove the recording electrode from the cell and retain the morphology of the cell (Swietek et al., 2016). In brief, the recording pipette was moved in slow alternating steps upward and outward in voltage-clamp mode while continuously monitoring the capacitive transients to reestablish a seal. Following resealing, the slice was left in the recording chamber for $\sim 3$ min to ensure transport of biocytin to distal processes. The slice was then removed from the recording chamber and immediately placed into $4 \%$ paraformaldehyde (PFA) solution in $0.1 \mathrm{M}$ phosphate buffer (PB), $\mathrm{pH} 7.4$, at $4^{\circ} \mathrm{C}$ for $48 \mathrm{~h}$, followed by $0.1 \mathrm{~m}$ PBS ( $\mathrm{pH} 7.4)$ with $0.01 \%$ sodium azide at $4^{\circ} \mathrm{C}$ until staining. Slices were rinsed with $0.1 \mathrm{M}$ PBS three times for $5 \mathrm{~min}$ at room temperature while shaking at a low speed, then incubated in PBS containing $0.1 \%$ Triton $\mathrm{X}-100$ for $10 \mathrm{~min}$. Samples were then incubated overnight, at $4^{\circ} \mathrm{C}$ and protected from light, in 1:500 Alexa Fluor 647 streptavidin (The Jackson Laboratory 016-600-084) in blocking solution containing $1.5 \%$ normal goat serum (NGS; Vector Labs), 0.1\% Triton X-100, 0.05\% Tween 20, and $1 \%$ bovine serum albumin (BSA). In minimal light, slices were then washed in $0.1 \mathrm{M}$ PBS four times for $30 \mathrm{~min}$ at room temperature. Slices were then cleared using increasing concentrations of 2,2'-thiodiethanol (TDE) for $10 \mathrm{~min}$ each using $10 \%, 30 \%, 60 \%$, and $80 \%$ concentrations (Costantini et al., 2015), followed by incubation in $97 \%$ TDE for $2 \mathrm{~h}$. Slices were then mounted on positivelycharged glass slides and covered with glass coverslips using $97 \%$ TDE.

Image acquisition, three-dimensional morphologic reconstruction, and analysis

Images of recovered biocytin-filled neurons were taken using a Nikon A1R laser scanning confocal microscope with a $40 \times$ oil-immersion objective. Gain and pinhole size were kept constant between experiments. Sequential acquisition of z-stacks was collected at $0.09-\mu \mathrm{m}$ steps. Images were collected at varying sizes, depending on the extension of the dendrites of each neuron, and were then automatically stitched on acquisition using NIS Elements software. To quantify neuronal morphology, z-stacks were analyzed using Neurolucida 360 (NeuroLucida 360, MBF Bioscience). Cell bodies were identified using automatic detection of a user-defined area and dendritic branches were traced using the user-guided tree-tracing function. To identify spines, automatic spine detection was performed using image noise filtering. The experimenter manually confirmed or rejected all parameters analyzed. Primary dendrites were defined as the dendrites directly extending from the soma. Secondary dendrites branched from primary dendrites, and tertiary dendrites were the branching points of secondary dendrites. Dendritic length was defined as the distance from the trunk of the branch to either the distal branching point, or the visible end of the projection. Spine density was calculated by counting the individual spines present on the dendrites and reported per $100 \mu \mathrm{m}$ of dendrite. Dendritic properties were obtained using branched-structure and Sholl analysis functions from NeuroLucida Explorer. The number of dendritic intersections at increasing radial distances from the soma, in 10- $\mu \mathrm{m}$ increments, were quantified and used for the Sholl analysis. Immunohistochemistry, image acquisition, and morphologic reconstruction was performed with the experimenter blind to cell type.

\section{Immunohistochemistry}

Sst-cre::Ai9 mice were deeply anesthetized with $1.25 \%$ Avertin (2,2,2-tribromoethanol and tert-amyl alcohol in $0.9 \% \mathrm{NaCl} ; 0.025 \mathrm{ml} / \mathrm{g}$ body weight) and were then perfused transcardially with $37^{\circ} \mathrm{C} 0.9 \% \mathrm{NaCl}$, followed by $100 \mathrm{ml}$ of ice-cold 4\% PFA/PB. The brains were carefully dissected and postfixed overnight in $4 \%$ PFA/PB at $4{ }^{\circ} \mathrm{C}$. After cryoprotection in $30 \%$ sucrose/PB for $48 \mathrm{~h}$, the brains were sliced in $30 \mu \mathrm{m}$ coronal sections using a freezing sliding microtome. The sections were stored in $0.1 \mathrm{M}$ PBS, pH 7.4 containing $0.01 \%$ sodium azide (Sigma) at $4^{\circ} \mathrm{C}$ until immunostaining. To begin staining, sections were rinsed in PBS, then incubated in PBS containing $0.1 \%$ Triton $\mathrm{X}-100$ for $10 \mathrm{~min}$ at room temperature, followed by blocking at room temperature for $30 \mathrm{~min}$ in blocking solution containing 5\% NGS (Vector Labs), 0.1\% Triton X-100, $0.05 \%$ Tween 20, and 1\% BSA. Sections were then incubated for $72 \mathrm{~h}$ at $4^{\circ} \mathrm{C}$ in mouse anti-PKC $\delta$ primary antibody (1:1000, BD Biosciences, 610397) in blocking solution containing 1.5\% NGS, $0.1 \%$ Triton X-100, 0.05\% Tween 20, and $1 \%$ BSA. Following the primary antibody incubation, sections were rinsed in PBS and incubated in Alexa Fluor 647-conjugated goat anti-mouse (1:100, Invitrogen, A21235) secondary antibody in blocking solution containing $1.5 \%$ NGS, $0.1 \%$ Triton X-100, 0.05\% Tween 20, and 1\% BSA for $2 \mathrm{~h}$ at room temperature and protected from light. Sections were rinsed in PBS, mounted on positively charged glass slides, and left overnight to air-dry before coverslips were set using Fluoromount-G (SouthernBiotech). Representative high-magnification images were collected using a Nikon A1R laser scanning confocal microscope and a 40× oil-immersion objective. Laser intensity, gain, and pinhole were kept constant between images. Sequential acquisition of multiple channels was used, and z-stacks were collected at $0.9-\mu \mathrm{m}$ steps. Images were collected at a size of $0.7 \times 0.59 \mathrm{~mm}$ and were automatically stitched on acquisition using NIS Elements software. Image stacks were converted into maximum intensity z-projections using the NIS Elements software. Anatomical limits of each region were identified using a mouse brain atlas (Franklin and Paxinos, 2008).

\section{Sciatic nerve surgeries and nociceptive testing Sciatic cuff implantation}

Sciatic nerve cuff and sham surgeries were performed as previously described (Benbouzid et al., 2008). In brief, 
13 male Prkcd-cre and 10 male Sst-cre mice were anesthetized using $2 \%$ isoflurane $(0.5 \mathrm{l} / \mathrm{min})$. A $1-\mathrm{cm}$ long incision was made along the proximal third of the lateral left thigh and the sciatic nerve was exteriorized and gently stretched using forceps. The nerve was either returned to its normal position (sham animals) or a 2-mm piece of PE20 non-toxic, sterile polyethylene tubing $(0.38 \mathrm{~mm}$ ID/1.09 $\mathrm{mm} \mathrm{OD)} \mathrm{was} \mathrm{split} \mathrm{along} \mathrm{and} \mathrm{slid} \mathrm{onto} \mathrm{the} \mathrm{sciatic} \mathrm{nerve}$ (cuff animals). After returning the nerve to its normal position, wound clips were used to close the skin. All electrophysiological and behavioral experiments were performed 6-14 d following surgeries.

\section{Nociceptive testing}

Mice were habituated to the $11 \times 11 \times 13 \mathrm{~cm}$ ventilated Plexiglas testing chambers placed on an elevated mesh platform (for von Frey and acetone tests) or a clear glass surface heated to $30^{\circ} \mathrm{C}$ (for Hargreaves test) for 1-3 h before testing. von Frey filaments (North Coast Medical) were used to assess mechanical sensitivity as previously described (Carrasquillo and Gereau, 2007). Beginning with the smallest fiber, the experimenter applied filaments to the hind-paw until the filament bent $\sim 30^{\circ}$ for $\sim 2 \mathrm{~s}$. The smallest filament to evoke a paw withdrawal response in at least three of five trials was recorded as the paw withdrawal threshold. Thermal sensitivity to heat was assessed using a modified version of the Hargreaves test (Hargreaves et al., 1988) as described previously (Carrasquillo and Gereau, 2007). A thermal stimulus with an active intensity of 35 was delivered from a constant radiant heat source through the glass bottom of the chamber to the plantar surface of the hind-paw (IITC Life Sciences) and the latency to elicit paw withdrawal was recorded. To measure sensitivity to cold, we adapted the acetone evaporative test (Choi et al., 1994). Acetone (Sigma) was drawn into a 1-ml syringe and a drop was lightly applied to the hind-paw through the wire mesh. The drop of acetone (and not the syringe tip) was placed against the plantar surface of the hind-paw. Nociceptive responses and pain-like behaviors were quantified for $60 \mathrm{~s}$ following acetone exposure. Response quantification was modeled after a previously reported scoring system (Colburn et al., 2007). Transient lifting, licking, or shaking of the hind-paw that subsided immediately was given a score of 0 ; the same behaviors continuing up to but not past 5-s after initial application was given a score of 1 ; repeated and prolonged lifting, licking, or shaking of the hind-paw was given a score of 2 . Three to five measurements were taken for each hind-paw on each behavioral assay and the average paw withdrawal thresholds (von Frey), paw withdrawal latencies (Hargreaves) and nociceptive scores (acetone) were calculated individually for each hindpaw. Hypersensitivity was assessed by comparing withdrawal thresholds in the paw ipsilateral to the side of sciatic nerve surgery compared with the paw contralateral to the side of sciatic nerve surgery. For all nociceptive tests, the experimenter was blind to whether the mouse had received cuff implantation or a sham surgery.

\section{Statistics}

Results are expressed as mean \pm SEM. Outliers were identified as values over 2 SDs above or below the mean of the sample and were subsequently excluded from analyses. Analysis was performed using either Student's unpaired $t$ tests (with or without Welch's correction for variance), Mann-Whitney $U$ tests, $\chi^{2}$ (one-sided) tests, or two-way ANOVAs followed by post hoc Tukey's, Sidak's, or Dunnett's multiple comparison tests. The appropriate statistical test was determined after assessing each dataset's normality and variance. All analyses were performed using GraphPad Prism (version 8), and $p$ values lower than 0.05 were considered significant and are reported in figure legends. Detailed information for all statistical tests performed are reported in Table 1.

\section{Data availability}

All data in this study is available from the corresponding author.

\section{Results}

\section{$\mathrm{Som}^{+}$cells are more excitable than $\mathrm{PKC} \delta^{+}$neurons}

Previous studies have shown cell-type-specific alterations in the firing responses of $\mathrm{PKC} \delta^{+}$and $\mathrm{Som}^{+}$neurons following fear conditioning or nerve injury (Ciocchi et al., 2010; Yu et al., 2016; Wilson et al., 2019), demonstrating that plasticity in the firing responses of these cells underlies changes in behavioral output. Whether the relative excitability of $\mathrm{PKC} \delta^{+}$and $\mathrm{Som}^{+}$neurons is different at baseline conditions, however, has not been determined. To do this, we crossed Prkcd-Cre or Sst-Cre mice with an Ai9 reporter strain to obtain offspring that expressed the fluorescent protein tdTomato in cells expressing $\mathrm{PKC} \delta$ or Som, respectively (Fig. 1A). Using an acute brain slice preparation, we performed whole-cell patchclamp recordings from a total of 124 visually identified fluorescent neurons in the right CeLC, corresponding to $\operatorname{PKC} \delta^{+}$and Som ${ }^{+}$cells and distributed across the rostro-caudal extension of the CeLC (Fig. 1B; Fig. 2). Consistent with previous studies (Martina et al., 1999; Schiess et al., 1999; Lopez de Armentia and Sah, 2004; Chieng et al., 2006), our experiments revealed that CeLC neurons display heterogeneous firing responses (Fig. 1C). Thus, three discrete firing phenotypes are observed: spontaneously active (S), late-firing (LF), and regularspiking (RS) neurons. Late-firing neurons are silent at rest, fire repetitively in response to a prolonged $(500 \mathrm{~ms})$ depolarizing current injection and have a substantial delay to firing action potentials, while regular-spiking cells are also silent at rest and fire repetitively in response to depolarizing current injections but have a much shorter onset to action potentials firing.

As illustrated in the representative traces in Figure 1C, all three firing types are readily observed in both $\operatorname{PKC} \delta^{+}$ and Som ${ }^{+}$CeLC neurons. Quantification of the proportion of cells with different firing types revealed, however, that the distribution of firing phenotypes is significantly different between PKC $\delta^{+}$and Som ${ }^{+}$cells (Fig. 1D). Of the 75 $\mathrm{PKC} \delta{ }^{+}$cells recorded, for example, the majority (36/75; $48 \%)$ are regular-spiking neurons, whereas only 13 of the $49(27 \%)$ Som $^{+}$neurons recorded are regular-spiking. In marked contrast, most $(27 / 49 ; 55 \%)$ of the Som ${ }^{+}$neurons recorded are spontaneously active at rest and only 20 of 
Table 1: Statistical analyses

\begin{tabular}{|c|c|c|c|c|}
\hline Figure & Data structure & Type of test & Sample size & Statistical data \\
\hline \multicolumn{5}{|l|}{ Figure 1} \\
\hline $1 D$ (\% cell types) & Parts of a whole & $\chi^{2}$ & $\begin{array}{l}\mathrm{PKC} \delta^{+}=75 \text { cells } \\
\mathrm{Som}^{+}=49 \text { cells }\end{array}$ & $\chi^{2}=10.42 ; \mathrm{df}=2 ; p=0.0055$ \\
\hline \multicolumn{5}{|l|}{ Figure 3} \\
\hline $3 A$ (IF curve LF) & $\begin{array}{l}\text { Two factors (cell type and current } \\
\text { injection) }\end{array}$ & Two-way ANOVA with RM & $\begin{array}{l}\mathrm{PKC} \delta^{+} \mathrm{LF}=19 \text { cells } \\
\mathrm{Som}^{+} \mathrm{LF}=9 \text { cells }\end{array}$ & $\begin{array}{l}\text { Cell type: } F_{(1,25)}=23.89 ; p<0.0001 \\
\text { Current injection: } F_{(1.708,42.71)}=238.4 ; p<0.0001\end{array}$ \\
\hline $3 A$ (IF curve RS) & $\begin{array}{l}\text { Two factors (genotype and current } \\
\text { injection) }\end{array}$ & Two-way ANOVA with RM & $\begin{array}{l}\mathrm{PKC} \delta^{+} \mathrm{RS}=36 \text { cells } \\
\mathrm{Som}^{+} \mathrm{RS}=12 \text { cells }\end{array}$ & $\begin{array}{l}\text { Cell type: } F_{(1,46)}=9.440 ; p=0.0036 \\
\text { Current injection: } F_{(1.785,82.13)}=185.7 ; p<0.0001\end{array}$ \\
\hline $3 B$ (latency LF) & Normal distribution, same variance & Unpaired $t$ test (two-tailed) & $\begin{array}{l}\mathrm{PKC} \delta^{+} \mathrm{LF}=16 \text { cells } \\
\mathrm{Som}^{+} \mathrm{LF}=9 \text { cells }\end{array}$ & $t=3.206 ; \mathrm{df}=23 ; p=0.0039 ; \eta^{2}=0.309$ \\
\hline $3 C$ (rheobase LF) & Normal distribution, same variance & Unpaired $t$ test (two-tailed) & $\begin{array}{l}\mathrm{PKC} \delta^{+} \mathrm{LF}=18 \text { cells } \\
\mathrm{Som}^{+} \mathrm{LF}=9 \text { cells }\end{array}$ & $t=2.012 ; \mathrm{df}=25 ; p=0.0551 ; \eta^{2}=0.139$ \\
\hline $3 D$, top $\left(R_{\text {in }} L F\right)$ & Non-normal distribution & Mann-Whitney $U$ test & $\begin{array}{l}\mathrm{PKC} \delta^{+} \mathrm{LF}=18 \text { cells } \\
\mathrm{Som}^{+} \mathrm{LF}=9 \text { cells }\end{array}$ & $p=0.0308$ (two-tailed); $U=39$ \\
\hline $3 E$, top $\left(\mathrm{V}_{\text {rest }} \mathrm{LF}\right)$ & $\begin{array}{l}\text { Normal distribution, different } \\
\text { variances }\end{array}$ & $\begin{array}{l}\text { Unpaired } t \text { test with Welch's } \\
\text { correction (two-tailed) }\end{array}$ & $\begin{array}{l}\mathrm{PKC} \delta^{+} \mathrm{LF}=18 \text { cells } \\
\mathrm{Som}^{+} \mathrm{LF}=9 \text { cells }\end{array}$ & $t=4.360 ; \mathrm{df}=24.99 ; p=0.0002 ; \eta^{2}=0.432$ \\
\hline $3 F$ (latency RS) & Normal distribution, same variance & Unpaired $t$ test (two-tailed) & $\begin{array}{l}\mathrm{PKC} \delta^{+} \mathrm{RS}=36 \text { cells } \\
\mathrm{Som}^{+} \mathrm{RS}=12 \text { cells }\end{array}$ & $t=1.720 ; \mathrm{df}=46 ; p=0.0921 ; \eta^{2}=0.060$ \\
\hline $3 G$ (rheobase RS) & Non-normal distribution & Mann-Whitney $U$ test & $\begin{array}{l}\mathrm{PKC} \delta^{+} \mathrm{RS}=36 \text { cells } \\
\mathrm{Som}^{+} \mathrm{RS}=12 \text { cells }\end{array}$ & $p=0.2807$ (two-tailed); $U=171$ \\
\hline $3 H\left(R_{\text {in }} R S\right)$ & Normal distribution, same variance & Unpaired $t$ test (two-tailed) & $\begin{array}{l}\mathrm{PKC} \delta^{+} \mathrm{RS}=36 \text { cells } \\
\mathrm{Som}^{+} \mathrm{RS}=12 \text { cells }\end{array}$ & $t=0.5057 ; \mathrm{df}=46 ; p=0.6155 ; \eta^{2}=0.006$ \\
\hline $3 /\left(V_{\text {rest }} R S\right)$ & Normal distribution, same variance & Unpaired $t$ test (two-tailed) & $\begin{array}{l}\mathrm{PKC} \delta^{+} \mathrm{RS}=35 \text { cells } \\
\mathrm{Som}^{+} \mathrm{RS}=12 \text { cells }\end{array}$ & $t=0.6467 ; \mathrm{df}=45 ; p=0.5211 ; \eta^{2}=0.009$ \\
\hline \multicolumn{5}{|l|}{ Figure 4} \\
\hline$V_{\text {sag }}$ LF & Normal distribution, same variance & Unpaired $t$ test (two-tailed) & $\begin{array}{l}\mathrm{PKC} \delta^{+}=18 \text { cells } \\
\mathrm{Som}^{+}=9 \text { cells }\end{array}$ & $t=1.723 ; \mathrm{df}=25 ; p=0.0971 ; \eta^{2}=0.1062$ \\
\hline$V_{\text {sag }} R S$ & Non-normal distribution & Mann-Whitney $U$ test & $\begin{array}{l}\mathrm{PKC} \delta^{+}=33 \text { cells } \\
\mathrm{Som}^{+}=13 \text { cells }\end{array}$ & $p=0.4961$ (two-tailed); $U=186$ \\
\hline \multicolumn{5}{|l|}{ Figure 5} \\
\hline $5 \mathrm{Ci}\left(\mathrm{PKC} \delta^{+}\right.$LF peak voltage $)$ & Normal distribution & Paired $t$ test (two-tailed) & $n=15$ cells & $t=8 ; \mathrm{df}=14 ; p<0.0001 ; \eta^{2}=0.8444$ \\
\hline 5 Cii (Som ${ }^{+}$LF peak voltage) & Normal distribution & Paired $t$ test (two-tailed) & $n=9$ cells & $t=7.088 ; \mathrm{df}=8 ; p<0.0001 ; \eta^{2}=0.8626$ \\
\hline 5Ciii (accommodation ratio LF) & Normal distribution, same variance & Unpaired $t$ test (two-tailed) & $\begin{array}{l}\mathrm{PKC} \delta^{+} \mathrm{LF}=15 \text { cells } \\
\mathrm{Som}^{+} \mathrm{LF}=9 \text { cells }\end{array}$ & $t=3.284 ; \mathrm{df}=22 ; p=0.0034 ; \eta^{2}=0.3289$ \\
\hline $5 D i\left(\mathrm{PKC} \delta^{+} \mathrm{RS}\right.$ peak voltage $)$ & Normal distribution & Paired $t$ test (two-tailed) & $n=36$ cells & $t=12.24 ; \mathrm{df}=35 ; p<0.0001 ; \eta^{2}=0.8107$ \\
\hline 5Dii (Som ${ }^{+}$RS peak voltage) & Normal distribution & Paired $t$ test (two-tailed) & $n=13$ cells & $t=4.923 ; \mathrm{df}=12 ; p=0.0004 ; \eta^{2}=0.6688$ \\
\hline 5Diii (accommodation ratio RS) & Non-normal distribution & Mann-Whitney $U$ test & $\begin{array}{l}\mathrm{PKC} \delta^{+} \mathrm{RS}=35 \text { cells } \\
\mathrm{Som}^{+} \mathrm{RS}=12 \text { cells }\end{array}$ & $p=0.0687$ (two-tailed); $U=135$ \\
\hline $5 E i$ (PKC $\delta^{+}$LF width) & Normal distribution & Paired $t$ test (two-tailed) & $n=14$ cells & $t=4.243 ; \mathrm{df}=13 ; p=0.0010 ; \eta^{2}=0.5807$ \\
\hline 5Eii (Som ${ }^{+}$LF width) & Normal distribution & Paired $t$ test (two-tailed) & $n=9$ cells & $t=5.307 ; \mathrm{df}=9 ; p=0.0007 ; \eta^{2}=0.7788$ \\
\hline $\begin{array}{l}\text { 5Eiii (width accommodation ratio } \\
\qquad \text { LF) }\end{array}$ & Normal distribution, same variance & Unpaired $t$ test (two-tailed) & $\begin{array}{l}\mathrm{PKC} \delta^{+} \mathrm{LF}=16 \text { cells } \\
\mathrm{Som}^{+} \mathrm{LF}=9 \text { cells }\end{array}$ & $t=0.6847 ; \mathrm{df}=23 ; p=0.5004 ; \eta^{2}=0.020$ \\
\hline $5 F i\left(\mathrm{PKC} \delta^{+} \mathrm{RS}\right.$ width $)$ & Normal distribution & Paired $t$ test (two-tailed) & $n=33$ cells & $t=6.279 ; \mathrm{df}=32 ; p<0.0001 ; \eta^{2}=0.5520$ \\
\hline 5Fii (Som ${ }^{+}$RS width) & Normal distribution & Paired $t$ test (two-tailed) & $n=13$ cells & $t=6.196 ; \mathrm{df}=12 ; p<0.0001 ; \eta^{2}=0.7618$ \\
\hline $\begin{array}{l}\text { 5Fiii (width accommodation ratio } \\
\text { RS) }\end{array}$ & Non-normal distribution & Mann-Whitney $U$ test & $\begin{array}{l}\mathrm{PKC} \delta^{+} \mathrm{RS}=36 \text { cells } \\
\mathrm{Som}^{+} \mathrm{RS}=12 \text { cells }\end{array}$ & $p=0.0520$ (two-tailed); $U=134.5$ \\
\hline $5 \mathrm{Gi}\left(\mathrm{PKC} \delta^{+} \mathrm{LF}\right.$ AHP) & Normal distribution & Paired $t$ test (two-tailed) & $n=16$ cells & $t=10.30 ; \mathrm{df}=15 ; p<0.0001 ; \eta^{2}=0.8760$ \\
\hline 5Gii (Som ${ }^{+}$LF AHP) & Normal distribution & Paired $t$ test (two-tailed) & $n=9$ cells & $t=9.170 ; \mathrm{df}=8 ; p<0.0001 ; \eta^{2}=0.9131$ \\
\hline $\begin{array}{l}\text { 5Giii (AHP accommodation ratio } \\
\qquad \text { LF) }\end{array}$ & Normal distribution, same variance & Unpaired $t$ test (two-tailed) & $\begin{array}{l}\mathrm{PKC} \delta^{+} \mathrm{LF}=16 \text { cells } \\
\mathrm{Som}^{+} \mathrm{LF}=9 \text { cells }\end{array}$ & $t=1.643 ; \mathrm{df}=23 ; p=0.1140 ; \eta^{2}=0.105$ \\
\hline $5 H i\left(\mathrm{PKC} \delta^{+} \mathrm{RS} A H P\right)$ & Normal distribution & Paired $t$ test (two-tailed) & $n=36$ cells & $t=11.03 ; \mathrm{df}=35 ; p<0.0001 ; \eta^{2}=0.7766$ \\
\hline $5 H$ ii $\left(\right.$ Som $^{+}$RS AHP) & Normal distribution & Paired $t$ test (two-tailed) & $n=12$ cells & $t=6.368 ; \mathrm{df}=11 ; p<0.0001 ; \eta^{2}=0.7866$ \\
\hline $\begin{array}{l}\text { 5Hiii (AHP accommodation ratio } \\
\quad \text { RS) }\end{array}$ & $\begin{array}{l}\text { Normal distribution, different } \\
\text { variances }\end{array}$ & $\begin{array}{l}\text { Unpaired } t \text { test with Welch's } \\
\text { correction (two-tailed) }\end{array}$ & $\begin{array}{l}\mathrm{PKC} \delta^{+} \mathrm{RS}=36 \text { cells } \\
\mathrm{Som}^{+} \mathrm{RS}=12 \text { cells }\end{array}$ & $t=2.821 ; \mathrm{df}=13.30 ; p=0.0142 ; \eta^{2}=0.375$ \\
\hline \multicolumn{5}{|l|}{ Figure 6} \\
\hline $6 B\left(I_{\text {threshold }} L F\right)$ & $\begin{array}{l}\text { Normal distribution, different } \\
\text { variances }\end{array}$ & $\begin{array}{l}\text { Unpaired } t \text { test with Welch's } \\
\text { correction (two-tailed) }\end{array}$ & $\begin{array}{l}\mathrm{PKC} \delta^{+} \mathrm{LF}=16 \text { cells } \\
\mathrm{Som}^{+} \mathrm{LF}=9 \text { cells }\end{array}$ & $t=5.323 ; \mathrm{df}=21.33 ; p<0.0001 ; \eta^{2}=0.5706$ \\
\hline $6 C\left(V_{\text {threshold }} \mathrm{LF}\right)$ & Non-normal distribution & Mann-Whitney $U$ test & $\begin{array}{l}\mathrm{PKC} \delta^{+} \mathrm{LF}=16 \text { cells } \\
\mathrm{Som}^{+} \mathrm{LF}=9 \text { cells }\end{array}$ & $p=0.1687$ (two-tailed); $U=47$ \\
\hline $6 D$ (rise LF) & Normal distribution, same variance & Unpaired $t$ test (two-tailed) & $\begin{array}{l}\mathrm{PKC} \delta^{+} \mathrm{LF}=16 \text { cells } \\
\mathrm{Som}^{+} \mathrm{LF}=9 \text { cells }\end{array}$ & $t=0.7270 ; \mathrm{df}=23 ; p=0.4746 ; \eta^{2}=0.022$ \\
\hline & & (Continued) & & \\
\hline
\end{tabular}


Table 1: Continued

\begin{tabular}{|c|c|c|c|c|}
\hline Figure & Data structure & Type of test & Sample size & Statistical data \\
\hline \multirow[t]{2}{*}{$6 E$ (decay LF) } & Non-normal distribution & Mann-Whitney $U$ test & $\mathrm{PKC} \delta^{+} \mathrm{LF}=16$ cells & $p<0.0001$ (two-tailed); $U=9$ \\
\hline & & & $\mathrm{Som}^{+} \mathrm{LF}=9$ cells & \\
\hline \multirow[t]{2}{*}{$6 F$ (width LF) } & Non-normal distribution & Mann-Whitney $U$ test & $\mathrm{PKC} \delta^{+} \mathrm{LF}=16$ cells & $p<0.0001$ (two-tailed); $U=0$ \\
\hline & & & $\mathrm{Som}^{+} \mathrm{LF}=9$ cells & \\
\hline \multirow[t]{2}{*}{$6 G$ (AHP LF) } & Normal distribution, same variance & Unpaired $t$ test (two-tailed) & $\mathrm{PKC} \delta^{+} \mathrm{LF}=16$ cells & $t=2.071 ; \mathrm{df}=23 ; p=0.0498 ; \eta^{2}=0.1572$ \\
\hline & & & $\mathrm{Som}^{+} \mathrm{LF}=9$ cells & \\
\hline \multirow{2}{*}{$6 H\left(I_{\text {threshold }} R S\right)$} & Non-normal distribution & Mann-Whitney $U$ test & $\mathrm{PKC} \delta^{+} \mathrm{RS}=31$ cells & $p=0.1067$ (two-tailed); $U=101.5$ \\
\hline & & & $\mathrm{Som}^{+} \mathrm{RS}=10$ cells & \\
\hline \multirow[t]{2}{*}{$6 /\left(\mathrm{V}_{\text {threshold }} \mathrm{RS}\right)$} & Normal distribution, same variance & Unpaired $t$ test (two-tailed) & $\mathrm{PKC} \delta^{+} \mathrm{RS}=31$ cells & $t=0.5674 ; \mathrm{df}=39 ; p=0.5737 ; \eta^{2}=0.008$ \\
\hline & & & $\mathrm{Som}^{+} \mathrm{RS}=10$ cells & \\
\hline \multirow[t]{2}{*}{$6 J$ (rise RS) } & Normal distribution, same variance & Unpaired $t$ test (two-tailed) & $\mathrm{PKC} \delta^{+} \mathrm{RS}=31$ cells & $t=1.068 ; \mathrm{df}=39 ; p=0.2919 ; \eta^{2}=0.028$ \\
\hline & & & Som $^{+} \mathrm{RS}=10$ cells & \\
\hline \multirow[t]{2}{*}{$6 K$ (decay RS) } & Non-normal distribution & Mann-Whitney $U$ test & $\mathrm{PKC} \delta^{+} \mathrm{RS}=31$ cells & $p=0.1720$ (two-tailed); $U=109.5$ \\
\hline & & & $\mathrm{Som}^{+} \mathrm{RS}=10$ cells & \\
\hline \multirow[t]{2}{*}{$6 L$ (width RS) } & Normal distribution, same variance & Unpaired $t$ test (two-tailed) & $\mathrm{PKC} \delta^{+} \mathrm{RS}=31$ cells & $t=1.740 ; \mathrm{df}=39 ; p=0.0898 ; \eta^{2}=0.072$ \\
\hline & & & Som $^{+} \mathrm{RS}=10$ cells & \\
\hline \multirow[t]{2}{*}{$6 M$ (AHP RS) } & Normal distribution, same variance & Unpaired $t$ test (two-tailed) & $\mathrm{PKC} \delta^{+} \mathrm{RS}=31$ cells & $t=3.631 ; \mathrm{df}=39 ; p=0.0008 ; \eta^{2}=0.2527$ \\
\hline & & & $\mathrm{Som}^{+} \mathrm{RS}=10$ cells & \\
\hline \multicolumn{5}{|l|}{ Figure 7} \\
\hline \multirow[t]{2}{*}{$7 C$ (frequency) } & Normal distribution, different & Unpaired $t$ test with Welch's & $\mathrm{PKC} \delta^{+}=18$ cells & $t=2.790 ; \mathrm{df}=36.20 ; p=0.0084 ; \eta^{2}=0.1770$ \\
\hline & variances & correction (two-tailed) & $\mathrm{Som}^{+}=23$ cells & \\
\hline \multirow[t]{2}{*}{$7 D$ (IS potential) } & Normal distribution, same variance & Unpaired $t$ test (two-tailed) & $\mathrm{PKC} \delta^{+}=17$ cells & $t=1.88 ; \mathrm{df}=38 ; p=0.077 ; \eta^{2}=0.080$ \\
\hline & & & $\mathrm{Som}^{+}=23$ cells & \\
\hline \multirow[t]{2}{*}{$7 E$ (capacitance) } & Non-normal distribution & Mann-Whitney $U$ test & $\mathrm{PKC} \delta^{+}=18$ cells & $p=0.1957$ (two-tailed); $U=157$ \\
\hline & & & $\mathrm{Som}^{+}=23$ cells & \\
\hline \multirow[t]{2}{*}{$7 F\left(\mathrm{R}_{\text {in }}\right)$} & Normal distribution, same variance & Unpaired $t$ test (two-tailed) & $\mathrm{PKC} \delta^{+}=10$ cells & $t=0.228 ; \mathrm{df}=24 ; p=0.8220 ; \eta^{2}=0.002$ \\
\hline & & & $\mathrm{Som}^{+}=17$ cells & \\
\hline \multirow[t]{2}{*}{$7 G$ (peak voltage) } & Normal distribution, same variance & Unpaired $t$ test (two-tailed) & $\mathrm{PKC} \delta^{+}=17$ cells & $t=1.458 ; \mathrm{df}=38 ; p=0.531 ; \eta^{2}=0.053$ \\
\hline & & & $\mathrm{Som}^{+}=23$ cells & \\
\hline \multirow[t]{2}{*}{$7 H\left(V_{\text {threshold }}\right)$} & Normal distribution, same variance & Unpaired $t$ test (two-tailed) & $\mathrm{PKC} \delta^{+}=16$ cells & $t=1.020 ; \mathrm{df}=37 ; p=0.315 ; \eta^{2}=0.027$ \\
\hline & & & $\mathrm{Som}^{+}=23$ cells & \\
\hline $7 I$ (rise) & Normal distribution, same variance & Unpaired $t$ test (two-tailed) & $\mathrm{PKC} \delta^{+}=15$ cells & $t=3.622 ; \mathrm{df}=36 ; p=0.0009 ; \eta^{2}=0.267$ \\
\hline & & & $\mathrm{Som}^{+}=23$ cells & \\
\hline $7 J$ (decay) & Normal distribution, different & Unpaired $t$ test with Welch's & $\mathrm{PKC} \delta^{+}=17$ cells & $t=4.604 ; \mathrm{df}=24.19 ; p=0.0001 ; \eta^{2}=0.4671$ \\
\hline & variances & correction (two-tailed) & $\mathrm{Som}^{+}=23$ cells & \\
\hline $7 K(\mathrm{APD})$ & Normal distribution, different & Unpaired $t$ test with Welch's & $\mathrm{PKC} \delta^{+}=17$ cells & $t=4.565 ; \mathrm{df}=29.88 ; p<0.0001 ; \eta^{2}=0.41$ \\
\hline & variances & correction (two-tailed) & $\mathrm{Som}^{+}=23$ cells & \\
\hline $7 L(\mathrm{AHP})$ & Normal distribution, same variance & Unpaired $t$ test (two-tailed) & $\mathrm{PKC} \delta^{+}=17$ cells & $t=3.031 ; \mathrm{df}=38 ; p=0.0044 ; \eta^{2}=0.1947$ \\
\hline & & & $\mathrm{Som}^{+}=23$ cells & \\
\hline Figure 9 & & & & \\
\hline 9Ci (\# of APs RS) & No assumptions made about & Linear regression & CeC: & CeC: \\
\hline & normality & & Bregma $-1.06=5$ cells & Slope $=-14.14 ; y$-intercept $=-12.20$ \\
\hline & & & Bregma $-1.34=1$ cell & $\mathrm{x}$-intercept $=-0.8624 ; r^{2}=0.5031 ; F_{(1,12)}=12.15$ \\
\hline & & & Bregma $-1.46=2$ cells & $p=0.0045$ \\
\hline & & & Bregma $-1.58=2$ cells & \\
\hline & & & Bregma $-1.70=3$ cells & \\
\hline & & & Bregma $-1.82=1$ cell & \\
\hline & & & CeL: & CeL: \\
\hline & & & Bregma $-1.06=3$ cells & Slope $=4.001 ; y$-intercept $=12.37$ \\
\hline & & & Bregma $-1.34=2$ cells & $\mathrm{x}$-intercept $t=-3.091 ; r^{2}=0.04838 ; F_{(1,16)}=0.8135$ \\
\hline & & & Bregma $-1.46=7$ cells & $p=0.3805$ \\
\hline & & & Bregma $-1.58=1$ cell & \\
\hline & & & Bregma $-1.70=3$ cells & \\
\hline & & & Bregma $-1.94=2$ cells & \\
\hline 9Cii (\# of APs LF) & No assumptions made about & Linear regression & CeC: & CeC: \\
\hline & normality & & Bregma $-0.94=1$ cell & Slope =2.696; y-intercept $=6.362$ \\
\hline & & & Bregma $-1.06=4$ cells & $\mathrm{x}$-intercept $=-2.36 ; r^{2}=0.1620 ; F_{(1,8)}=1.546$ \\
\hline & & & Bregma $-1.46=2$ cells & $p=0.2489$ \\
\hline & & & Bregma $-1.58=3$ cells & \\
\hline & & (Continued) & & \\
\hline
\end{tabular}


Table 1: Continued

\begin{tabular}{|c|c|c|c|c|}
\hline Figure & Data structure & Type of test & Sample size & Statistical data \\
\hline & & & $\begin{array}{l}\text { CeL: } \\
\text { Bregma }-1.06=1 \text { cell } \\
\text { Bregma }-1.46=4 \text { cells } \\
\text { Bregma }-1.70=1 \text { cell } \\
\text { Bregma }-1.82=1 \text { cell }\end{array}$ & $\begin{array}{l}\text { CeL: } \\
\text { Slope }=-2.828 ; y \text {-intercep } t=-0.6382 ; \\
x \text {-intercept }=-0.2257 ; r^{2}=0.06547 ; F_{(1,5)}=0.3503 ; \\
p=0.5797\end{array}$ \\
\hline 9Di (rheobase RS) & $\begin{array}{l}\text { No assumptions made about } \\
\text { normality }\end{array}$ & Linear regression & $\begin{array}{l}\text { CeC: } \\
\text { Bregma }-1.06=5 \text { cells } \\
\text { Bregma }-1.34=1 \text { cell } \\
\text { Bregma }-1.46=2 \text { cells } \\
\text { Bregma }-1.58=2 \text { cells } \\
\text { Bregma }-1.70=3 \text { cells } \\
\text { Bregma }-1.82=1 \text { cell } \\
\text { CeL: } \\
\text { Bregma }-1.06=3 \text { cells } \\
\text { Bregma }-1.34=2 \text { cells } \\
\text { Bregma }-1.46=7 \text { cells } \\
\text { Bregma }-1.58=1 \text { cell } \\
\text { Bregma }-1.70=3 \text { cells } \\
\text { Bregma }-1.94=2 \text { cells }\end{array}$ & $\begin{array}{l}\text { CeC: } \\
\text { Slope =119.2; y-intercept }=254.3 \\
\text { x-intercept } t=-2.134 ; r^{2}=0.5193 ; F_{(1,12)}=12.96 ; \\
p=0.0036 \\
\text { CeL: } \\
\text { Slope }=-34.19 ; y \text {-intercept }=44.65 ; \\
\text { x-intercept }=1.306 ; r^{2}=0.08181 ; F_{(1,15)}=1.336 ; \\
p=0.2657\end{array}$ \\
\hline 9Dii (rheobase LF) & $\begin{array}{l}\text { No assumptions made about } \\
\text { normality }\end{array}$ & Linear regression & $\begin{array}{l}\text { CeC: } \\
\text { Bregma }-0.94=1 \text { cell } \\
\text { Bregma }-1.06=4 \text { cells } \\
\text { Bregma }-1.46=2 \text { cells } \\
\text { Bregma }-1.58=3 \text { cells } \\
\text { CeL: } \\
\text { Bregma }-1.06=1 \text { cell } \\
\text { Bregma }-1.46=4 \text { cells } \\
\text { Bregma }-1.70=1 \text { cell } \\
\text { Bregma }-1.82=1 \text { cell }\end{array}$ & $\begin{array}{l}\text { CeC: } \\
\text { Slope }=-50.70 ; y \text {-intercept }=138.9 \\
x \text {-intercept }=2.740 ; r^{2}=0.063 ; F_{(1,8)}=0.5384 \\
p=0.4840 \\
\text { CeL: } \\
\text { Slope }=82.66 ; y \text {-intercept }=320.2 \\
x \text {-intercept } t=-3.873 ; r^{2}=0.1674 ; F_{(1,5)}=1.005 \\
p=0.3621\end{array}$ \\
\hline 9Ei (latency RS) & $\begin{array}{l}\text { No assumptions made about } \\
\text { normality }\end{array}$ & Linear regression & $\begin{array}{l}\text { CeC: } \\
\text { Bregma }-1.06=5 \text { cells } \\
\text { Bregma }-1.34=1 \text { cell } \\
\text { Bregma }-1.46=2 \text { cells } \\
\text { Bregma }-1.58=2 \text { cells } \\
\text { Bregma }-1.70=3 \text { cells } \\
\text { Bregma }-1.82=1 \text { cell } \\
\text { CeL: } \\
\text { Bregma }-1.06=3 \text { cells } \\
\text { Bregma }-1.34=2 \text { cells } \\
\text { Bregma }-1.46=7 \text { cells } \\
\text { Bregma }-1.58=1 \text { cell } \\
\text { Bregma }-1.70=3 \text { cells } \\
\text { Bregma }-1.94=2 \text { cells }\end{array}$ & $\begin{array}{l}\text { CeC: } \\
\text { Slope }=406.1 ; y \text {-intercept }=725.4 ; \\
x \text {-intercept }=-1.786 ; r^{2}=0.4858 ; F_{(1,10)}=9.447 \\
p=0.0118 \\
\text { CeL: } \\
\text { slope }=28.59 ; y \text {-intercept }=178.3 ; \\
x \text {-intercept }=-6.235 ; r^{2}=0.006 ; F_{(1,14)}=0.080 \\
p=0.7808\end{array}$ \\
\hline \multicolumn{5}{|l|}{ Figure 9} \\
\hline 9Eii (latency LF) & $\begin{array}{l}\text { No assumptions made about } \\
\text { normality }\end{array}$ & Linear regression & $\begin{array}{l}\text { CeC: } \\
\text { Bregma }-0.94=1 \text { cell } \\
\text { Bregma }-1.06=4 \text { cells } \\
\text { Bregma }-1.46=2 \text { cells } \\
\text { Bregma }-1.58=3 \text { cells } \\
\text { CeL: } \\
\text { Bregma }-1.06=1 \text { cell } \\
\text { Bregma }-1.46=4 \text { cells } \\
\text { Bregma }-1.70=1 \text { cell } \\
\text { Bregma }-1.82=1 \text { cell }\end{array}$ & $\begin{array}{l}\text { CeC: } \\
\text { Slope }=-8.872 ; y \text {-intercept }=208.5 \\
\text { x-intercept } t=23.51 ; r^{2}=0.001 ; F_{(1,7)}=0.010 \\
p=0.9234 \\
\text { CeL: } \\
\text { Slope }=-130.9 ; y \text {-intercept }=73.09 \\
\text { x-intercept } t=0.5584 ; r^{2}=0.026 ; F_{(1,4)}=0.1087 \\
p=0.7582\end{array}$ \\
\hline \multicolumn{5}{|l|}{ Figure 10} \\
\hline $10 C$ (Sholl analysis) & $\begin{array}{l}\text { Two factors (cell type and radial } \\
\text { distance) }\end{array}$ & $\begin{array}{l}\text { Two-way ANOVA with RM } \\
\text { (Continued) }\end{array}$ & $\begin{array}{l}\mathrm{PKC} \delta^{+}=7 \text { cells } \\
\mathrm{Som}^{+}=6 \text { cells }\end{array}$ & $\begin{array}{l}\text { cell type: } F_{(1,11)}=11.05 ; p=0.0068 \\
\text { radial distance: } F_{(2.209,24.30)}=15.52 ; p<0.0001\end{array}$ \\
\hline
\end{tabular}

(Continued) 
Table 1: Continued

\begin{tabular}{|c|c|c|c|c|}
\hline Figure & Data structure & Type of test & Sample size & Statistical data \\
\hline $10 D$ (\# dendrites) & $\begin{array}{l}\text { Two factors (cell type and dendritic } \\
\text { branch order) }\end{array}$ & $\begin{array}{l}\text { Two-way ANOVA with RM, } \\
\text { post hoc Tukey's multiple } \\
\text { comparisons test }\end{array}$ & $\begin{array}{l}\operatorname{PKC} \delta^{+}=7 \text { cells } \\
\text { Som }^{+}=6 \text { cells }\end{array}$ & $\begin{array}{l}\text { Two-way ANOVA: } \\
\text { cell type: } F_{(1,11)}=11.85 ; p=0.0055 \\
\text { dendritic branch order: } F_{(1.286,14.14)}=5.824 ; p=0.0236 \\
\text { Post hoc Tukey's test: } \\
\text { PKC } \delta^{+} \text {primary v secondary dendrites: } p=0.1497 \\
\text { PKC } \delta^{+} \text {primary v tertiary dendrites: } p=0.9342 \\
\text { PKC } \delta^{+} \text {secondary v tertiary dendrites: } p=0.7940 \\
\text { Som }{ }^{+} \text {primary v secondary dendrites: } p=0.0037 \\
\text { Som }{ }^{+} \text {primary v tertiary dendrites: } p=0.0277 \\
\text { Som }{ }^{+} \text {sec } \\
\text { ondary v tertiary dendrites: } p=0.7567\end{array}$ \\
\hline $10 E$ (dendrite length) & $\begin{array}{l}\text { Two factors (cell type and dendritic } \\
\text { branch order) }\end{array}$ & $\begin{array}{l}\text { Mixed-effects model, Post hoc } \\
\text { Tukey's multiple compari- } \\
\text { sons test }\end{array}$ & $\begin{array}{l}\mathrm{PKC} \delta^{+}=7 \text { cells } \\
\mathrm{Som}^{+}=6 \text { cells }\end{array}$ & $\begin{array}{l}\text { Mixed-effects: } \\
\text { cell type: } F_{(1,11)}=4.820 ; p=0.0505 \\
\text { dendritic branch order: } F_{(1.320,13.20)}=19.30 ; p=0.0004 \\
\text { Post hoc Tukey's test: } \\
\text { PKC } \delta^{+} \text {primary } v \text { secondary dendrites: } p=0.0029 \\
\text { PKC } \delta^{+} \text {primary v tertiary dendrites: } p=0.0940 \\
\text { PKC } \delta^{+} \text {secondary v tertiary dendrites: } p=0.5862 \\
\text { Som }{ }^{+} \text {primary v secondary dendrites: } p=0.1438 \\
\text { Som }^{+} \text {primary v tertiary dendrites: } p=0.0062 \\
\text { Som }^{+} \text {secondary v tertiary dendrites: } p=0.0899\end{array}$ \\
\hline $10 F$ (spine density) & $\begin{array}{l}\text { Two factors (cell type and dendritic } \\
\text { branch order) }\end{array}$ & $\begin{array}{l}\text { Mixed-effects model, Post hoc } \\
\text { Tukey's multiple compari- } \\
\text { sons test }\end{array}$ & $\begin{array}{l}\mathrm{PKC} \delta^{+}=7 \text { cells } \\
\mathrm{Som}^{+}=6 \text { cells }\end{array}$ & $\begin{array}{l}\text { Mixed-effects: } \\
\text { cell type: } F_{(1,11)}=3.730 ; p=0.0796 \\
\text { dendritic branch order: } F_{(1.046,10.46)}=8.740 ; p=0.0131 \\
\text { Post hoc Tukey's test: } \\
\text { PKC } \delta^{+} \text {primary v secondary dendrites: } p=0.0873 \\
\text { PKC } \delta^{+} \text {primary v tertiary dendrites: } p=0.9562 \\
\text { PKC } \delta^{+} \text {secondary v tertiary dendrites: } p=0.4953 \\
\text { Som }{ }^{+} \text {primary v secondary dendrites: } p=0.0227 \\
\text { Som }{ }^{+} \text {primary v tertiary dendrites: } p=0.0437 \\
\text { Som }^{+} \text {secondary v tertiary dendrites: } p=0.0805\end{array}$ \\
\hline 10G (capacitance LF) & $\begin{array}{l}\text { Normal distribution, different } \\
\text { variances }\end{array}$ & $\begin{array}{l}\text { Unpaired } t \text { test with Welch's } \\
\text { correction (two-tailed) }\end{array}$ & $\begin{array}{l}\mathrm{PKC} \delta^{+} \mathrm{LF}=19 \text { cells } \\
\mathrm{Som}^{+} \mathrm{LF}=9 \text { cells }\end{array}$ & $\begin{array}{l}t=3.483 ; \mathrm{df}=25.33 ; p=0.0018 \\
\eta^{2}=0.3238\end{array}$ \\
\hline $10 H$ (capacitance v spikes LF) & $\begin{array}{l}\text { No assumptions made about } \\
\text { normality }\end{array}$ & Linear regression & $\begin{array}{l}n=27\left(18 \mathrm{PKC} \delta^{+}+\right. \\
\left.9 \mathrm{Som}^{+}\right)\end{array}$ & $\begin{array}{l}\text { slope }=-0.0352 ; y \text {-intercept }=10.87 \\
x \text {-intercept }=308.6 ; r^{2}=0.2876 ; F_{(1,25)}=10.09 \\
p=0.0039\end{array}$ \\
\hline 10/ (capacitance RS) & $\begin{array}{l}\text { Normal distribution, different } \\
\text { variances }\end{array}$ & $\begin{array}{l}\text { Unpaired } t \text { test with Welch's } \\
\text { correction (two-tailed) }\end{array}$ & $\begin{array}{l}\mathrm{PKC} \delta^{+} \mathrm{RS}=36 \text { cells } \\
\mathrm{Som}^{+} \mathrm{RS}=13 \text { cells }\end{array}$ & $\begin{array}{l}t=1.665 ; \mathrm{df}=36.78 ; p=0.1045 \\
\eta^{2}=0.07006\end{array}$ \\
\hline $10 H$ (capacitance v spikes RS) & $\begin{array}{l}\text { No assumptions made about } \\
\text { normality }\end{array}$ & Linear regression & $\begin{array}{l}n=48\left(35 \mathrm{PKC} \delta^{+}+\right. \\
\left.13 \mathrm{Som}^{+}\right)\end{array}$ & $\begin{array}{l}\text { slope }=-0.0837 ; y \text {-intercept }=19.47 \\
\text { x-intercept }=232.6 ; r^{2}=0.3189 ; F_{(1,46)}=21.54 \\
p<0.0001\end{array}$ \\
\hline \multicolumn{5}{|l|}{ Figure 11} \\
\hline $11 A i$ (acetone) & Non-normal distribution & Mann-Whitney $U$ test & $\begin{array}{l}\text { Ipsilateral }=21 \text { mice } \\
\text { Contralateral }=21 \text { mice }\end{array}$ & $p<0.0001$ (two-tailed); $U=0$ \\
\hline 11Aii (Hargreaves) & Non-normal distribution & Mann-Whitney $U$ test & $\begin{array}{l}\text { Ipsilateral }=21 \text { mice } \\
\text { Contralateral }=21 \text { mice }\end{array}$ & $p<0.0001$ (two-tailed); $U=2$ \\
\hline 11Aiii (von Frey) & Non-normal distribution & Mann-Whitney $U$ test & $\begin{array}{l}\text { Ipsilateral }=8 \text { mice } \\
\text { Contralateral }=8 \text { mice }\end{array}$ & $p<0.0002$ (two-tailed); $U=0$ \\
\hline 11Bi (IF curve LF) & $\begin{array}{l}\text { Two factors (cell type and current } \\
\text { injection) }\end{array}$ & Mixed-effects model & $\begin{array}{l}\mathrm{PKC} \delta^{+}=12 \text { cells } \\
\mathrm{Som}^{+}=7 \text { cells }\end{array}$ & $\begin{array}{l}\text { cell type: } F_{(1,17)}=1.814 ; p=0.1957 \\
\text { current injection: } F_{(1.378,23)}=124.6 ; p<0.0001\end{array}$ \\
\hline 11Bii (IF curve RS) & $\begin{array}{l}\text { Two factors (cell type and current } \\
\text { injection) }\end{array}$ & Mixed-effects model & $\begin{array}{l}\mathrm{PKC} \delta^{+}=18 \text { cells } \\
\mathrm{Som}^{+}=21 \text { cells }\end{array}$ & $\begin{array}{l}\text { cell type: } F_{(1,37)}=0.001 ; p=0.9739 \\
\text { current injection: } F_{(1.549,55.5)}=144.8 ; p<0.0001\end{array}$ \\
\hline $\begin{array}{l}11 \mathrm{Ci}(\mathrm{APs} \text { at } \\
180 \mathrm{pA} \text { LF) }\end{array}$ & Non-normal distribution & Mann-Whitney $U$ test & $\begin{array}{l}\operatorname{PKC} \delta^{+}=12 \text { cells } \\
\text { Som }^{+}=7 \text { cells }\end{array}$ & $p=0.0314$ (two-tailed); $U=17$ \\
\hline $\begin{array}{l}\text { 11Cii (APs at } \\
360 \mathrm{pA} \text { LF) }\end{array}$ & Non-normal distribution & Mann-Whitney $U$ test & $\begin{array}{l}\mathrm{PKC} \delta^{+}=11 \text { cells } \\
\text { Som }^{+}=7 \text { cells }\end{array}$ & $p=0.8788$ (two-tailed); $U=36.50$ \\
\hline $\begin{array}{l}11 \text { Ciii (APs at } \\
100 \text { pA RS) }\end{array}$ & Non-normal distribution & Mann-Whitney $U$ test & $\begin{array}{l}\mathrm{PKC} \delta^{+}=18 \text { cells } \\
\mathrm{Som}^{+}=21 \text { cells }\end{array}$ & $p=0.4719$ (two-tailed); $U=163.5$ \\
\hline $\begin{array}{l}11 \text { Civ (APs at } \\
200 \text { pA RS) }\end{array}$ & $\begin{array}{l}\text { Normal distribution, different } \\
\quad \text { variances }\end{array}$ & $\begin{array}{l}\text { Unpaired } t \text { test with Welch's } \\
\text { correction (two-tailed) } \\
\text { (Continued) }\end{array}$ & $\begin{array}{l}\mathrm{PKC} \delta^{+}=16 \text { cells } \\
\mathrm{Som}^{+}=20 \text { cells }\end{array}$ & $t=0.7728 ; \mathrm{df}=28.89 ; p=0.4459 ; \eta^{2}=0.0203$ \\
\hline
\end{tabular}


Table 1: Continued

\begin{tabular}{|c|c|c|c|c|}
\hline Figure & Data structure & Type of test & Sample size & Statistical data \\
\hline \multicolumn{5}{|l|}{ Figure 12} \\
\hline$V_{\text {rest }} L F$ pain & Normal distribution, same variance & Unpaired $t$ test (two-tailed) & $\begin{array}{l}\mathrm{PKC} \delta^{+}=12 \text { cells } \\
\text { Som }^{+}=7 \text { cells }\end{array}$ & $t=1.317 ; \mathrm{df}=17 ; p=0.2052 ; \eta^{2}=0.09262$ \\
\hline$V_{\text {rest }} R S$ pain & Normal distribution, same variance & Unpaired $t$ test (two-tailed) & $\begin{array}{l}\mathrm{PKC} \delta^{+}=18 \text { cells } \\
\mathrm{Som}^{+}=21 \text { cells }\end{array}$ & $t=1.165 ; \mathrm{df}=37 ; p=0.2515 ; \eta^{2}=0.0354$ \\
\hline $\mathrm{R}_{\text {in }} \mathrm{LF}$ pain & Non-normal distribution & Mann-Whitney $U$ test & $\begin{array}{l}\mathrm{PKC} \delta^{+}=12 \text { cells } \\
\mathrm{Som}^{+}=7 \text { cells }\end{array}$ & $p=0.1195$ (two-tailed); $U=23$ \\
\hline $\mathrm{R}_{\text {in }} \mathrm{RS}$ pain & Normal distribution, same variance & Unpaired $t$ test (two-tailed) & $\begin{array}{l}\mathrm{PKC} \delta^{+}=18 \text { cells } \\
\mathrm{Som}^{+}=21 \text { cells }\end{array}$ & $t=1.580 ; \mathrm{df}=37 ; p=0.1227 ; \eta^{2}=0.0632$ \\
\hline rheobase LF pain & $\begin{array}{l}\text { Normal distribution, different } \\
\text { variances }\end{array}$ & $\begin{array}{l}\text { Unpaired } t \text { test with Welch's } \\
\text { correction (two-tailed) }\end{array}$ & $\begin{array}{l}\mathrm{PKC} \delta^{+}=12 \text { cells } \\
\mathrm{Som}^{+}=7 \text { cells }\end{array}$ & $t=2.050 ; \mathrm{df}=7.092 ; p=0.0790 ; \eta^{2}=0.3721$ \\
\hline rheobase RS pain & Normal distribution, same variance & Unpaired $t$ test (two-tailed) & $\begin{array}{l}\mathrm{PKC} \delta^{+}=18 \text { cells } \\
\mathrm{Som}^{+}=21 \text { cells }\end{array}$ & $t=1.466 ; \mathrm{df}=37 ; p=0.1510 ; \eta^{2}=0.0549$ \\
\hline latency LF pain & Non-normal distribution & Mann-Whitney $U$ test & $\begin{array}{l}\mathrm{PKC} \delta^{+}=12 \text { cells } \\
\mathrm{Som}^{+}=6 \text { cells }\end{array}$ & $p=0.9636$ (two-tailed); $U=35$ \\
\hline latency RS pain & Non-normal distribution & Mann-Whitney $U$ test & $\begin{array}{l}\mathrm{PKC} \delta^{+}=18 \text { cells } \\
\mathrm{Som}^{+}=21 \text { cells }\end{array}$ & $p=0.8564$ (two-tailed); $U=182$ \\
\hline \multicolumn{5}{|l|}{ Table 2} \\
\hline$V_{\text {rest }} L F$ & $\begin{array}{l}\text { Normal distribution, different } \\
\text { variances }\end{array}$ & $\begin{array}{l}\text { Unpaired } t \text { test with Welch's } \\
\text { correction (two-tailed) }\end{array}$ & $\begin{array}{l}\mathrm{Na}=9 \text { cells } \\
\mathrm{Ac}=8 \text { cells }\end{array}$ & $t=0.3887 ; \mathrm{df}=10.42 ; p=0.7053 ; \eta^{2}=0.0143$ \\
\hline $\mathrm{V}_{\text {rest }} \mathrm{RS}$ & Normal distribution, same variances & Unpaired $t$ test (two-tailed) & $\begin{array}{l}\mathrm{Na}=17 \text { cells } \\
\mathrm{Ac}=18 \text { cells }\end{array}$ & $t=2.920 ; \mathrm{df}=33 ; p=0.0063 ; \eta^{2}=0.2052$ \\
\hline $\mathrm{R}_{\text {in }} \mathrm{LF}$ & $\begin{array}{l}\text { Normal distribution, different } \\
\text { variances }\end{array}$ & $\begin{array}{l}\text { Unpaired } t \text { test with Welch's } \\
\text { correction (two-tailed) }\end{array}$ & $\begin{array}{l}\mathrm{Na}=9 \text { cells } \\
\mathrm{Ac}=9 \text { cells }\end{array}$ & $t=0.3179 ; \mathrm{df}=11.09 ; p=0.7565 ; \eta^{2}=0.0090$ \\
\hline \multicolumn{5}{|l|}{ Table 2} \\
\hline $\mathrm{R}_{\text {in }} \mathrm{RS}$ & Normal distribution, same variances & Unpaired $t$ test (two-tailed) & $\begin{array}{l}\mathrm{Na}=17 \text { cells } \\
\mathrm{Ac}=18 \text { cells }\end{array}$ & $t=0.7474 ; \mathrm{df}=33 ; p=0.4601 ; \eta^{2}=0.0167$ \\
\hline Rheobase LF & $\begin{array}{l}\text { Normal distribution, different } \\
\text { variances }\end{array}$ & $\begin{array}{l}\text { Unpaired } t \text { test with Welch's } \\
\text { correction (two-tailed) }\end{array}$ & $\begin{array}{l}\mathrm{Na}=9 \text { cells } \\
\mathrm{Ac}=9 \text { cells }\end{array}$ & $t=0.0923 ; \mathrm{df}=10.98 ; p=0.9282 ; \eta^{2}=0.001$ \\
\hline Rheobase RS & Non-normal distribution & Unpaired $t$ test (two-tailed) & $\begin{array}{l}\mathrm{Na}=17 \text { cells } \\
\mathrm{Ac}=19 \text { cells }\end{array}$ & $p=0.6639$ (two-tailed); $U=147.5$ \\
\hline Latency LF & Normal distribution, same variances & Unpaired $t$ test (two-tailed) & $\begin{array}{l}\mathrm{Na}=8 \text { cells } \\
\mathrm{Ac}=7 \text { cells }\end{array}$ & $t=0.3191 ; \mathrm{df}=13 ; p=0.7547 ; \eta^{2}=0.008$ \\
\hline Latency RS & Normal distribution, same variances & Unpaired $t$ test (two-tailed) & $\begin{array}{l}\mathrm{Na}=15 \text { cells } \\
\mathrm{Ac}=15 \text { cells }\end{array}$ & $t=1.640 ; \mathrm{df}=28 ; p=0.1122 ; \eta^{2}=0.088$ \\
\hline ISI LF & Non-normal distribution & Mann-Whitney $U$ test & $\begin{array}{l}\mathrm{Na}=8 \text { cells } \\
\mathrm{Ac}=7 \text { cells }\end{array}$ & $p=0.0003 ; U=0$ \\
\hline ISI RS & Normal distribution, same variances & Uunpaired $t$ test (two-tailed) & $\begin{array}{l}\mathrm{Na}=17 \text { cells } \\
\mathrm{Ac}=18 \text { cells }\end{array}$ & $t=10.38 ; \mathrm{df}=33 ; p<0.0001 ; \eta^{2}=0.7656$ \\
\hline Amplitude accommodation LF & Normal distribution, same variances & Unpaired $t$ test (two-tailed) & $\begin{array}{l}\mathrm{Na}=9 \text { cells } \\
\mathrm{Ac}=7 \text { cells }\end{array}$ & $t=1.170 ; \mathrm{df}=14 ; p=0.2616 ; \eta^{2}=0.089$ \\
\hline Amplitude accommodation RS & $\begin{array}{l}\text { Normal distribution, different } \\
\text { variances }\end{array}$ & $\begin{array}{l}\text { Unpaired } t \text { test with Welch's } \\
\text { correction (two-tailed) }\end{array}$ & $\begin{array}{l}\mathrm{Na}=14 \text { cells } \\
\mathrm{Ac}=20 \text { cells }\end{array}$ & $t=4.787 ; \mathrm{df}=22.08 ; p<0.0001 ; \eta^{2}=0.509$ \\
\hline Width accommodation LF & Non-normal distribution & Mann-Whitney $U$ test & $\begin{array}{l}\mathrm{Na}=9 \text { cells } \\
\mathrm{Ac}=7 \text { cells }\end{array}$ & $p>0.9999$ (two-tailed); $U=31$ \\
\hline Width accommodation RS & Non-normal distribution & Mann-Whitney $U$ test & $\begin{array}{l}\mathrm{Na}=12 \text { cells } \\
\mathrm{Ac}=16 \text { cells }\end{array}$ & $p=0.3470$ (two-tailed); $U=75$ \\
\hline AHP accommodation LF & Normal distribution, same variances & Unpaired $t$ test (two-tailed) & $\begin{array}{l}\mathrm{Na}=9 \text { cells } \\
\mathrm{Ac}=7 \text { cells }\end{array}$ & $t=0.1568 ; \mathrm{df}=14 ; p=0.8776 ; \eta^{2}=0.0018$ \\
\hline AHP accommodation RS & Normal distribution, same variances & Unpaired $t$ test (two-tailed) & $\begin{array}{l}\mathrm{Na}=12 \text { cells } \\
\mathrm{Ac}=16 \text { cells }\end{array}$ & $t=1.740 ; \mathrm{df}=34 ; p=0.0908 ; \eta^{2}=0.082$ \\
\hline$I_{\text {threshold }}$ LF & Normal distribution, same variances & Unpaired $t$ test (two-tailed) & $\begin{array}{l}\mathrm{Na}=9 \text { cells } \\
\mathrm{Ac}=7 \text { cells }\end{array}$ & $t=0.5140 ; \mathrm{df}=14 ; p=0.6153 ; \eta^{2}=0.0185$ \\
\hline I threshold $_{\text {RS }}$ & Non-normal distribution & Mann-Whitney $U$ test & $\begin{array}{l}\mathrm{Na}=13 \text { cells } \\
\mathrm{Ac}=18 \text { cells }\end{array}$ & $p=0.2218$ (two-tailed); $U=86$ \\
\hline $\mathrm{V}_{\text {threshold }} \mathrm{LF}$ & Normal distribution, same variances & Unpaired $t$ test (two-tailed) & $\begin{array}{l}\mathrm{Na}=9 \text { cells } \\
\mathrm{Ac}=7 \text { cells }\end{array}$ & $t=0.4831 ; \mathrm{df}=14 ; p=0.6365 ; \eta^{2}=0.016$ \\
\hline $\mathrm{V}_{\text {threshold }} \mathrm{RS}$ & Normal distribution, same variances & Unpaired $t$ test (two-tailed) & $\begin{array}{l}\mathrm{Na}=13 \text { cells } \\
\mathrm{Ac}=18 \text { cells }\end{array}$ & $t=0.50904 ; \mathrm{df}=29 ; p=0.5595 ; \eta^{2}=0.012$ \\
\hline Rise LF & Normal distribution, same variance & Unpaired $t$ test (two-tailed) & $\begin{array}{l}\mathrm{Na}=9 \text { cells } \\
\mathrm{Ac}=7 \text { cells }\end{array}$ & $t=0.5678 ; \mathrm{df}=14 ; p=0.5792 ; \eta^{2}=0.023$ \\
\hline & & (Continued) & & \\
\hline
\end{tabular}


Table 1: Continued

\begin{tabular}{|c|c|c|c|c|}
\hline Figure & Data structure & Type of test & Sample size & Statistical data \\
\hline \multirow[t]{2}{*}{ Rise RS } & Normal distribution, same variance & Unpaired $t$ test (two-tailed) & $\mathrm{Na}=13$ cells & $t=1.089 ; \mathrm{df}=29 ; p=0.2851 ; \eta^{2}=0.039$ \\
\hline & & & $\mathrm{Ac}=18$ cells & \\
\hline \multirow[t]{2}{*}{ Decay LF } & Non-normal distribution & Mann-Whitney $U$ test & $\mathrm{Na}=9$ cells & $p>0.9999$ (two-tailed); $U=31.50$ \\
\hline & & & $A c=7$ cells & \\
\hline \multirow[t]{2}{*}{ Decay RS } & Normal distribution, different & Unpaired $t$ test with Welch's & $\mathrm{Na}=13$ cells & $t=0.007 ; \mathrm{df}=23.94 ; p=0.9946 ; \eta^{2}=0$ \\
\hline & variances & correction (two-tailed) & $\mathrm{Ac}=18$ cells & \\
\hline \multirow[t]{2}{*}{ Width LF } & Non-normal distribution & Mann-Whitney $U$ test & $\mathrm{Na}=9$ cells & $p=0.6065$ (two-tailed); $U=26$ \\
\hline & & & $\mathrm{Ac}=7$ cells & \\
\hline \multirow[t]{2}{*}{ Width RS } & Normal distribution, different & Unpaired $t$ test with Welch's & $\mathrm{Na}=13$ cells & $t=0.4235 ; \mathrm{df}=24.70 ; p=0.6756 ; \eta^{2}=0.007$ \\
\hline & variances & correction (two-tailed) & $\mathrm{Ac}=18$ cells & \\
\hline \multirow[t]{2}{*}{ AHP LF } & Non-normal distribution & Mann-Whitney $U$ test & $\mathrm{Na}=9$ cells & $t=1.277 ; \mathrm{df}=14 ; p=2225 ; \eta^{2}=0.1043$ \\
\hline & & & $\mathrm{Ac}=7$ cells & \\
\hline \multirow[t]{2}{*}{ AHP RS } & Non-normal distribution & Mann-Whitney $U$ test & $\mathrm{Na}=13$ cells & $p=0.1348$ (two-tailed); $U=79$ \\
\hline & & & $\mathrm{Ac}=18 \mathrm{cells}$ & \\
\hline
\end{tabular}

Detailed information about data structure, statistical tests and results, and sample sizes. LF = late-firing; RS = regular-spiking; IF = current-frequency plot; RM = repeated measures; $F(D F n, D F d)=d f$ for the numerator of the $F$ ratio, for the denominator of the $F$ ratio; $d f=$ degrees of freedom; Rin $=$ input resistance; $V_{\text {rest }}=$ resting membrane potential; $\mathrm{AHP}=$ afterhyperpolarization; $I_{\text {threshold }}=$ current threshold; $\mathrm{V}_{\text {threshold }}=$ voltage threshold; IS = interspike; $\mathrm{AP}=$ action potential; Na = non-accommodating; $\mathrm{Ac}=$ accommodating; $I S I$ = interspike interval; $V_{\text {sag }}=$ voltage sag.

the $75(27 \%) \operatorname{PKC} \delta^{+}$neurons recorded are spontaneously active. The remaining $\mathrm{PKC} \delta{ }^{+}$and $\mathrm{Som}^{+}$cells were late-firing and the proportion of this firing type, relative to the total cells, is similar between $\operatorname{PKC} \delta^{+}(19 / 75$;
$25 \%)$ and Som $^{+}(9 / 49 ; 18 \%)$ neurons. Together, these results demonstrate that while firing phenotypes are heterogeneous in $\mathrm{PKC} \delta^{+}$and $\mathrm{Som}^{+}$CeLC cells, the proportion of cells with different firing types is cell-
A

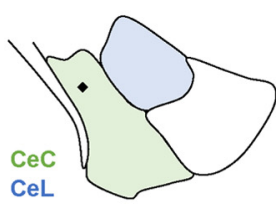

ํo

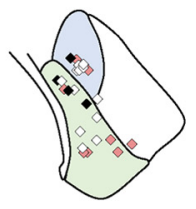

Bregma -1.06

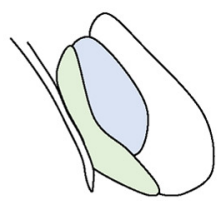

Bregma -1.22

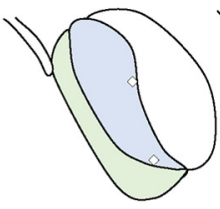

Bregma -1.34

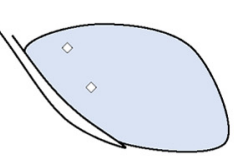

Bregma - 1.94

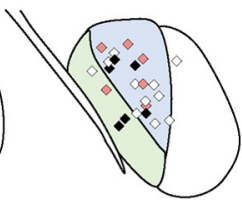

Bregma -1.46

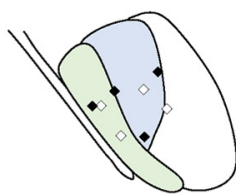

Bregma -1.58

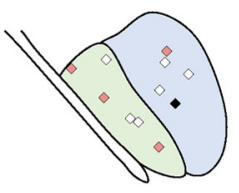

Bregma -1.70

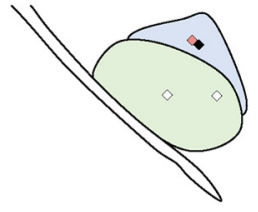

Bregma -1.82

\section{$\checkmark$ LF \\ $\diamond \mathrm{RS}$
$\diamond \mathrm{S}$}

B
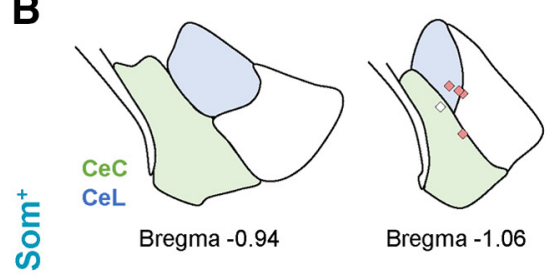

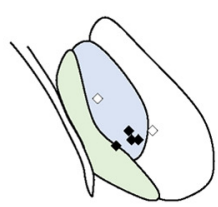

Bregma -1.22

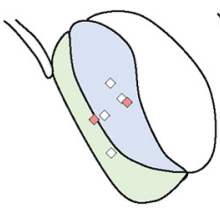

Bregma -1.34

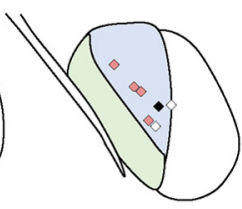

Bregma -1.46

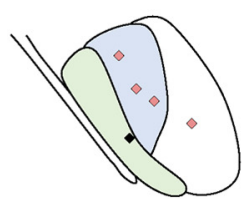

Bregma -1.58

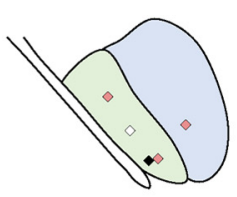

Bregma -1.70

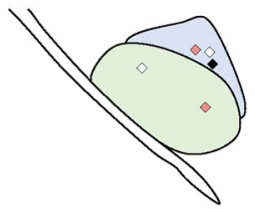

Bregma -1.82

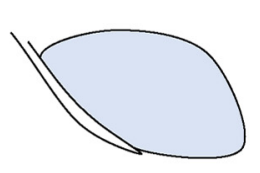

LF

Bregma -1.94

Figure 2. Anatomical location of electrophysiology recordings. Rostro-caudal anatomic locations of recorded PKC $\delta^{+}(\boldsymbol{A})$ and Som ${ }^{+}$ (B) cells, represented as a schematic of the CeLC, created using Franklin and Paxinos (2008). The capsular (CeC) and lateral (CeL) subdivisions of the $\mathrm{CeA}$ are shown in green and blue, respectively. LF = late-firing; $\mathrm{RS}=$ regular-spiking; $\mathrm{S}=\mathrm{spontaneous}$. 

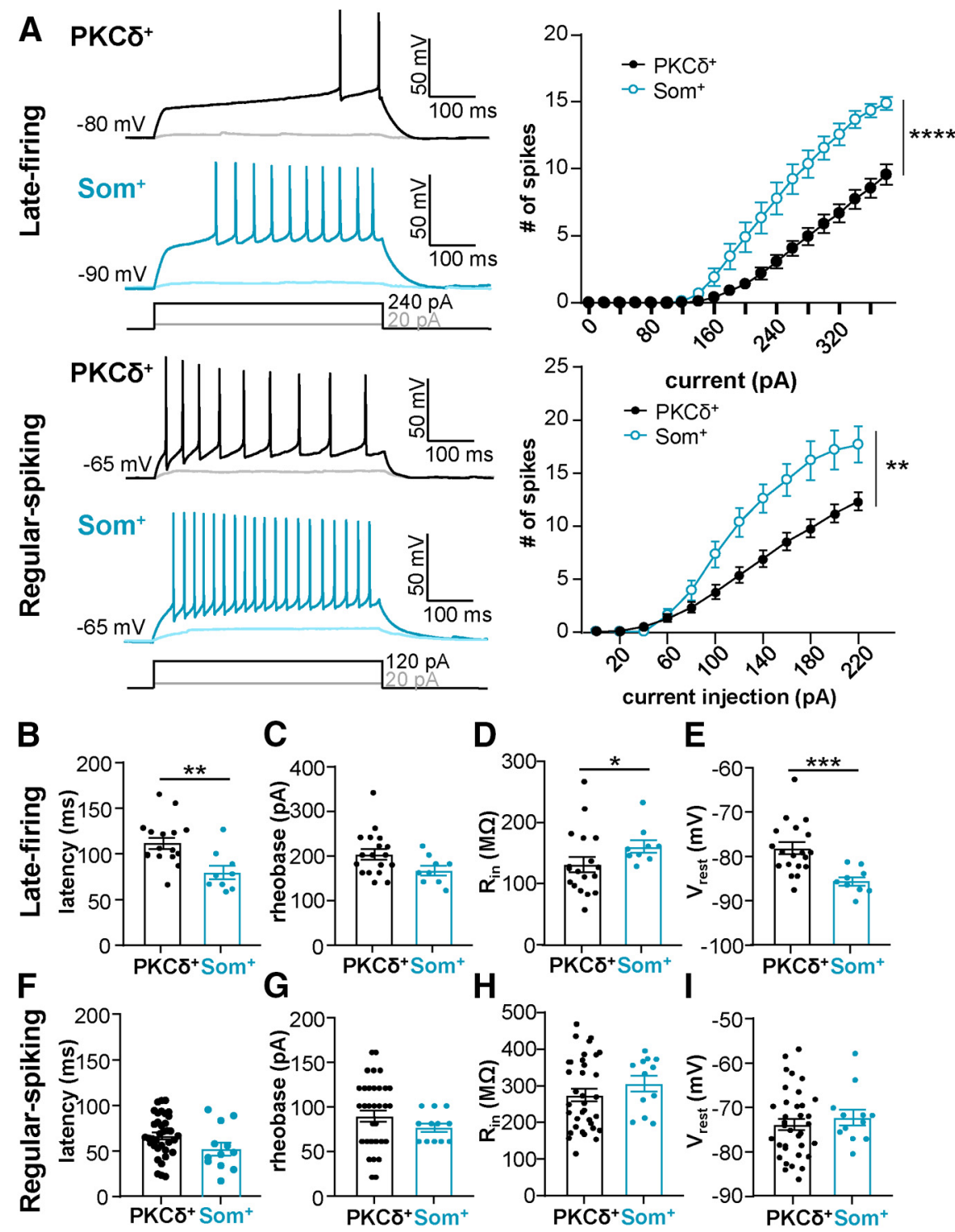

Figure 3. Som ${ }^{+}$CeLC neurons are more excitable than $\mathrm{PKC} \delta^{+}$cells. $\boldsymbol{A}$, Representative voltage traces of late-firing (top left) or regular-spiking (bottom left) $\mathrm{PKC} \delta^{+}$cells (black) or Som ${ }^{+}$cells (blue) in response to depolarizing current injections. Right panel shows the number of spikes elicited as a function of the current injection amplitude; ${ }^{* \star *} p<0.0001,{ }^{* *} p<0.0036$, two-way ANOVA. $\boldsymbol{B}-\boldsymbol{I}$, Latency to first spike $(\boldsymbol{B}, \boldsymbol{F})$, rheobase $(\boldsymbol{C}, \boldsymbol{G}), \mathrm{R}_{\text {in }}(\boldsymbol{D}, \boldsymbol{H})$, and resting membrane potential $\left(\mathrm{V}_{\text {rest }} ; \boldsymbol{E}, \boldsymbol{I}\right)$ for late-firing $(\boldsymbol{B}-\boldsymbol{E})$ and regularspiking $(\boldsymbol{F}-\boldsymbol{I})$ neurons; ${ }^{* *} p=0.0039$, unpaired two-tailed $t$ test; ${ }^{*} p=0.0308$, Mann-Whitney $U$ test; ${ }^{* * *} p=0.0002$, unpaired two-tailed $t$ test with Welch's correction. For PKC $\delta^{+}$cells: $n=16-19$ cells for late-firing and $n=35-36$ regular-spiking. For Som ${ }^{+}$cells: $n=9$ for late-firing and $n=12$ for regular-spiking. All values are expressed as mean \pm SEM.

type-specific. The greater proportion of spontaneously active Som ${ }^{+}$cells suggests that these cells have a larger overall output compared with $\mathrm{PKC} \delta{ }^{+}$cells in the CeLC.

In the next set of experiments, we generated input-output curves to determine whether the relative excitability of $\mathrm{PKC} \delta \delta^{+}$and $\mathrm{Som}^{+}$neurons is also different in late-firing and regular-spiking cells. Output in these experiments is defined as action potential firing rates in response to depolarizing current injections of increasing amplitudes. As illustrated in Figure $3 A$, prolonged $(500 \mathrm{~ms})$ depolarizing current injections elicited repetitive firing in both late-firing and regular-spiking $\mathrm{PKC} \delta{ }^{+}$and $\mathrm{Som}^{+}$neurons, with firing responses increasing as a function of the current injection amplitude in all four cell types. Evoked repetitive firing responses in late-firing and regular-spiking Som ${ }^{+}$neurons are significantly higher than in late-firing and regular-spiking $\mathrm{PKC} \delta^{+}$cells, respectively, underscoring the notion that $\mathrm{Som}^{+}$cell output far outpaces that of $\mathrm{PKC} \delta{ }^{+}$neurons in the CeLC.

Consistent with the relative hyperexcitable phenotype of Som ${ }^{+}$late-firing neurons, compared with $\mathrm{PKC} \delta^{+}$latefiring cells, the latency to first spike is significantly shorter in these cells $(79.54 \pm 7.32 \mathrm{~ms})$, compared with $\mathrm{PKC} \delta^{+}$ late-firing cells $(111.5 \pm 6.23 \mathrm{~ms}$; Fig. $3 B)$. The minimal current amplitude that elicits an action potential 

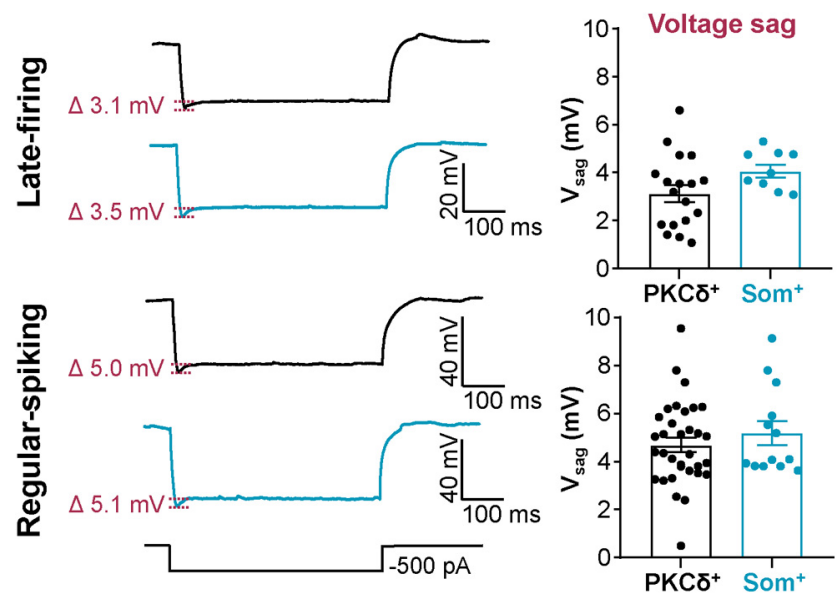

Figure 4. Voltage sag is indistinguishable in $\mathrm{PKC} \delta^{+}$and $\mathrm{Som}^{+}$ cells. Representative traces of late-firing (top) and regular-spiking (bottom) neurons in response to a 500-ms hyperpolarizing current injection, with $\mathrm{PKC} \delta{ }^{+}$cells shown in black and Som ${ }^{+}$ cells in blue. Values are reported as mean \pm SEM. For PKC $\delta^{+}$ cells: $n=18$ cells for late-firing and $n=33$ regular-spiking. For Som $^{+}$cells: $n=9$ for late-firing and $n=13$ for regular-spiking. Voltage sag $=\mathrm{V}_{\text {sag }}$.

(rheobase) as well as the voltage sag in response to a hyperpolarizing current injection, however, were indistinguishable between $\mathrm{PKC} \delta{ }^{+}$and $\mathrm{Som}^{+}$late-firing neurons (Fig. $3 C$ and Fig. 4).

Subthreshold membrane properties, like $R_{\text {in }}$ and resting membrane potential, can strongly influence the firing responses of a neuron in response to stimulation. To determine whether subthreshold membrane properties contribute to the relative hyperexcitable phenotype of $\mathrm{Som}^{+} \mathrm{CeLC}$ neurons, we measured and compared these two parameters in $\operatorname{PKC} \delta{ }^{+}$and $\mathrm{Som}^{+}$late-firing and regular-spiking neurons. Our analyses showed that $\mathrm{R}_{\text {in }}$ is significantly higher in Som ${ }^{+}$ $(160.5 \pm 10.23 \mathrm{M} \Omega)$ compared with $\mathrm{PKC} \delta{ }^{+}$late-firing cells (131.4 $\pm 12.51 \mathrm{M} \Omega$; Fig. $3 D$ ), suggesting that differences in subthreshold conductances might contribute to the differences in excitability observed in $\mathrm{PKC} \delta{ }^{+}$and $\mathrm{Som}^{+}$neurons. Notably, the membrane potentials of late-firing $\mathrm{Som}^{+}$neurons $(-84.44 \pm 0.96 \mathrm{mV}$ ) are significantly hyperpolarized relative to the resting membrane potentials in $\mathrm{PKC} \delta{ }^{+}$late-firing cells $(-78.14 \pm 1.37 \mathrm{mV}$; Fig. $3 E)$, demonstrating that the greater excitability of late-firing Som ${ }^{+}$cells is independent of the resting membrane potential. In contrast, despite the pronounced differences in evoked firing responses of $\mathrm{Som}^{+}$and $\mathrm{PKC} \delta{ }^{+}$regular-spiking neurons, all other passive and active membrane properties measured are indistinguishable between these two genetically distinct cell types (Fig. 3F-I and Fig. 4). Of note, however, despite the indistinguishable properties in regular-spiking neurons, the values for rheobase to fire action potentials in individual $\mathrm{PKC} \delta{ }^{+}$neurons were nonnormally distributed (Fig. 3G), suggesting heterogeneity within this neuronal population.

Together, these results demonstrate that the output of Som ${ }^{+}$cells outpaces that of $\mathrm{PKC} \delta{ }^{+}$cells in the CeLC but that the cellular mechanisms underlying the differences in excitability in $\mathrm{Som}^{+}$and $\mathrm{PKC} \delta{ }^{+}$neurons are distinct for late-firing and regular-spiking cells.

\section{PKC $\delta^{+}$, but not Som ${ }^{+}$, CeLC neurons display accommodation of repetitive firing}

ISI accommodation reflects the ability of neurons to sustain the frequency of firing in response to prolonged depolarizing input. The presence of ISI accommodation has been previously reported in CeLC neurons and has been widely used as a parameter to classify neurons in this brain region (Schiess et al., 1999; Zhu and Pan, 2004; Hunt et al., 2017).

To further determine whether firing properties in the CeLC are cell-type-specific and to gain additional insight into the mechanisms driving the differences in excitability of these cells, we measured and compared ISI accommodation between $\mathrm{Som}^{+}$and $\mathrm{PKC} \delta{ }^{+}$CeLC neurons. Prolonged (500 ms) current injections elicited repetitive firing in late-firing and regular-spiking $\mathrm{Som}^{+}$and $\mathrm{PKC} \delta{ }^{+} \mathrm{CeLC}$ neurons (Fig. 5A). Quantification of the number of cells that display ISI accommodation further revealed that approximately half of the late-firing and half of the regular-spiking $\mathrm{PKC} \delta{ }^{+}$neurons undergo ISI accommodation (Fig. 5B). In marked contrast, however, only one of the $21 \mathrm{Som}^{+}$neurons analyzed exhibited ISI accommodation in response to depolarizing current injection. The almost complete lack of ISI accommodation in Som ${ }^{+}$neurons is consistent with the overall higher output of these CeLC cells, compared with the $\mathrm{PKC} \delta{ }^{+}$neurons. Further analyses of firing responses, as well as passive and active membrane properties, in accommodating and non-accommodating $\operatorname{PKC} \delta{ }^{+}$neurons with either latefiring or regular-spiking phenotypes revealed that some of these properties were different in regular-spiking accommodating and non-accommodating neurons (Table 2). The amplitude accommodation ratio between first and last spikes, for example, is significantly smaller in accommodating $\mathrm{PKC} \delta{ }^{+}$cells $(0.7 \pm 0.03)$ than in non-accommodating $\mathrm{PKC} \delta{ }^{+}$cells $(0.8 \pm 0.01)$. In addition, resting membrane potential is significantly hyperpolarized in non-accommodating $\mathrm{PKC} \delta^{+}$cells $(-77.4 \pm 0.8 \mathrm{mV})$, compared with accommodating $\mathrm{PKC} \delta{ }^{+}$cells $(-70.6 \pm 1.8 \mathrm{mV})$. The differences in resting potentials between accommodating and non-accommodating regular-spiking neurons might contribute to the non-normal distribution of the resting potential values that we measured in the pooled data from regular-spiking $\mathrm{PKC} \delta{ }^{+}$neurons presented in Figure $3 /$.

All other properties measured in regular-spiking neurons and all properties measured in late-firing neurons, however, were indistinguishable in $\mathrm{PKC} \delta{ }^{+}$and $\mathrm{Som}^{+}$neurons. Given the few differences in passive and active membrane within firing types, for the remainder of this study, accommodating and non-accommodating $\mathrm{PKC} \delta{ }^{+}$neurons were pooled and compared with non-accommodating Som ${ }^{+}$cells.

Frequency-dependent changes in spike amplitude, width and AHP are three additional parameters used to measure the ability of neurons to sustain repetitive firing in response to prolonged depolarizing input. The presence of spike amplitude accommodation, spike broadening and AHP amplitude accommodation within an evoked train of action potentials are commonly used to classify and electrophysiologically characterize neurons in other brain regions, reflecting the repertoire of ion channels and ionic conductance of a cell (Bean, 2007). It is unknown, 
A

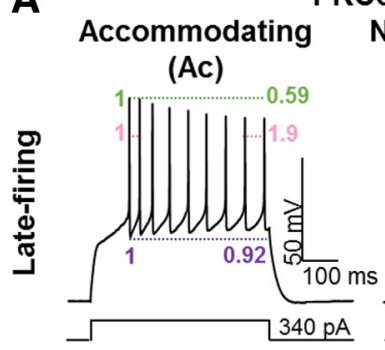

$\mathrm{PKC}^{+}$

Non-accommodating

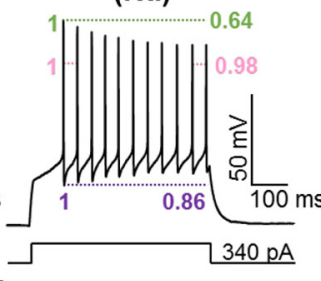

ISI …. Amplitude …. AHP

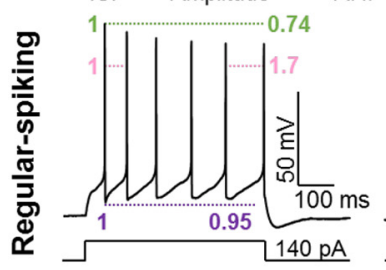

$-$

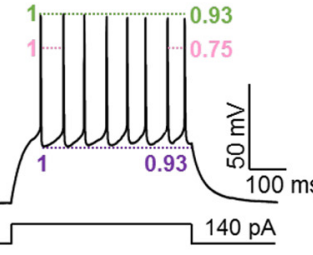

(Na)

Som ${ }^{+}$

(Na)

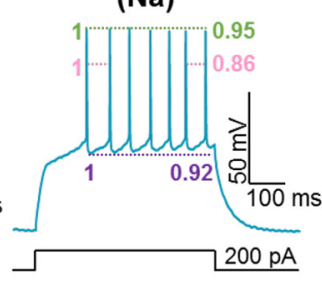

$1+0.93$

Late-firing

C
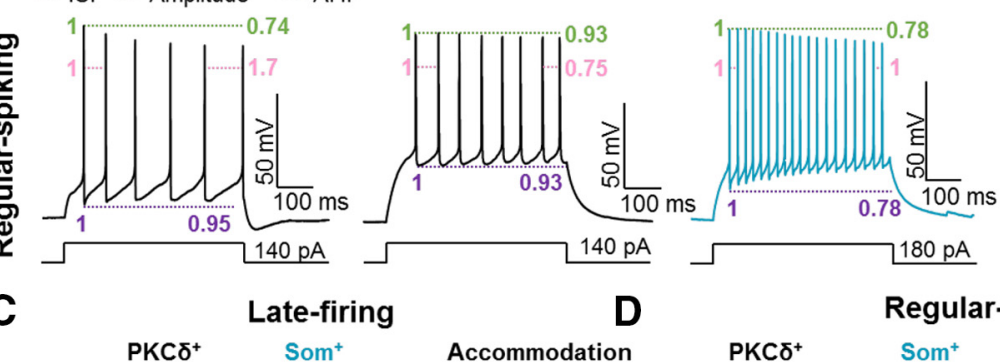

B
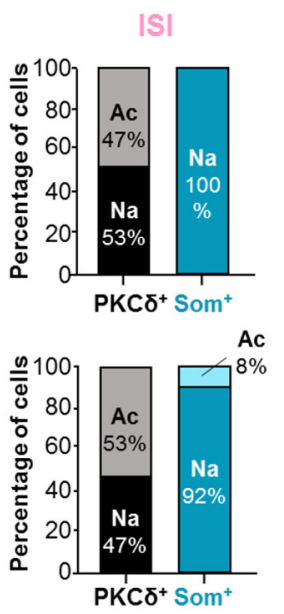
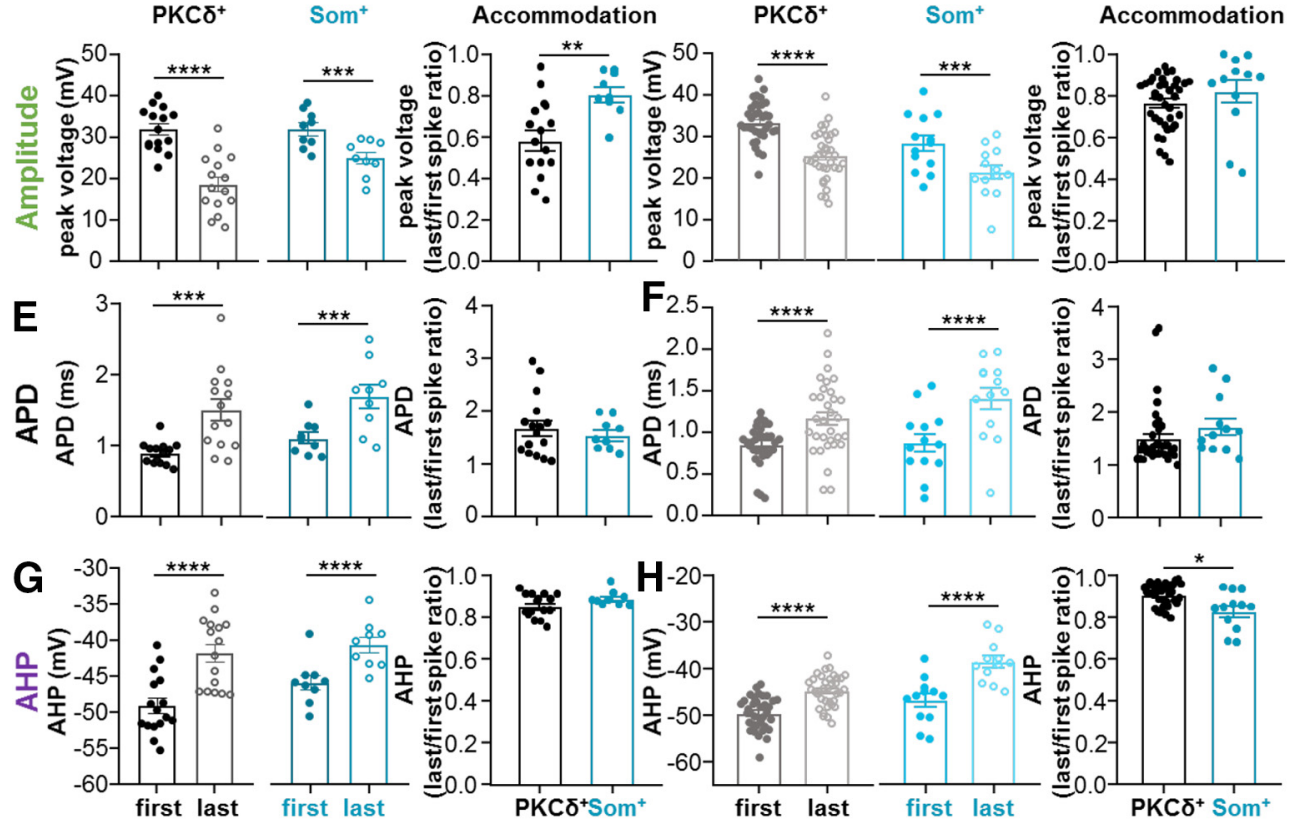

Figure 5. Accommodation is selective to $\mathrm{PKC} \delta^{+}$, but not Som ${ }^{+}$, neurons. $\boldsymbol{A}$, Representative voltage records of $\mathrm{PKC} \delta^{+}$accommodating (Ac, left) and non-accommodating ( $\mathrm{Na}$, center) cells and Som ${ }^{+} \mathrm{Na}$ cells (right) for late-firing (top) regular-spiking (bottom) cells. Pink annotations depict ISI accommodation, green denotes spike amplitude accommodation, and purple shows AHP amplitude accommodation. $\boldsymbol{B}$, The proportions of $\mathrm{Na}$ and Ac late-firing and regular-spiking $\mathrm{PKC} \delta^{+}$and Som ${ }^{+}$cells. $\boldsymbol{C}-\boldsymbol{H}$, Spike amplitude accommodation $(\boldsymbol{C}, \boldsymbol{D})$, APD accommodation $(\boldsymbol{E}, \boldsymbol{F})$, and AHP amplitude accommodation $(\boldsymbol{G}, \boldsymbol{H})$ for late-firing (left) and regularspiking (right) $\mathrm{PKC} \delta{ }^{+}$and Som ${ }^{+}$cells; ${ }^{* * *} p<0.0001$, ${ }^{* \star *} p<0.005$, paired two-tailed $t$ test; ${ }^{* \star} p=0.0034$, unpaired two-tailed $t$ test; ${ }^{*} p=0.0142$, unpaired two-tailed $t$ test with Welch's correction. For $\mathrm{PKC} \delta^{+}$cells: $n=14-16$ cells for late-firing and $n=33-36$ regularspiking. For Som ${ }^{+}$cells: $n=9$ for late-firing and $n=12-13$ for regular-spiking. All values are expressed as mean \pm SEM.

however, whether CeLC neurons display frequency-dependent changes in spike amplitude, width or AHP and, if they do, whether these changes are also cell-typespecific.

Measurements and comparisons of the amplitudes, widths and AHPs of the first and last spike within an evoked train of action potentials in late-firing and regularspiking $\mathrm{Som}^{+}$and $\mathrm{PKC} \delta{ }^{+}$CeLC neurons demonstrated that all CeLC neurons display robust and significant frequency-dependent changes in spike amplitude, width and AHP amplitude in response to depolarizing current injections (Fig. 5C-H). In all cells analyzed, for example, the amplitude of the last spike in an evoked train of action potentials is significantly shorter than the amplitude of the first spike within the same train (Fig. $5 C, D$ ). Notably, while frequency-dependent shortening of the action potential is indistinguishable in $\mathrm{PKC} \delta \delta^{+}$and $\mathrm{Som}^{+}$regular-spiking neurons (Fig. 5D), it is significantly larger in $\mathrm{PKC} \delta^{+}(0.58 \pm 0.05)$ than in $\mathrm{Som}^{+}$latefiring cells $(0.80 \pm 0.04$; Fig. $5 C)$. 
Table 2: Passive membrane, repetitive firing, and single action potential properties of PKC $\delta^{+}$non-accommodating and accommodating cells

\begin{tabular}{|c|c|c|c|c|}
\hline & \multicolumn{2}{|c|}{ Late-firing } & \multicolumn{2}{|c|}{ Regular-spiking } \\
\hline & Non-accommodating & Accommodating & Non-accommodating & Accommodating \\
\hline \multicolumn{5}{|l|}{ Passive membrane properties } \\
\hline $\mathrm{V}_{\text {rest }}(\mathrm{mV})$ & $\begin{array}{l}-78.7 \pm 2.0 \\
(n=9)\end{array}$ & $\begin{array}{l}-79.5 \pm 0.8 \\
(n=8)\end{array}$ & $\begin{array}{l}-77.4 \pm 0.8^{*} \\
(n=17)\end{array}$ & $\begin{array}{l}-70.6 \pm 1.8^{*} \\
(n=18)\end{array}$ \\
\hline $\mathrm{R}_{\text {in }}(\mathrm{M} \Omega)$ & $\begin{array}{l}135.5 \pm 23.5 \\
(n=9)\end{array}$ & $\begin{array}{l}127.3 \pm 10.5 \\
(n=8)\end{array}$ & $\begin{array}{l}285.6 \pm 25.6 \\
(n=17)\end{array}$ & $\begin{array}{l}260.6 \pm 21.6 \\
(n=18)\end{array}$ \\
\hline \multicolumn{5}{|l|}{ Repetitive firing properties } \\
\hline Rheobase (pA) & $\begin{array}{l}204.4 \pm 22.05 \\
(n=9)\end{array}$ & $\begin{array}{l}202.2 \pm 9.7 \\
(n=9)\end{array}$ & $\begin{array}{l}92.9 \pm 8.7 \\
(n=17)\end{array}$ & $\begin{array}{l}76.7 \pm 4.8 \\
(n=19)\end{array}$ \\
\hline Latency (ms) & $\begin{array}{l}110.5 \pm 9.8 \\
(n=8)\end{array}$ & $\begin{array}{l}114.8 \pm 9.3 \\
(n=7)\end{array}$ & $\begin{array}{l}69.9 \pm 5.0 \\
(n=15)\end{array}$ & $\begin{array}{l}58.4 \pm 4.9 \\
(n=15)\end{array}$ \\
\hline ISI accommodation & $\begin{array}{l}1.2 \pm 0.1^{\star *} \\
(n=8)\end{array}$ & $\begin{array}{l}2.0 \pm 0.1^{\star \star} \\
(n=7)\end{array}$ & $\begin{array}{l}1.0 \pm 0.06^{\star * *} \\
(n=17)\end{array}$ & $\begin{array}{l}1.9 \pm 0.06^{\star * *} \\
(n=18)\end{array}$ \\
\hline Amplitude accommodation ratio & $\begin{array}{l}0.6 \pm 0.06 \\
(n=9)\end{array}$ & $\begin{array}{l}0.7 \pm 0.12 \\
(n=7)\end{array}$ & $\begin{array}{l}0.8 \pm 0.01^{\#} \\
(n=14)\end{array}$ & $\begin{array}{l}0.7 \pm 0.03^{\#} \\
(n=19)\end{array}$ \\
\hline Width accommodation ratio & $\begin{array}{l}1.7 \pm 0.2 \\
(n=9)\end{array}$ & $\begin{array}{l}1.7 \pm 0.2 \\
(n=7)\end{array}$ & $\begin{array}{l}1.3 \pm 0.04 \\
(n=17)\end{array}$ & $\begin{array}{l}1.2 \pm 0.05 \\
(n=16)\end{array}$ \\
\hline AHP accommodation ratio & $\begin{array}{l}0.8 \pm 0.02 \\
(n=19)\end{array}$ & $\begin{array}{l}0.9 \pm 0.02 \\
(n=7)\end{array}$ & $\begin{array}{l}0.9 \pm 0.01 \\
(n=17)\end{array}$ & $\begin{array}{l}0.9 \pm 0.01 \\
(n=19)\end{array}$ \\
\hline \multicolumn{5}{|l|}{ Single action potential properties } \\
\hline Current threshold $(\mathrm{pA})$ & $\begin{array}{l}1708 \pm 177 \\
(n=9)\end{array}$ & $\begin{array}{l}1823 \pm 108 \\
(n=7)\end{array}$ & $\begin{array}{l}808 \pm 71 \\
(n=13)\end{array}$ & $\begin{array}{l}706 \pm 103 \\
(n=18)\end{array}$ \\
\hline $\mathrm{V}_{\text {threshold }}(\mathrm{mV})$ & $\begin{array}{l}-36.4 \pm 2.4 \\
(n=9)\end{array}$ & $\begin{array}{l}-34.9 \pm 1.9 \\
(n=7)\end{array}$ & $\begin{array}{l}-39.7 \pm 1.9 \\
(n=13)\end{array}$ & $\begin{array}{l}-41.2 \pm 1.6 \\
(n=18)\end{array}$ \\
\hline Rise (ms) & $\begin{array}{l}0.25 \pm 0.02 \\
(n=9)\end{array}$ & $\begin{array}{l}0.26 \pm 0.01 \\
(n=7)\end{array}$ & $\begin{array}{l}0.27 \pm 0.01 \\
(n=13)\end{array}$ & $\begin{array}{l}0.29 \pm 0.02 \\
(n=18)\end{array}$ \\
\hline Decay (ms) & $\begin{array}{l}0.58 \pm 0.02 \\
(n=9)\end{array}$ & $\begin{array}{l}0.57 \pm 0.02 \\
(n=7)\end{array}$ & $\begin{array}{l}0.79 \pm 0.03 \\
(n=13)\end{array}$ & $\begin{array}{l}0.79 \pm 0.06 \\
(n=18)\end{array}$ \\
\hline Width (ms) & $\begin{array}{l}1.09 \pm 0.03 \\
(n=9)\end{array}$ & $\begin{array}{l}1.3 \pm 0.02 \\
(n=7)\end{array}$ & $\begin{array}{l}1.2 \pm 0.04 \\
(n=13)\end{array}$ & $\begin{array}{l}1.5 \pm 0.07 \\
(n=18)\end{array}$ \\
\hline $\mathrm{AHP}(\mathrm{mV})$ & $\begin{array}{l}-61.0 \pm 1.0 \\
(n=9)\end{array}$ & $\begin{array}{l}-59.2 \pm 0.9 \\
(n=7)\end{array}$ & $\begin{array}{l}-55.0 \pm 1.0 \\
(n=13)\end{array}$ & $\begin{array}{l}-57.4 \pm 0.9 \\
(n=18)\end{array}$ \\
\hline
\end{tabular}

All values are expressed as mean $\pm \mathrm{SEM}^{*} p=0.0063$, unpaired two-tailed $t$ test, comparing $\mathrm{V}_{\text {rest }}$ in regular-spiking accommodating and non-accommodating $\mathrm{PKC} \delta{ }^{+}$cells; ${ }^{* *} p=0.0003$, Mann-Whitney $U$ test, comparing ISI accommodation in accommodating and non-accommodating late-firing PKC $\delta{ }^{+}$ cells; ${ }^{\star \star \star} p<0.0001$, unpaired two tailed $t$ test, comparing ISI accommodation in accommodating and non-accommodating regular-spiking PKC $\delta{ }^{+}$cells; $\# p<0.0001$, unpaired two-tailed $t$ test with Welch's correction, comparing amplitude accommodation in regular-spiking PKC $\delta^{+}$cells. $\mathrm{V}_{\text {rest }}=$ resting membrane potential; $R_{\text {in }}=$ input resistance; ISI = interspike interval; $V_{\text {threshold }}=$ voltage threshold; $A H P=$ afterhyperpolarization.

Quantification of APD in the first and last spike further demonstrated that all four different cell types also exhibit robust APD accommodation, but that frequency-dependent APD broadening is indistinguishable between the different cell types (Fig. 5E, F).

Finally, analysis of frequency-dependent AHP amplitude accommodation further revealed that all CeLC cell types exhibit significant AHP amplitude accommodation within an evoked train of action potentials and that AHP amplitude accommodation is significantly larger in Som ${ }^{+}$ regular-spiking $(0.83 \pm 0.03)$ than in $\mathrm{PKC} \delta^{+}$regular-spiking neurons $(0.91 \pm 0.01$; Fig. $5 G, H)$.

Our combined results, showing that ISI accommodation in response to depolarizing current injections is selective to $\mathrm{PKC} \delta^{+}$neurons and that frequency-dependent spike amplitude accommodation is more robust in $\mathrm{PKC} \delta$ than in $\mathrm{Som}^{+}$, neurons demonstrates that the ability of $\mathrm{PKC} \delta^{+}$ neurons to sustain firing in response to input is lower than that of Som ${ }^{+}$cells and that differences in intrinsic membrane properties at the suprathreshold level contribute to these differences. These results are consistent with the findings discussed in the previous sections of this study and suggest that firing phenotypes in the CeLC are cell- type-specific, with $\mathrm{Som}^{+}$cells displaying a larger overall output than $\mathrm{PKC} \delta^{+}$cells in the CeLC.

\section{Action potential repolarization is slower in Som ${ }^{+}$than in $\mathrm{PKC} \boldsymbol{\delta}^{+}$CeLC neurons}

Suprathreshold membrane properties, including the membrane potential at which an action potential is initiated $\left(V_{\text {threshold }}\right)$ and the rates of depolarization and repolarization of individual action potentials can also strongly influence neuronal excitability (Bean, 2007). To gain additional insight into the mechanisms underlying the differences in the excitability of $\mathrm{PKC} \delta^{+}$and Som ${ }^{+}$cells, we examined the properties of single action potential waveforms elicited by a short $(5 \mathrm{~ms})$ depolarizing current injection in these cells (Fig. 6A).

Consistent with the hyperexcitable phenotype of Som ${ }^{+}$ late-firing neurons, the current amplitude required to induce an action potential (current threshold) is significantly smaller in $\mathrm{Som}^{+}(1111 \pm 56.31 \mathrm{pA})$ than $\mathrm{PKC} \delta{ }^{+}$late-firing neurons (1758 $\pm 107.8 \mathrm{pA}$; Fig. $6 B)$. Analyses of the depolarizing phase of the action potentials further demonstrated that voltage thresholds and rise times are indistinguishable between $\mathrm{PKC} \delta^{+}$and $\mathrm{Som}^{+}$late-firing 

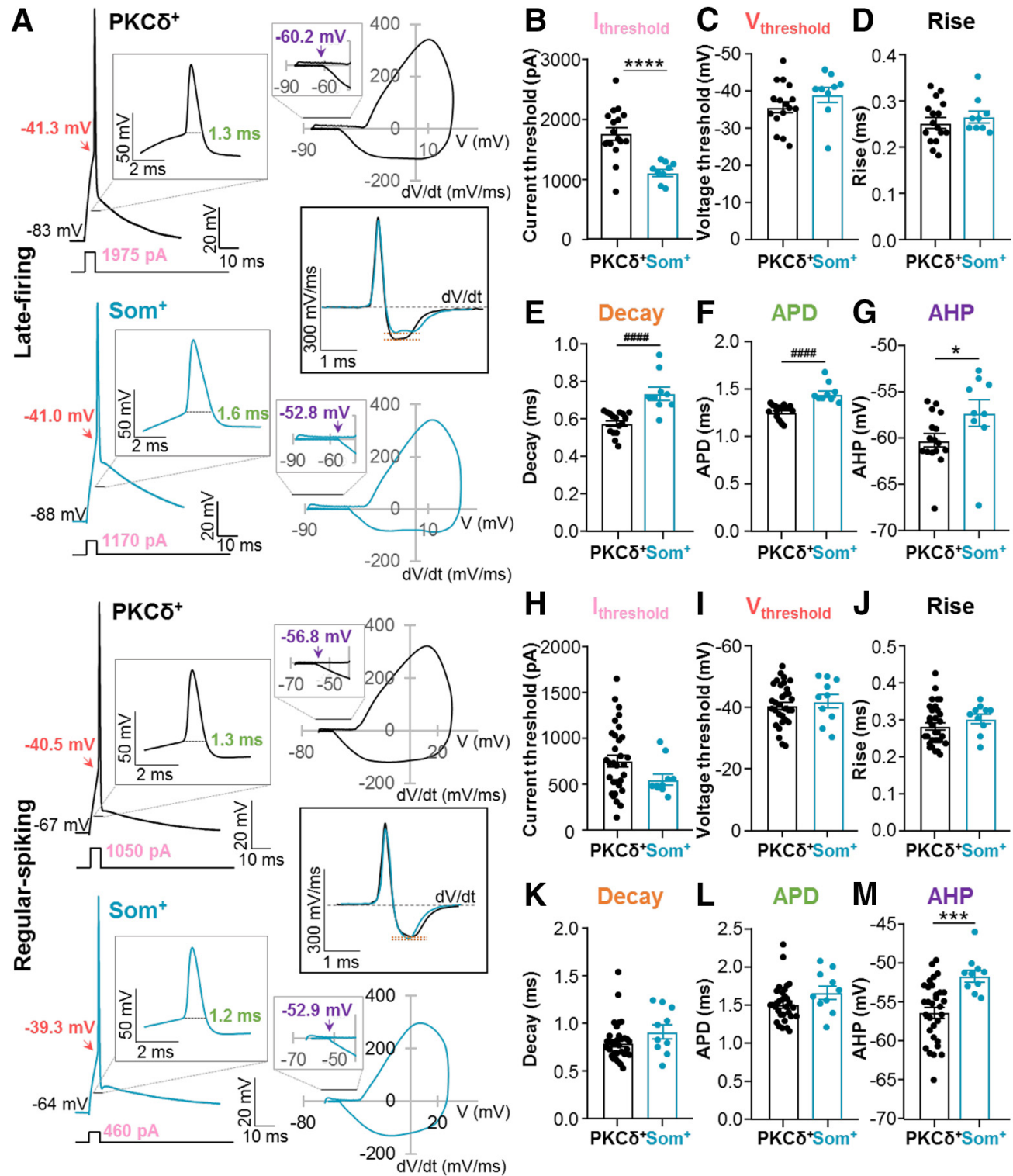

Figure 6. Slower repolarization in Som ${ }^{+}$, than in $\mathrm{PKC} \delta^{+}$neurons. $\boldsymbol{A}$, Representative single action potentials (left) elicited by 5-ms depolarizing current injections, phase plots (right) and plots of the first derivatives as a function of time (middle) of late-firing (top) and regular-spiking (bottom) $\mathrm{PKC} \delta^{+}$(black) and Som ${ }^{+}$(blue) neurons. Insets depict expanded timescales. Single action potential analyses for late-firing (B-G) and regular-spiking $(\boldsymbol{H}-\boldsymbol{M}) \mathrm{PKC} \delta^{+}$and Som ${ }^{+}$neurons. Current $(\boldsymbol{B}, \boldsymbol{H})$ and voltage $(\boldsymbol{C}, \boldsymbol{I})$ thresholds to fire a single action potential. Action potential rise time $(\boldsymbol{D}, \boldsymbol{J})$, action potential decay time $(\boldsymbol{E}, \boldsymbol{K})$, APD $(\boldsymbol{F}, \boldsymbol{L})$, and AHP amplitudes $(\boldsymbol{G}, \boldsymbol{M})$; ${ }^{* \star \star} p<0.0001$, unpaired two-tailed $t$ test with Welch's correction; ${ }^{\# \# \#} p<0.0001$, Mann-Whitney $U$ test; ${ }^{*} p=0.0498,{ }^{* \star *} p=0.0008$, unpaired two-tailed $t$ test. For PKC $\delta^{+}$cells: $n=16$ cells for late-firing and $n=31$ regular-spiking. For Som ${ }^{+}$cells: $n=9$ for late-firing and $n=10$ for regular-spiking. All values are expressed as mean \pm SEM.

cells (Fig. 6C,D). In contrast, decay times are significantly longer, action potentials significantly prolonged and AHPs significantly depolarized in Som ${ }^{+}$(decay time, $0.74 \pm 0.04 \mathrm{~ms}$; APD, $1.45 \pm 0.03 \mathrm{~ms}$; and AHP, $-57.26 \pm$ $1.46 \mathrm{mV}$ ) compared with $\mathrm{PKC} \delta^{+}$neurons (decay time, $0.58 \pm 0.01 \mathrm{~ms} ;$ APD, $1.25 \pm 0.02 \mathrm{~ms}$; and AHP, $-60.25 \pm$ $0.72 \mathrm{mV}$; Fig. $6 E-G)$. These combined results demonstrate that while the depolarizing phase of action potentials is indistinguishable in $\mathrm{PKC} \delta{ }^{+}$and $\mathrm{Som}^{+}$late-firing CeLC neurons, the repolarizing phase is slower in $\mathrm{Som}^{+}$than in $\mathrm{PKC} \delta{ }^{+}$latefiring CeLC cells, likely contributing to the hyperexcitable phenotype observed in these cells.
Consistent with the indistinguishable subthreshold membrane properties and accommodation observed in $\operatorname{PKC} \delta^{+}$ and Som ${ }^{+}$regular-spiking CeLC neurons (Figs. 3, 5), most of the suprathreshold membrane properties measured are also indistinguishable in these cells (Fig. 6H-L). An exception to this was the AHP in regular-spiking neurons, which was significantly depolarized $(-51.65 \pm 0.76 \mathrm{mV})$ in Som ${ }^{+}$ neurons compared with $\mathrm{PKC} \delta \delta^{+}$neurons $(-56.37 \pm 0.69$ mV; Fig. 6M).

Together, these results suggest that differences in the intrinsic membrane properties of $\mathrm{PKC} \delta{ }^{+}$and $\mathrm{Som}^{+}$late-firing neurons contribute to the greater output of $\mathrm{Som}^{+}$late-firing 
A

$\mathrm{PKCD}^{+}$

B

Som ${ }^{+}$

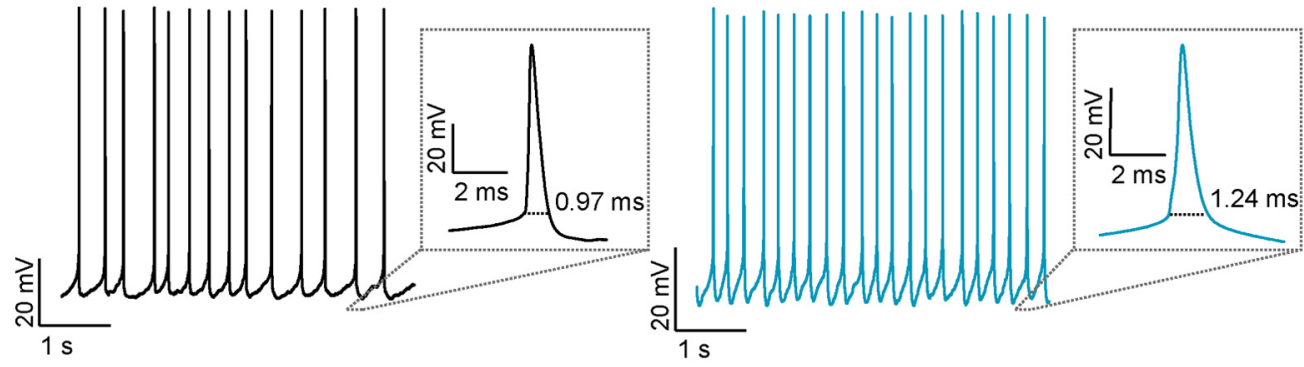

C
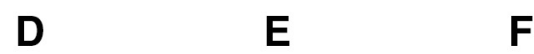

G
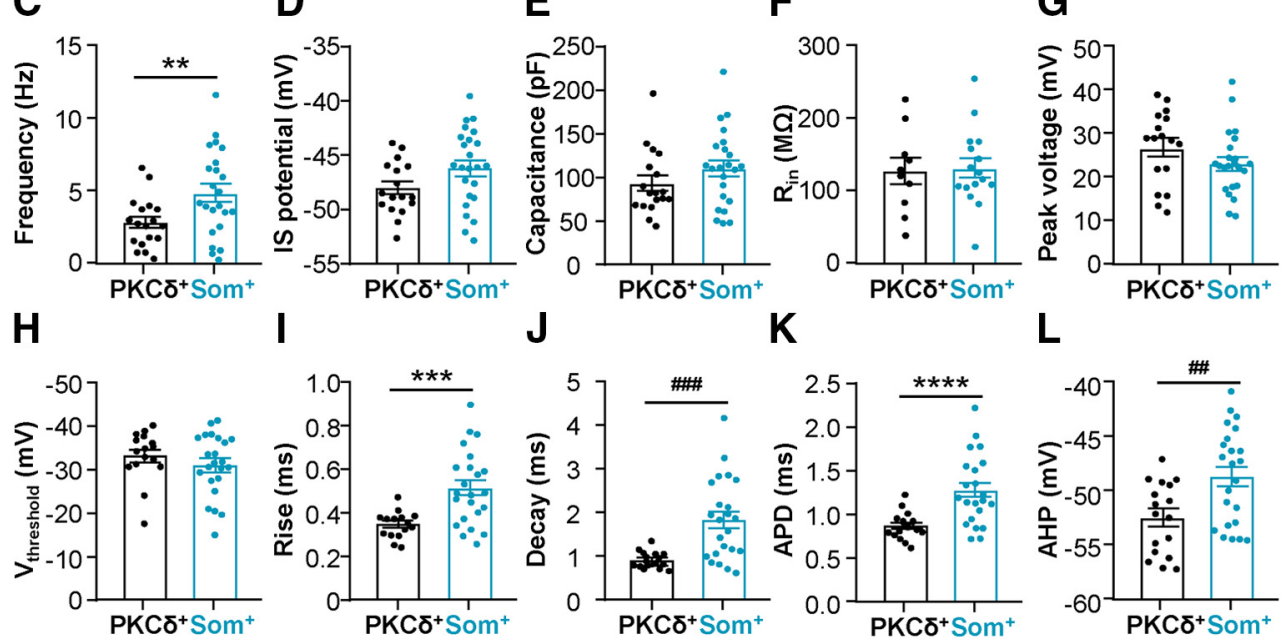

Figure 7. Spontaneous Som ${ }^{+}$CeLC neurons are more active and fire longer action potentials than $\mathrm{PKC} \delta^{+}$cells. Representative spontaneous action potentials of $\operatorname{PKC} \delta^{+}(\boldsymbol{A})$ and $\mathrm{Som}^{+}(\boldsymbol{B})$ neurons. Insets depict expanded timescales of single action potentials $(\boldsymbol{B}-\mathbf{G})$ and regular-spiking $(\boldsymbol{H}-\boldsymbol{L}) \mathrm{PKC} \delta^{+}$and Som ${ }^{+}$neurons. Frequency of action potential firing $(\boldsymbol{C})$, IS potential $(\boldsymbol{D})$, capacitance $(\boldsymbol{E}), \mathrm{R}_{\text {in }}(\boldsymbol{F})$, peak voltage $(\boldsymbol{G}), \mathrm{V}_{\text {threshold }}(\boldsymbol{H})$, rise $(\boldsymbol{I})$, decay $(\boldsymbol{J})$, duration $(\boldsymbol{K})$, and AHP amplitudes $(\boldsymbol{L})$ for $\mathrm{PKC} \delta^{+}$and $\mathrm{Som}^{+}$cells; ${ }^{* *} p<0.01$, unpaired two-tailed $t$ test with Welch's correction; ${ }^{* *} p<0.001$, unpaired two-tailed $t$ test; \#\#\#p $<0.0002$, unpaired twotailed $t$ test with Welch's correction; ${ }^{\star \star \star \star} p<0.0001$, unpaired two-tailed $t$ test with Welch's correction; \#\#p $<0.005$, unpaired twotailed $t$ test. For PKC $\delta^{+}$cells: $n=10-18$ cells. For Som ${ }^{+}$cells: $n=17-23$ cells. All values are expressed as mean \pm SEM.

cells. The differences in excitability in $\mathrm{Som}^{+}$and $\mathrm{PKC} \delta^{+}$ regular-spiking neurons, however, seems to be independent of the intrinsic membrane properties of the cells, further supporting that the cellular mechanisms underlying the greater output of Som ${ }^{+}$neurons are distinct for late-firing and regular-spiking CeLC cells.

\section{Som $^{+}$neurons display greater spontaneous firing rates and prolonged APDs compared with $\mathrm{PKC} \delta^{+}$ neurons}

A substantial population of $\mathrm{PKC} \delta^{+}$and $\mathrm{Som}^{+}$neurons are spontaneously active (Fig. 1C,D). The next set of experiments aimed to further characterize the firing and intrinsic membrane properties of spontaneously active $\mathrm{PKC} \delta^{+}$and $\mathrm{Som}^{+}$cells. As illustrated in Figure 7, both subtypes of neurons display low frequency spontaneous firing. Quantification of spontaneous firing rates revealed, however, that Som ${ }^{+}$spontaneously firing cells display higher firing frequencies $(4.89 \pm 0.60 \mathrm{~Hz})$ than $\mathrm{PKC} \delta^{+}$cells $(2.83 \pm 0.39 \mathrm{~Hz}$; Fig. $7 C)$. IS potential, capacitance, and $R_{\text {in }}$ were indistinguishable between cells (Fig. 7D-F). Analysis of single action potentials showed that while peak voltage and $V_{\text {threshold }}$ to fire an action potential are indistinguishable between $\mathrm{Som}^{+}$and $\mathrm{PKC} \delta^{+}$neurons (Fig. 7G,H), APDs are significantly prolonged in $\mathrm{Som}^{+}$neurons $(1.27 \pm 0.08 \mathrm{~ms})$ compared with $\mathrm{PKC} \delta^{+}$cells $(0.92 \pm 0.06 \mathrm{~ms}$; Fig. $7 K)$. Consistently, both rise and decay times are prolonged in $\mathrm{Som}^{+}$neurons compared with $\mathrm{PKC} \delta \delta^{+}$cells. Thus, the mean \pm SEM rise time was $0.51 \pm 0.03 \mathrm{~ms}$ in $\mathrm{Som}^{+}$neurons, compared with only $0.40 \pm 0.03 \mathrm{~ms}$ in $\mathrm{PKC} \delta^{+}$cells (Fig. 7I). Similarly, the mean \pm SEM decay time was $1.84 \pm 0.19 \mathrm{~ms}^{\text {in Som }}{ }^{+}$ cells but only $1.0 \pm 0.07 \mathrm{~ms}$ in $\mathrm{PKC} \delta^{+}$neurons (Fig. $7 \mathrm{~J}$ ). AHP amplitude of Som ${ }^{+}$neurons $(-48.75 \pm 0.89 \mathrm{mV})$ was also depolarized compared with AHP amplitude in $\mathrm{PKC} \delta^{+}$neurons $(-51.56 \pm 1.25 \mathrm{mV}$; Fig. $7 L)$.

Our combined results, demonstrating that $\mathrm{Som}^{+}$spontaneous neurons have greater firing frequencies than $\mathrm{PKC} \delta{ }^{+}$neurons, underscore the finding that $\mathrm{Som}^{+}$cells display greater excitability than $\mathrm{PKC} \delta^{+}$neurons in the $\mathrm{CeA}$, regardless of firing phenotype. The wider action potentials and depolarized AHPs observed in Som ${ }^{+}$neurons relative to $\operatorname{PKC} \delta^{+}$cells suggest that the mechanisms underlying greater excitability in spontaneously active $\mathrm{Som}^{+}$neurons are different from those in late-firing and regular-spiking Som ${ }^{+}$cells. 
A
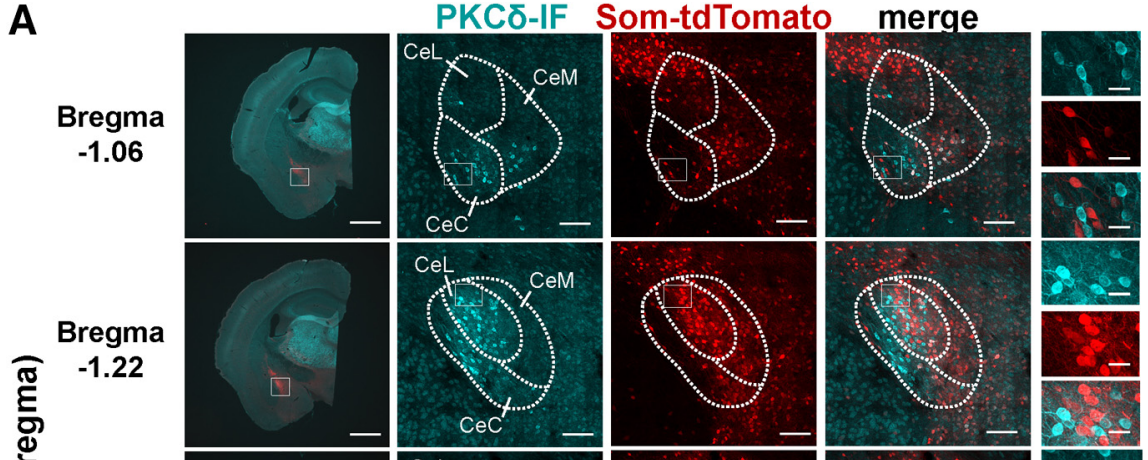

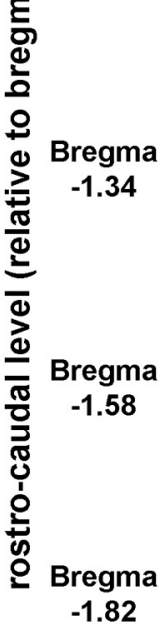

-
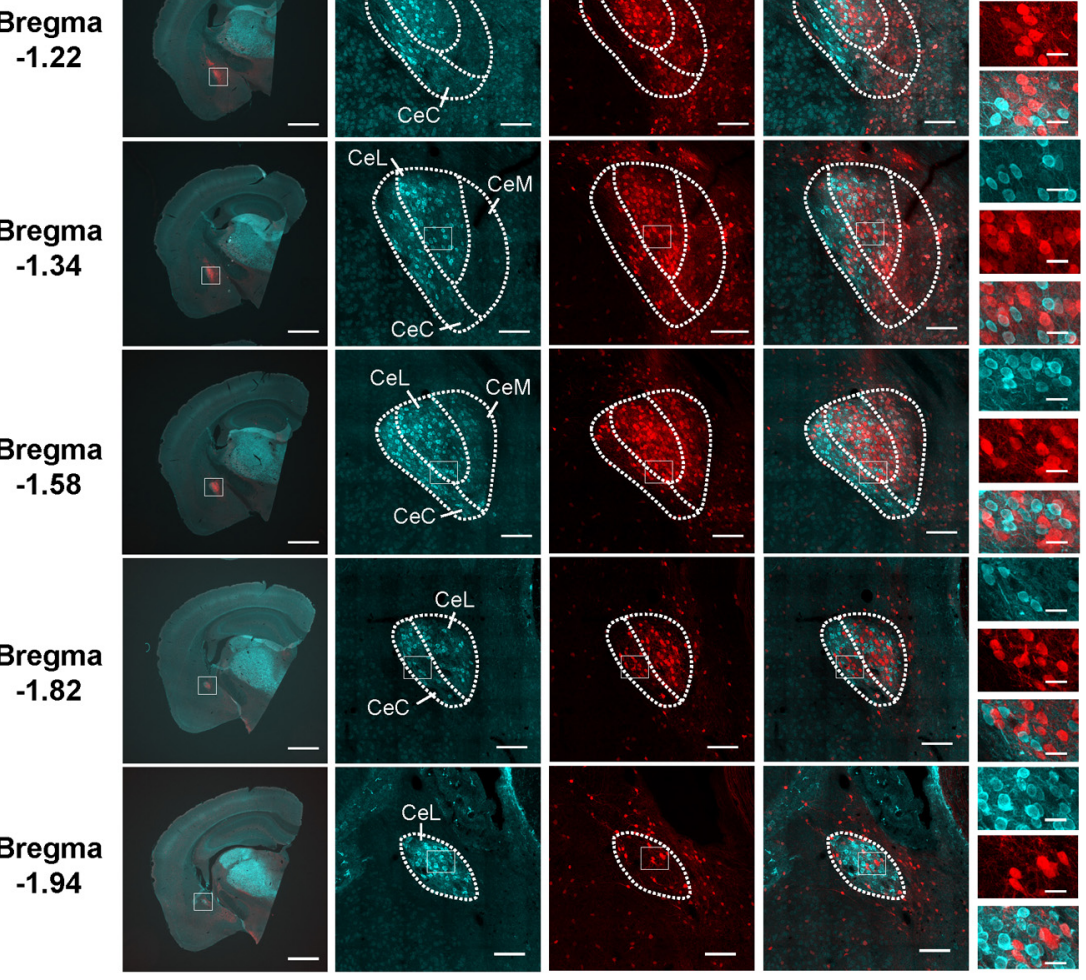

B

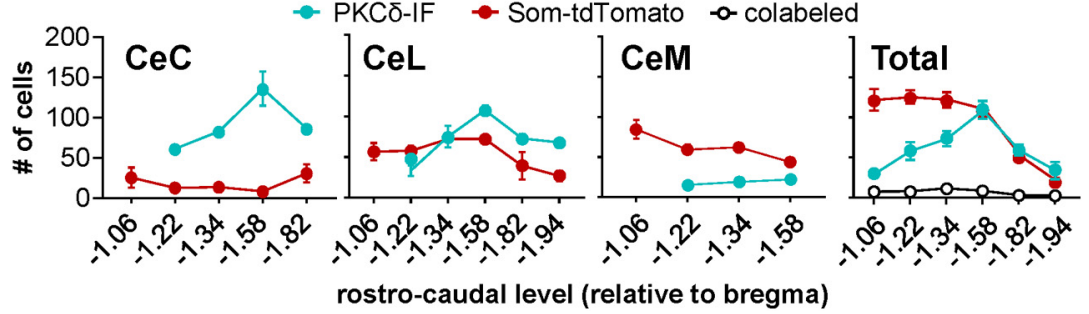

Figure 8. Rostro-caudal distribution of $\mathrm{PKC} \delta^{+}$and $\mathrm{Som}^{+}$neurons in the CeA. $\boldsymbol{A}$, Representative low-magnification (left) and high-magnification (second to fifth panels) images of coronal CeA slices immunostained for PKC $\delta$ (PKC $\delta$-IF, cyan), with cells positive for Som-tdTomato shown in red. Merged signals between PKC $\delta$-IF and Som-tdTomato are shown in the fourth panels. Rightmost panels depict high-magnification images of areas delineated by the white box. Scale bars: $1 \mathrm{~mm}$ (left panels), $100 \mu \mathrm{m}$ (middle panels), and $20 \mu \mathrm{m}$ (right panels). B, Mean \pm SEM number of cells positive for PKC $\delta$ (cyan), Som (red), or colabeled with both (white circles) in the capsular $(\mathrm{CeC})$, lateral $(\mathrm{CeL})$, or medial $(\mathrm{CeM})$ subdivisions of the CeA, as well as the total number of positive cells, are shown as a function of the rostro-caudal distribution relative to bregma; $n=1-8$ slices per rostrocaudal level from a total of 2-10 mice.

\section{Regular-spiking PKC $\delta^{+}$neurons excitability is dependent on the rostro-caudal anatomic localization within the $\mathrm{CeC}$}

Previous studies have shown that genetically distinct cells are differentially distributed throughout the CeLC (Han et al., 2015; Kim et al., 2017; McCullough et al., 2018; Wilson et al., 2019). As illustrated in Figure 8, and consistent with previous reports, for example, $\operatorname{PKC} \delta^{+}$ cells are localized mostly to the lateral (CeL) and capsular
(CeC) subdivisions of the CeLC, while Som ${ }^{+}$cells are predominantly located in the $\mathrm{CeL}$ and medial subdivision (CeM) of the CeA (Fig. 8B). Previous work has also demonstrated that although both cell types are found throughout the rostro-caudal axis, $\mathrm{Som}^{+}$expression is greater in the anterior amygdala and decreases posteriorly, while $\mathrm{PKC} \delta^{+}$cells are expressed more abundantly in the middle of the CeLC (Fig. 8B; Han et al., 2015; Wilson et al., 2019). 
Table 3: Firing phenotypes of PKC $\delta^{+}$and Som ${ }^{+}$CeLC cells by anatomic location

\begin{tabular}{llll}
\hline & $\begin{array}{l}\text { Anterior } \\
\text { (number } \\
\text { of cells) }\end{array}$ & $\begin{array}{l}\text { Middle } \\
\text { (number } \\
\text { of cells) }\end{array}$ & $\begin{array}{l}\text { Posterior } \\
\text { (number } \\
\text { of cells) }\end{array}$ \\
\hline CeC-PKC $\delta^{+}$ & & & \\
S & $4 / 14$ & $0 / 4$ & $2 / 11$ \\
LF & $5 / 15$ & $2 / 4$ & $3 / 11$ \\
RS & $6 / 15$ & $2 / 4$ & $6 / 11$ \\
CeL-PKC $\delta^{+}$ & & & \\
S & $2 / 8$ & $5 / 16$ & $3 / 12$ \\
LF & $1 / 8$ & $4 / 16$ & $3 / 12$ \\
RS & $5 / 8$ & $7 / 16$ & $6 / 12$ \\
CeC-Som ${ }^{+}$ & & & \\
S & $1 / 2$ & $0 / 1$ & $1 / 4$ \\
LF & $0 / 2$ & $0 / 1$ & $2 / 4$ \\
RS & $1 / 2$ & $1 / 1$ & $1 / 4$ \\
CeL-Som ${ }^{+}$ & & & \\
S & $7 / 15$ & $5 / 8$ & $3 / 5$ \\
LF & $4 / 15$ & $1 / 8$ & $1 / 5$ \\
RS & $4 / 15$ & $2 / 8$ & $1 / 5$ \\
\hline
\end{tabular}

Proportions of cells with different firing phenotypes are shown for $\mathrm{PKC} \delta^{+}$and $\mathrm{Som}^{+}$neurons in the capsular $(\mathrm{CeC})$ and lateral $(\mathrm{CeL})$ subdivisions of the central amygdala $(\mathrm{CeA})$. Anterior is defined as the $\mathrm{CeA}$ between bregma -0.94 and bregma -1.34; middle as the $\mathrm{CeA}$ at bregma -1.46; and posterior as the CeA between bregma -1.58 and bregma -1.94 . $\mathrm{S}=$ spontaneous; $L F=$ latefiring; $\mathrm{RS}$ = regular-spiking; $\mathrm{CeC}$ = capsular subdivision of the $\mathrm{CeA} ; \mathrm{CeL}=$ lateral subdivision of the CeA.

At the anatomic and electrophysiological levels, projection-specific neurons have been shown to be topographically organized within the CeLC and to exhibit distinct firing responses ( $\mathrm{Li}$ and Sheets, 2018). It is unknown, however, whether the firing phenotypes of genetically distinct cells are dependent on their anatomic localization within the CeLC. We began to evaluate this by comparing the proportions of the three observed firing types (spontaneous, late-firing, and regular-spiking; Fig. 1) in $\mathrm{PKC} \delta^{+}$ and $\mathrm{Som}^{+}$cells localized to different subnuclei or rostrocaudal levels within the CeLC.

Our analyses revealed that firing types of all $\mathrm{PKC} \delta^{+}$ and $\mathrm{Som}^{+}$cells are independent of their anatomic localization within the CeLC (Table 3). Further correlational analyses revealed, however, that the excitability of $\mathrm{PKC} \delta^{+}$regular-spiking neurons in the $\mathrm{CeC}$ correlates with the rostro-caudal localization of these cells (Fig. 9). Thus, a significant positive correlation is seen for the number of spikes elicited in response to prolonged $(500 \mathrm{~ms})$ depolarizing current injection, with higher responses in neurons located in the posterior than in the anterior $\mathrm{CeC}$ (Fig. 9C). Consistently, a significant negative correlation is observed for rheobase and latency to first spike, with lower values in neurons located in the posterior $\mathrm{CeC}$, compared with neurons in the anterior CeC (Fig. 9D,E). These rostro-caudal and subdivision-dependent differences in rheobase could contribute to the non-normal distribution of the values for rheobase that we measured in the pooled data from regular-spiking $\mathrm{PKC} \delta^{+}$neurons presented in Figure 3G. Firing responses to depolarizing current injections are indistinguishable in $\mathrm{PKC} \delta^{+}$regular-spiking neurons in the $\mathrm{CeL}$ as well as in all $\mathrm{PKC} \delta^{+}$late-firing neurons independently of their location within the rostro-caudal axis (Fig. 9C-E).
Together, these findings demonstrate that anatomic localization within the $\mathrm{CeC}$ is yet another source of heterogeneity that influences neuronal excitability in a cell-type specific manner in the CeA.

\section{PKC $\delta^{+}$and Som ${ }^{+}$neurons are morphologically distinct}

It is widely known that neuronal morphology and dendritic spines impact the electrophysiological properties, and therefore cellular output, of neurons (Connors and Regehr, 1996; Mainen and Sejnowski, 1996; Stiefel and Sejnowski, 2007). While previous studies have demonstrated that neurons in the CeLC are both morphologically and electrophysiologically heterogeneous (Martina et al., 1999; Schiess et al., 1999; Chieng et al., 2006), a correlational link between the morphology and function of CeLC neurons is still missing.

Based on our electrophysiological findings demonstrating that excitability is markedly different in $\operatorname{PKC} \delta^{+}$and $\mathrm{Som}^{+}$neurons in the right CeLC, we hypothesized that these two subpopulations of CeLC cells are also morphologically distinct. To test this hypothesis, we filled some of the neurons that were used for the electrophysiological studies by including biocytin in the recording pipette solution (Fig. 10A). A total of seven $\mathrm{PKC} \delta{ }^{+}$cells and six Som ${ }^{+}$ biocytin-filled cells were successfully recovered and three-dimensionally reconstructed using this approach (Fig. 10B).

Consistent with previous reports, the morphology of all CeLC neurons recovered resembled that of medium spiny neurons in the striatum. Notably, however, visual inspection of the reconstructed biocytin-filled neurons demonstrated that $\mathrm{PKC} \delta \delta^{+}$cells display more polarity (triangular or bipolar) than Som ${ }^{+}$cells, which have dendrites radiating in most directions outwards from the soma (Movies 1 and 2). One PKC $\delta^{+}$cell (Fig. 10B, gray) was the only exception to this pattern. These qualitative observations suggested that the complexity of dendritic branching and dendritic length are different between $\mathrm{PKC} \delta{ }^{+}$and $\mathrm{Som}^{+}$ CeLC neurons.

To quantify these qualitative differences in neuronal morphology, we performed Sholl analyses, which allows the quantification and comparison of the number of dendritic intersections as a function of distance from the soma. The total number of primary, secondary and tertiary dendrites, as well as dendritic lengths and spine densities were also quantified in all cells. It is important to note, however, that given that these neurons were filled and reconstructed from coronal brain slices, the analyses presented here represent dendrites extending toward the dorsoventral and mediolateral direction and within the $250-\mu \mathrm{m}$ thickness of the slice in the rostro-caudal direction.

As illustrated in Figure 10C, Sholl analyses revealed that the number of dendritic intersections is dependent on the distance from soma in both $\mathrm{PKC} \delta^{+}$and Som ${ }^{+} \mathrm{CeLC}$ neurons, with maximal number of intersections observed at $\sim 50 \mu \mathrm{m}$ from the soma in both cell types. The number of dendritic intersections, however, was significantly higher in $\mathrm{Som}^{+}$than in $\mathrm{PKC} \delta^{+}$neurons, demonstrating that 
A

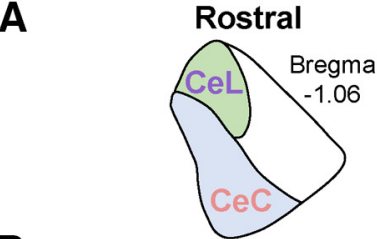

B

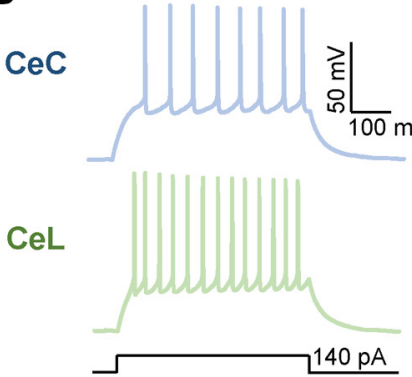

$\mathrm{CeC}$

C
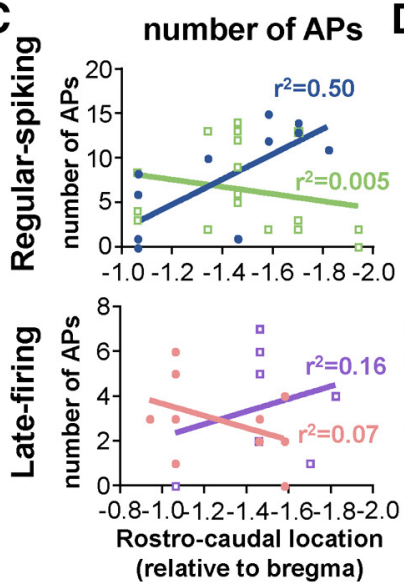

Middle
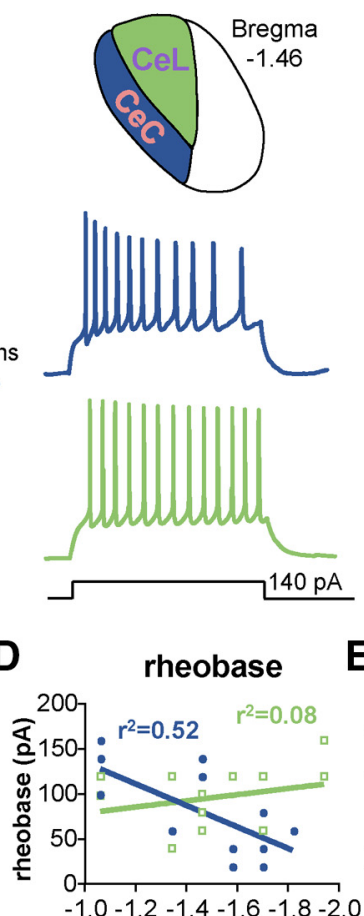

$-10-12-1.4-16-1.8-20$

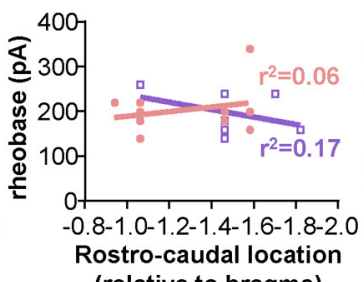

(relative to bregma)
Caudal
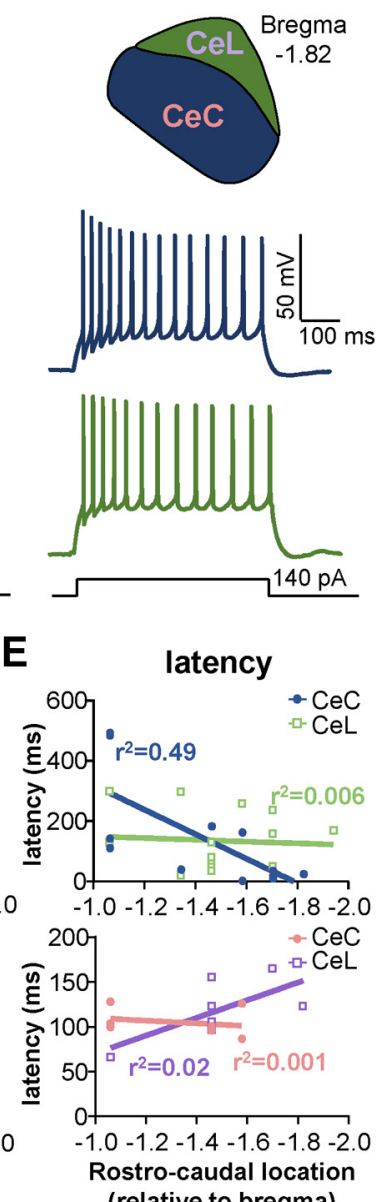

Figure 9. Firing responses in regular-spiking $\mathrm{PKC} \delta^{+}$neurons correlate with rostro-caudal anatomic location within the CeC. $\boldsymbol{A}$, Schematics of rostral, middle, and caudal regions of the CeLC, with the CeL represented in green and purple and the $\mathrm{CeC}$ represented in blue and pink. B, Representative voltage traces of evoked firing responses in regular-spiking $\operatorname{PKC} \delta^{+}$neurons in the rostral, middle, and caudal $\mathrm{CeC}$ (top panel, blue) and $\mathrm{CeL}$ (bottom panel, green). C-E, Correlational plots between the number of evoked action potentials $(\boldsymbol{C})$, rheobase $(\boldsymbol{D})$, or latency to fire $(\boldsymbol{E})$ and the rostro-caudal location of regular-spiking (top) and late-firing (bottom) cells. Prolonged $(500 \mathrm{~ms})$ depolarizing current injections of 140 and $240 \mathrm{pA}$ were used to evoke repetitive firing in regular-spiking and late-firing cells, respectively. For regular-spiking neurons in the $\mathrm{CeC}$, there was a positive correlation between the number of evoked action potentials and the rostro-caudal level $\left(p=0.0045, r^{2}=0.5031\right.$, linear regression analysis) and a negative correlation between rheobase $\left(p=0.0036, r^{2}=\right.$ 0.5193 , linear regression analysis) and latency to first spike $\left(p=0.0118, r^{2}=0.4858\right.$, linear regression analysis) with the rostro-caudal level. None of the measured parameters in the $\mathrm{CeL}$ and in late-firing cells in the $\mathrm{CeC}$ correlated with the rostro-caudal level. For CeL: $n=7$ cells for late-firing and $n=18$ for regular-spiking. For $\mathrm{CeC}: n=10$ for late-firing and $n=14$ for regular-spiking.

dendritic arborizations are more complex in these cells compared with $\mathrm{PKC} \delta^{+}$cells. Consistent with the observed polarity of $\mathrm{PKC} \delta^{+}$cells, the total number of dendrites was significantly smaller in these neurons compared with the number of dendrites in $\mathrm{Som}^{+}$cells (Fig. 10D). In addition, post hoc analysis revealed that both the number and length of dendrites increases as a function of branch order in Som ${ }^{+}$cells, but it is indistinguishable between primary, secondary, and tertiary dendrites of $\mathrm{PKC} \delta^{+}$cells (Fig. 10D,E). Lastly, while dendritic spine densities increased as a function of branching order in Som ${ }^{+}$ neurons, it was indistinguishable between primary, secondary, and tertiary dendrites in $\mathrm{PKC} \delta^{+}$cells (Fig. 10F).

Together, these results demonstrate that neuronal morphology differs in genetically distinct subpopulations of cells in the CeLC, with more complex dendritic branching patterns observed in Som ${ }^{+}$neurons, than in $\mathrm{PKC} \delta^{+}$cells.

The combined results from our electrophysiological and morphologic reconstruction of $\mathrm{PKC} \delta^{+}$and $\mathrm{Som}^{+}$CeLC neurons strongly suggest that the morphologic properties of $\mathrm{PKC} \delta^{+}$and $\mathrm{Som}^{+}$neurons contribute to the differences in excitability displayed by these two populations of CeLC cells, with more compact $\mathrm{Som}^{+}$neurons displaying higher excitability than the less compact $\mathrm{PKC} \delta{ }^{+}$cells. To test this hypothesis, we used patch-clamp electrophysiology to measure and compare whole-cell capacitance in $\mathrm{PKC} \delta^{+}$and $\mathrm{Som}^{+}$CeLC neurons. Whole-cell capacitance is commonly used to measure the total surface area of a cell, and therefore, reflects the size or compactness of a neuron, with lower whole-cell capacitance seen in smaller, more compact neurons and vice versa. 
A
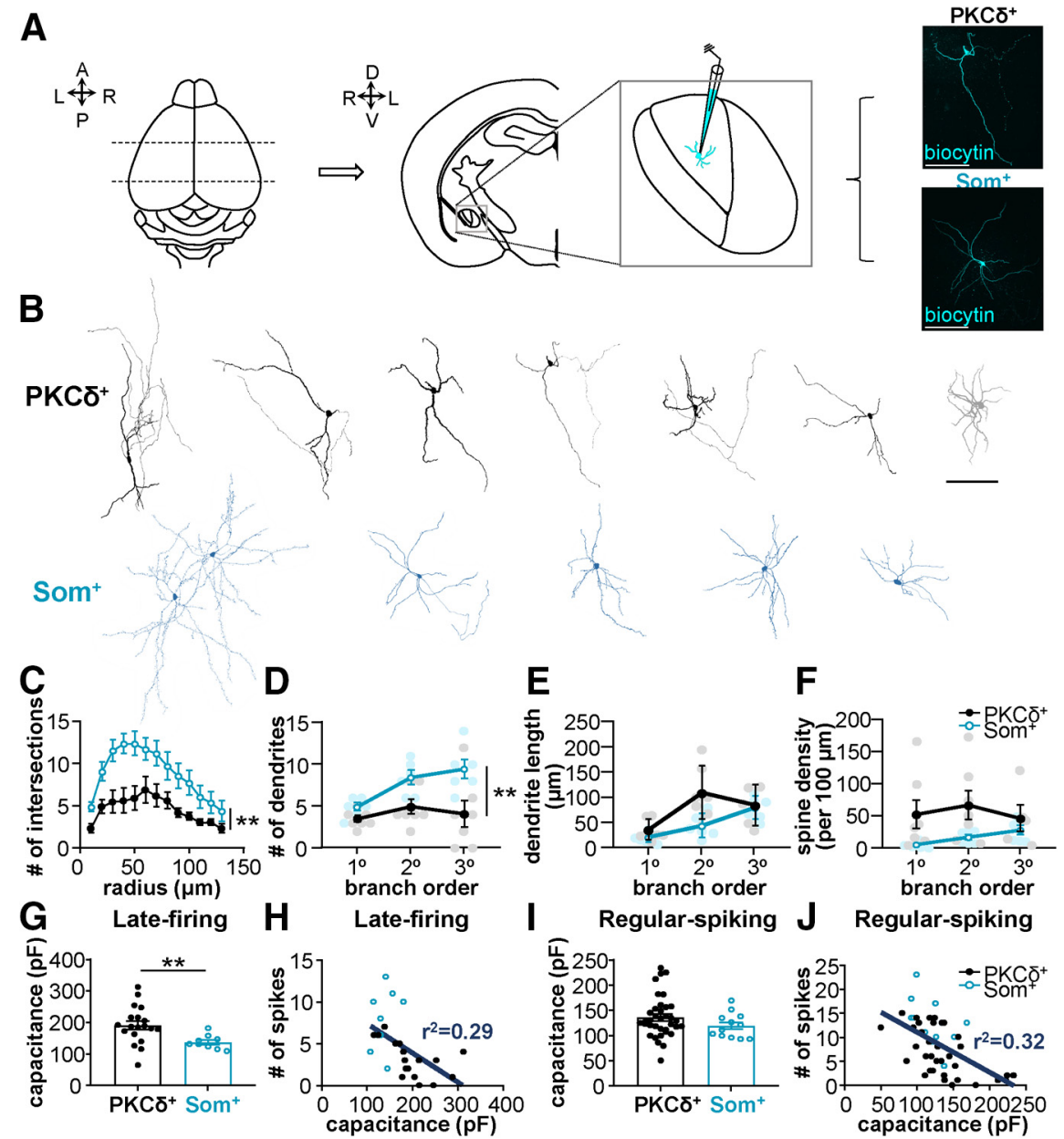

Figure 10. $\mathrm{PKC} \delta^{+}$and $\mathrm{Som}^{+}$cells are morphologically distinct. $\boldsymbol{A}$, Morphologic reconstruction of biocytin-filled cells in acute brain slices. CeLC cells were filled with biocytin during whole-cell patch-clamp recordings in acute amygdala slices. Representative images of biocytin-filled $\mathrm{PKC} \delta \delta^{+}$and Som ${ }^{+}$cells are shown in cyan in the right panel. Scale bars: $100 \mu \mathrm{m}$. B, Morphologic reconstruction of $\mathrm{PKC} \delta^{+}$(top) and Som ${ }^{+}$biocytin-filled neurons. Scale bar: $100 \mu \mathrm{m}$. C, Sholl analysis for number of dendritic intersections as a function of radial distance from soma. $\boldsymbol{D}-\boldsymbol{F}$, Numbers $(\boldsymbol{D})$, lengths $(\boldsymbol{E})$, and spine densities $(\boldsymbol{F})$ of primary $\left(1^{\circ}\right)$, secondary $\left(2^{\circ}\right)$, and tertiary $\left(3^{\circ}\right)$ dendrites for $\mathrm{PKC} \delta^{+}$and Som ${ }^{+}$CeA cells; ${ }^{*} p<0.01$, two-way ANOVA. G, $\boldsymbol{I}$, Whole-cell membrane capacitance for late-firing $(\boldsymbol{G})$ and regular-spiking $(\boldsymbol{I}) \mathrm{PKC} \delta^{+}$and $\mathrm{Som}^{+} \mathrm{CeA}$ cells. $\boldsymbol{H}, \boldsymbol{J}$, Correlational plots between the number of action potentials evoked in response to prolonged $(500 \mathrm{~ms})$ depolarizing current injections of either $140 \mathrm{pA}$ (regular-spiking) or $240 \mathrm{pA}$ (late-firing) and whole-cell membrane capacitance in late-firing $(\boldsymbol{H})$ and regular-spiking $(\boldsymbol{J}) \operatorname{PKC} \delta^{+}$(black) and Som ${ }^{+}$(blue) CeA cells. A negative correlation was found in both late-firing $\left(p=0.0039, r^{2}=0.29\right.$, linear regression analysis) and regular-spiking $\left(p<0.0001, r^{2}=0.32\right.$, linear regression analysis) neurons. For PKC $\delta$ cells: $n=7$ cells for morphology; $n=18-19$ late-firing and $n=35-36$ for regular-spiking. For Som ${ }^{+}$cells: $n=6$ cells for morphology; $n=9$ late-firing and $n=13$ for regular-spiking. All values are expressed as mean \pm SEM.

Consistent with the results of our morphologic reconstructions that show $\mathrm{Som}^{+}$neurons as more compact than $\mathrm{PKC} \delta^{+}$CeLC neurons, our electrophysiological measurements revealed that whole-cell capacitance is significantly lower in $\mathrm{Som}^{+}$than in $\mathrm{PKC} \delta{ }^{+} \mathrm{CeLC}$ late-firing neurons (Fig. 10G). Notably, the number of evoked spikes significantly correlated with whole-cell capacitance in both late-firing and regular-spiking cells, with greater number of spikes seen in neurons with lower whole-cell capacitance (Fig. 10H,J). These results demonstrate that more compact CeLC neurons are more excitable than larger cells, establishing a direct link between the distinct morphologic properties of $\mathrm{PKC} \delta^{+}$and $\mathrm{Som}^{+}$ CeLC neurons and their excitability output.

\section{Nerve injury occludes differences in excitability between $\mathrm{PKC} \delta^{+}$and Som ${ }^{+}$cells}

The results of the experiments presented in Figure 3, performed in the absence of injury, show that $\mathrm{Som}^{+}$cells in the CeLC are hyperexcitable compared with $\operatorname{PKC} \delta^{+}$ neurons in this brain region. In a mouse model of neuropathic pain, however, previous studies have shown that nerve injury induces increases in the excitability of $\mathrm{PKC} \delta{ }^{+}$neurons but that, in complete contrast, it decreases the excitability of Som ${ }^{+}$CeLC cells (Wilson et al., 2019). These results suggest that nerve injury affects the excitability differences normally seen in $\mathrm{PKC} \delta^{+}$and $\mathrm{Som}^{+}$neurons, ultimately affecting the overall output gain in the CeA. Whether and how cell-type-specific changes in excitability 


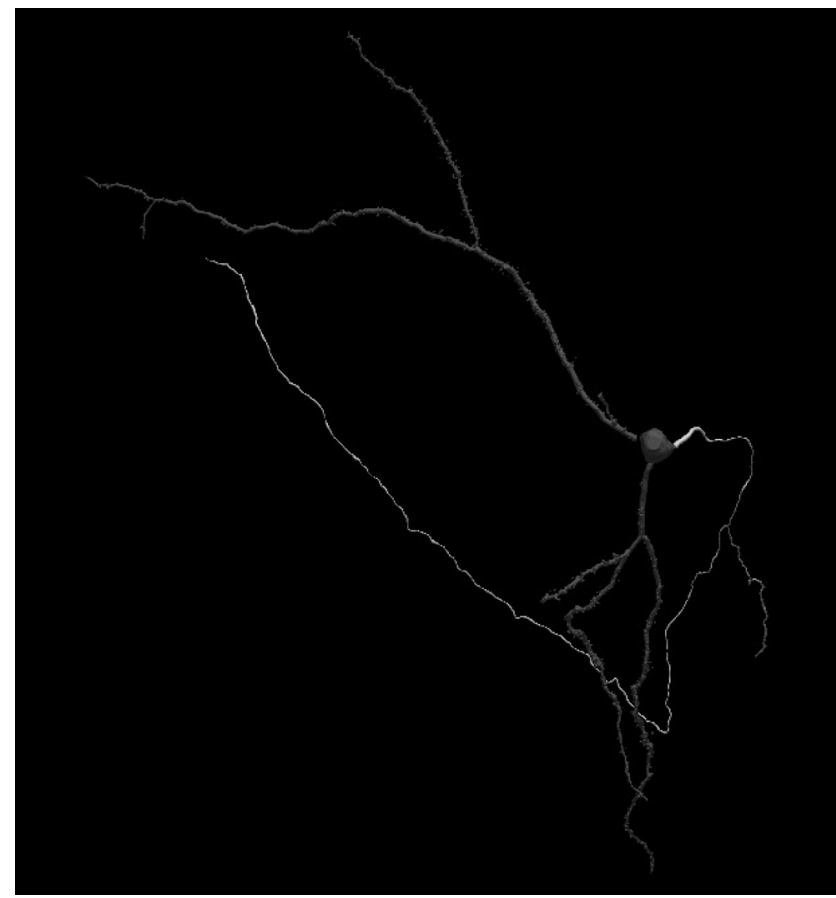

Movie 1. Three-dimensional morphological reconstruction of a biocytin-filled $\mathrm{PKC} \delta^{+} \mathrm{CeA}$ neuron. CeLC cells were filled with biocytin during whole-cell patch-clamp recordings in acute amygdala slices. Representative movie of a biocytin-filled $\mathrm{PKC} \delta^{+}$cell is shown in grey. The direction of the $\mathrm{x}(\mathrm{red}), \mathrm{y}$ (green) and $z$ (blue) axes are displayed by the compass on the bottom left. [View online]

following nerve injury affect the relative output of $\mathrm{PKC} \delta^{+}$ and $\mathrm{Som}^{+}$neurons in the CeLC remains unknown.

To investigate this, we used the mouse cuff model of neuropathic pain in combination with whole-cell patch-clamp in acute brain slices (Fig. 11A). Consistent with previous reports using this neuropathic pain model (Benbouzid et al., 2008; Wilson et al., 2019), cuff implantation on the left sciatic nerve elicited robust and significant hypersensitivity to cold, heat and tactile stimulation in the hindpaw ipsilateral to treatment compared with the paw contralateral to cuff placement (Fig. 11A). Cold, heat, and tactile hypersensitivity were assessed using the acetone, Hargreaves and von Frey tests, respectively.

As illustrated in Figure $11 B$, and similar to what is seen in uninjured conditions (Fig. 3), prolonged $(500 \mathrm{~ms})$ depolarizing current injections elicited repetitive firing in all four CeLC cell types following injury, with the number of evoked spikes increasing as a function of current injection amplitude. Notably, however, the number of spikes in response to prolonged depolarizing current injections is indistinguishable in $\mathrm{PKC} \delta^{+}$and $\mathrm{Som}^{+}$neurons following injury, in both late-firing and regular-spiking cells. This is in marked contrast to the pronounced differences seen in uninjured animals (Fig. 3) and demonstrates that nerve injury occludes differences in excitability between $\mathrm{PKC} \delta^{+}$and $\mathrm{Som}^{+}$cells in the CeLC. Notably, the loss of difference in excitability is primarily because of an increase in excitability of PKC $\delta^{+}$neurons following nerve injury, suggesting differential engagement of CeLC neuronal populations in different conditions. Importantly, the differences in evoked firing

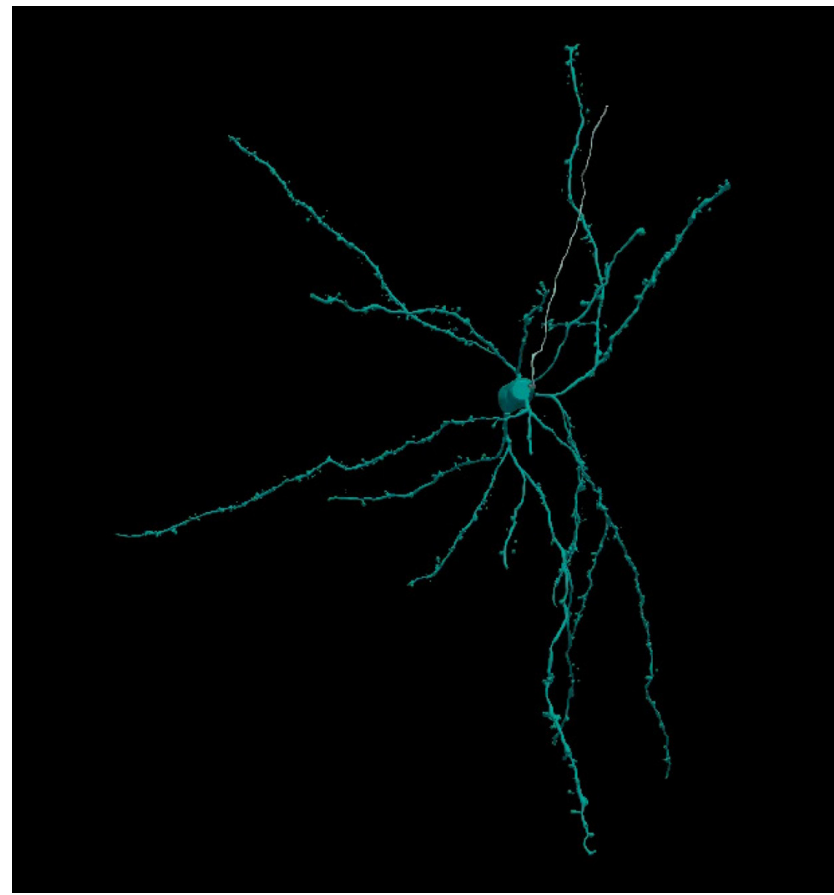

Movie 2. Three-dimensional morphological reconstruction of a biocytin-filled Som + CeA neuron. CeLC cells were filled with biocytin during whole-cell patch-clamp recordings in acute amygdala slices. Representative movie of a biocytin-filled $\mathrm{Som}^{+}$cell is shown in cyan. The direction of the $x$ (red), $y$ (green) and $z$ (blue) axes are displayed by the compass on the bottom left. [View online]

responses between $\mathrm{PKC} \delta^{+}$and $\mathrm{Som}^{+}$late-firing neurons is dependent on the amplitude of the depolarizing current injected (Fig. 11C). Thus, while the number of spikes elicited by high-amplitude (360 pA) current injection is indistinguishable in $\mathrm{PKC} \delta{ }^{+}$and $\mathrm{Som}^{+}$late-firing neurons, firing responses to low-amplitude (180 pA) current injections were significantly lower in $\mathrm{Som}^{+}$than in $\mathrm{PKC} \delta^{+}$neurons in the CeLC. Firing responses of regular-spiking neurons, in contrast, were indistinguishable independently of the amplitude of current injected, supporting further that the mechanisms driving excitability of late-firing and regularspiking neurons are distinct.

Consistent with the nerve injury-induced masking of neuronal excitability differences in $\mathrm{PKC} \delta^{+}$and $\mathrm{Som}^{+}$CeLC neurons, the differences in resting membrane potential, $R_{\text {in }}$, and latency to fire that we observed between $\operatorname{PKC} \delta^{+}$and $\mathrm{Som}^{+}$CeLC late-firing neurons in uninjured conditions (Fig. $3 B-E$ ) were also occluded in $\mathrm{PKC} \delta^{+}$and $\mathrm{Som}^{+}$cells following nerve injury (Fig. 12).

Together, these results demonstrate that following nerve injury, the relative excitability of $\mathrm{PKC} \delta{ }^{+}$and $\mathrm{Som}^{+}$ cells is disrupted. These data suggest that within different contexts, CeLC neuronal populations are differentially engaged and thus affect the contribution of these cells to overall output in the CeLC.

\section{Discussion}

The CeLC has been recently hailed as a critical hub for modulating an array of behaviors, ranging from 

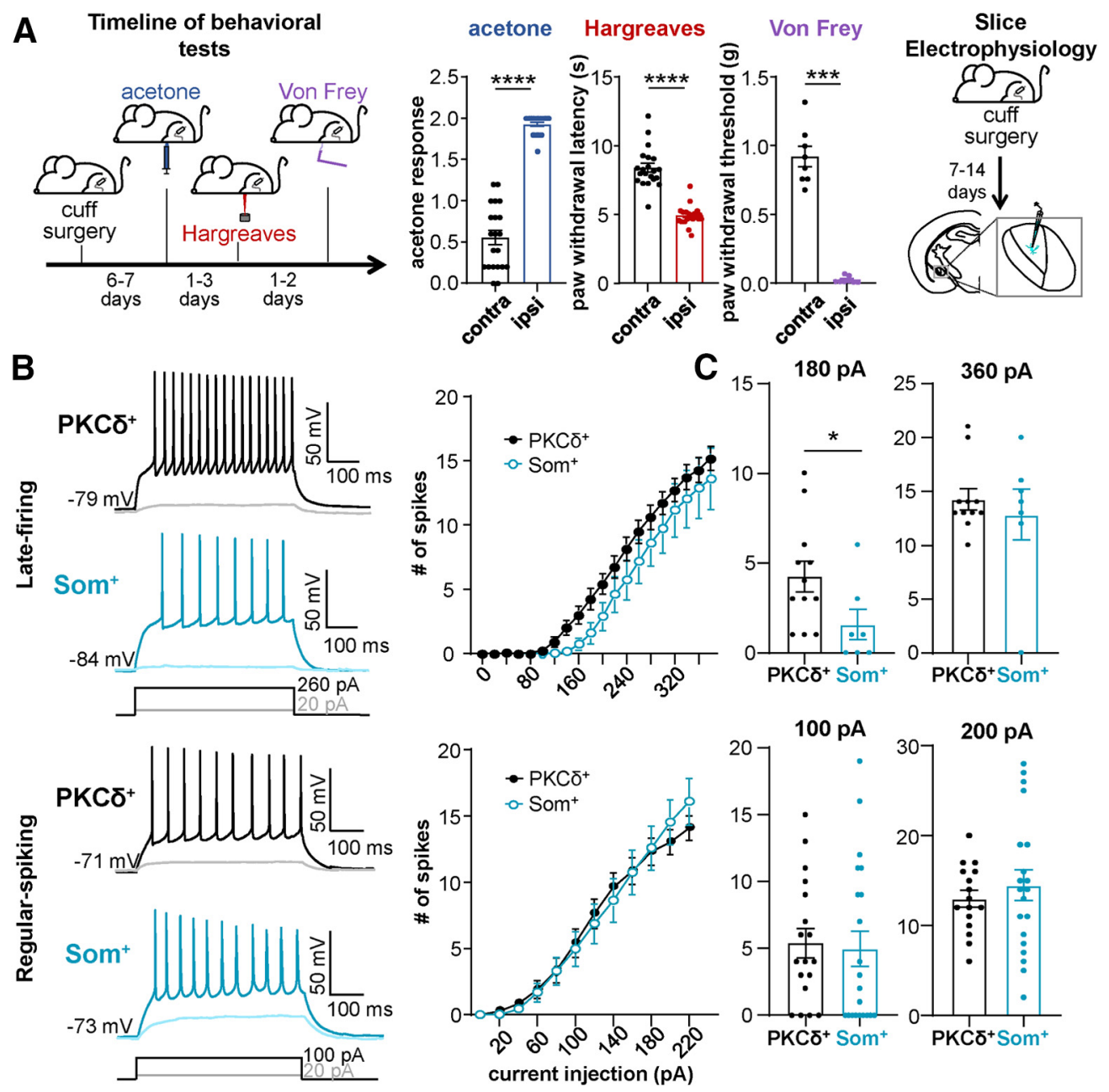

Figure 11. Excitability differences between $\mathrm{PKC} \delta^{+}$and $\mathrm{Som}^{+}$cells are occluded in the context of persistent pathologic pain. $\boldsymbol{A}$, Cuff model of neuropathic pain used in electrophysiological experiments. Following placement of the sciatic nerve cuff, mice developed hypersensitivity to cold (acetone test), heat (Hargreaves test), and tactile (von Frey test) stimulation on hindpaws ipsilateral to nerve injury, compared with the contralateral hindpaws. Acute brain slices for electrophysiological experiments were collected following cuff placement in the sciatic nerve of Prkcd-Cre::Ai9 or Sst-Cre::Ai9 mice. B, Representative voltage recordings of late-firing (top) and regular-spiking (bottom) $\mathrm{PKC} \delta^{+}$(black) and Som ${ }^{+}$(blue) cells in response to depolarizing current injections. Right panels show the number of spikes elicited as a function of the current injection amplitude. $\boldsymbol{C}$, The number of action potentials elicited in response to 180- and 360-pA depolarizing current injections in late-firing (top) and regular-spiking (bottom) $\mathrm{PKC} \delta^{+}$(black) and $\mathrm{Som}^{+}$(blue) CeA cells; ${ }^{\star \star *} p<0.0001,{ }^{\star * *} p<0.0002$, ${ }^{*} p=0.0314$, Mann-Whitney $U$ test. $n=8-21$ mice for behavioral tests. For $\mathrm{PKC} \delta^{+}$cells: $n=11-12$ late-firing and $n=16-18$ for regular-spiking. For Som ${ }^{+}$cells: $n=7$ late-firing and $n=20-21$ for regular-spiking. All values are expressed as mean \pm SEM.

food-seeking to pain responses (Neugebauer et al., 2004; Janak and Tye, 2015; Kim et al., 2017). The two predominantly expressed cell types in the CeLC, $\mathrm{PKC} \delta^{+}$and Som ${ }^{+}$cells, have been shown to modulate many of these behaviors, often in opposing ways (Ciocchi et al., 2010; Haubensak et al., 2010; Li et al., 2013; Wilson et al., 2019). In the present study, we show that $\mathrm{PKC} \delta^{+}$and Som ${ }^{+}$CeLC neurons have different electrophysiological and morphologic properties, supporting their distinct and diverse range of function. The results from our experiments demonstrate that while the firing phenotypes of these two genetically distinct CeLC cell types are heterogeneous, there is a marked difference between the excitability of these cells, with Som ${ }^{+}$neurons displaying a much greater output than $\operatorname{PKC} \delta{ }^{+}$neurons.
In addition to the marked differences in excitability, our biocytin-based morphologic reconstructions demonstrate that $\mathrm{PKC} \delta \delta^{+}$and $\mathrm{Som}^{+}$CeLC neurons are morphologically distinct, with more complex dendritic arborization patterns seen in $\mathrm{Som}^{+}$than in $\mathrm{PKC} \delta{ }^{+}$neurons. Importantly, our last set of experiments demonstrates that differences in the excitability of $\mathrm{PKC} \delta^{+}$and $\mathrm{Som}^{+}$neurons are occluded in a mouse model of neuropathic pain, suggesting that maladaptive plastic changes that alter the relative output of CeLC cell types underlies the differential modulation of CeA-dependent behavior by these cells.

Together, the findings presented here identify fundamentally important differences in $\mathrm{PKC} \delta^{+}$and $\mathrm{Som}^{+}$neurons that support the functional heterogeneity in the CeLC, shedding insight into how distinct subpopulations of neurons within this small brain structure can 

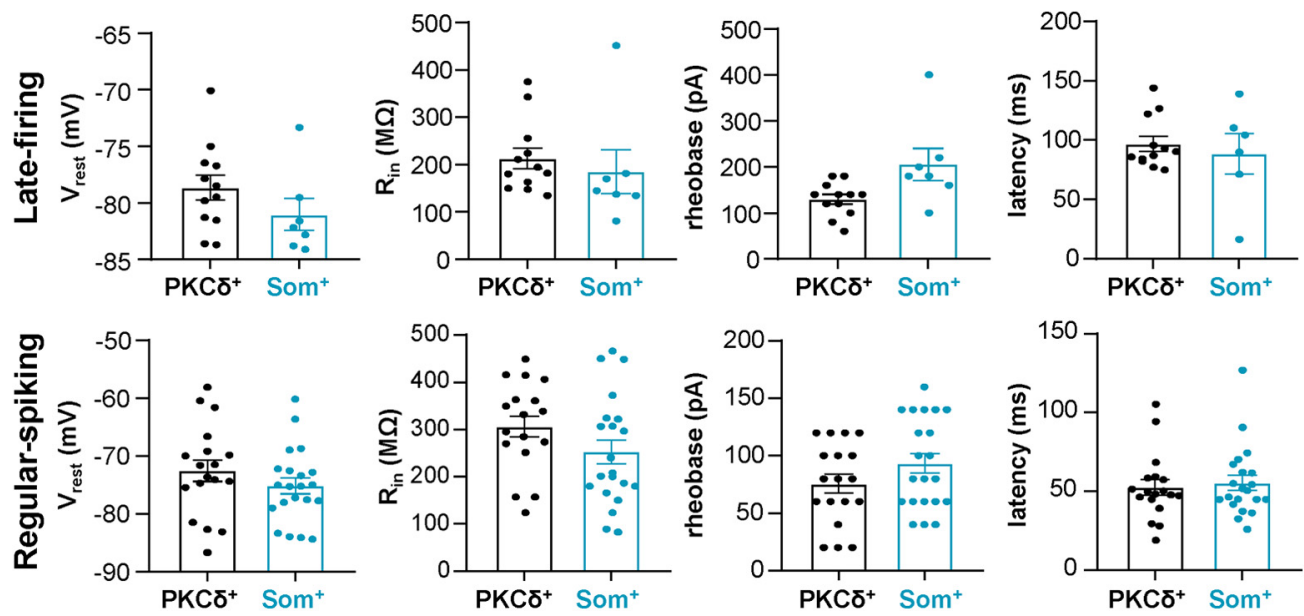

Figure 12. Passive membrane and repetitive firing properties of $\mathrm{PKC} \delta^{+}$and $\mathrm{Som}^{+}$cells following nerve injury. All data are reported as mean \pm SEM. For PKC $\delta^{+}$cells: $n=12$ cells for late-firing and $n=18$ regular-spiking. For Som ${ }^{+}$cells: $n=6-7$ for late-firing and $n=21$ for regular-spiking. $V_{\text {rest }}=$ resting membrane potential; $\mathrm{R}_{\mathrm{in}}=$ input resistance.

differentially contribute to the modulation of multiple behavioral outputs.

\section{Greater output is a common feature of Som ${ }^{+}$CeLC neurons of all firing types}

Previous studies have demonstrated that $\mathrm{PKC} \delta^{+}$and $\mathrm{Som}^{+}$CeLC neurons have distinct, and often opposite, functions in the modulation of behaviors (Janak and Tye, 2015; Kim et al., 2017; Wilson et al., 2019). The cellular features that distinguish these two functionally distinct populations of CeLC neurons, however, are unknown. The results presented here demonstrate that $\mathrm{PKC} \delta^{+}$and $\mathrm{Som}^{+}$neurons are electrophysiologically distinct. Despite the heterogeneity in firing responses in both cell types (Fig. 1), a common and robust feature of all Som ${ }^{+}$CeLC neurons is that they exhibit greater firing responses than $\mathrm{PKC} \delta^{+}$neurons within the same firing type (Figs. 3, 7). This is important because it suggests that the firing responses to input, as well as the overall output of these cells are distinct, demonstrating that information processing is different in $\mathrm{PKC} \delta^{+}$and $\mathrm{Som}^{+}$cells at baseline. Differences in how these cells respond to input might, therefore, contribute to their selective or differential influence on behavioral outputs.

Identifying the source of cell-type-specific differential excitability in the CeLC is a crucial step toward understanding their opposite function. The results from the experiments presented here suggest that there are multiple distinct sources for the cell-type-specific differential excitability of $\mathrm{PKC} \delta{ }^{+}$and $\mathrm{Som}^{+}$CeLC cells. Differences in both passive and active intrinsic membrane properties, for example, seem to drive the relative hyperexcitability in $\mathrm{Som}^{+}$late-firing neurons but do not contribute to the differences in excitability in regular-spiking cells (Figs. 3-6). In contrast, changes in active, but not passive, intrinsic membrane properties seem to underlie the relative hyperexcitability of $\mathrm{Som}^{+}$spontaneously active cells (Fig. 7). The greater $\mathrm{R}_{\text {in }}$, slower repolarization, shorter latencies and lower current thresholds for action potential generation, as well as the lack of ISI accommodation in late-firing Som ${ }^{+}$ neurons (compared with $\mathrm{PKC} \delta^{+}$) are consistent with differences in potassium conductances between these cells. Similarly, the hyperpolarized resting potential of late-firing $\mathrm{Som}^{+}$neurons, relative to late-firing $\mathrm{PKC} \delta{ }^{+}$neurons suggest differences in the resting potassium conductance between these cells. On the other hand, the action potential broadening coupled with slower rise and decay durations and depolarized AHP amplitude in spontaneously active $\mathrm{Som}^{+}$cells (compared with $\mathrm{PKC} \delta^{+}$) suggests that differences in slowly inactivating sodium and fast-activating potassium currents underlie the relative hyperexcitability in these cells. Future investigation of the mechanism underlying the excitability differences between $\mathrm{Som}^{+}$and $\mathrm{PKC} \delta \delta^{+}$ neurons is needed to further our understanding of functional heterogeneity within the CeA.

Our results demonstrate that regular-spiking Som ${ }^{+}$ neurons are also much more excitable than $\mathrm{PKC} \delta{ }^{+}$regular-spiking CeLC cells, but unlike the late-firing neurons, most of the passive and active membrane properties are indistinguishable in these cells (Figs. 3-6). Since synaptic blockers were not used in our experiments, these results suggest that the higher output in regular-spiking Som ${ }^{+}$ neurons could be synaptically driven, which could result from higher excitatory inputs, lower inhibitory inputs, or a combination of both. The lateral and basolateral amygdala, as well as the lateral parabrachial nucleus are sources of excitatory inputs to the CeLC (Bernard and Besson, 1990; Lopez de Armentia and Sah, 2004). Previous work has demonstrated that both Som ${ }^{+}$and Som ${ }^{-}$CeLC cells receive monosynaptic excitatory inputs from these brain regions (Li et al., 2013; Li and Sheets, 2019; Wilson et al., 2019). In all these studies, however, glutamatergic inputs to Som ${ }^{-}$cells are stronger than those to Som ${ }^{+}$neurons in the $\mathrm{CeC}$ (Li et al., 2013; Li and Sheets, 2019). Since $\mathrm{PKC} \delta^{+}$and Som ${ }^{+}$neurons comprise most of the CeLC and are mutually exclusive (Li et al., 2013; Kim et al., 2017; Wilson et al., 2019), it is likely that most of the Som ${ }^{-}$ neurons that receive stronger monosynaptic excitatory inputs are $\mathrm{PKC} \delta^{+}$cells. These results are somewhat 
counterintuitive because $\mathrm{PKC} \delta^{+}$cells show lower excitability than $\mathrm{Som}^{+}$CeLC neurons, suggesting that differences in excitatory inputs do not contribute to higher excitability in $\mathrm{Som}^{+} \mathrm{CeLC}$ neurons. Previous reports show, however, that $\mathrm{PKC} \delta{ }^{+}$and $\mathrm{Som}{ }^{+}$CeLC neurons are interconnected and inhibit each other (Haubensak et al., 2010; Hunt et al., 2017), raising the possibility that differences in inhibitory inputs at the microcircuit level might contribute to the higher output of $\mathrm{Som}^{+}$CeLC neurons. An important variable to consider when trying to integrate the results of the present study with the results of the synaptic studies mentioned above is that the experiments described here were conducted in the dark phase of the cycle, whereas the synaptic experiments referenced above were performed in the light phase of the cycle. This is particularly important given recent work demonstrating that the sleep-wake state of an animal influences the activity of CeLC neurons (Ma et al., 2019). Defining the intrinsic and synaptic mechanisms underlying the differences in excitability between genetically distinct cells in the CeLC will be essential to fully understand their differential function in the modulation of behaviors.

\section{Cell-type-specific morphology as a predictor of function}

CeLC neurons have been morphologically defined as medium spiny neurons with heterogeneous dendritic branching complexities (Martina et al., 1999; Schiess et al., 1999; Chieng et al., 2006). Our biocytin-based morphologic reconstruction of $\mathrm{PKC} \delta^{+}$and $\mathrm{Som}^{+}$CeLC neurons revealed distinct morphologic features in these cells (Fig. 8). These results are surprising given the heterogeneous firing phenotypes of these genetically distinct populations of cells (Fig. 1) but, at the same time, are consistent with previous studies that have failed to correlate morphologic properties of CeLC neurons with firing phenotypes (Schiess et al., 1999; Chieng et al., 2006; Amano et al., 2012).

The two common distinguishing features we found between $\mathrm{Som}^{+}$and $\mathrm{PKC} \delta^{+}$CeLC neurons are their morphology and relative excitability. Thus, $\mathrm{Som}^{+}$neurons are more compact, with lower whole-cell capacitance, a more complex dendritic branching pattern and a much greater overall firing output. $\mathrm{PKC} \delta{ }^{+}$neurons, in contrast, have fewer (but longer) dendrites, higher whole-cell capacitance and a much lower overall firing output than Som ${ }^{+}$ neurons (Figs. 3, 10, Movies 1 and 2).

Previous studies have shown similar correlations between morphology and excitability in striatal medium spiny and cortical pyramidal neurons (Gertler et al., 2008; van der Velden et al., 2012). Thus, neurons expressing the D2 dopamine receptor are compact, have lower wholecell capacitance and are more excitable, (similar to our $\mathrm{Som}^{+}$neurons) than those expressing the D1 receptor (Gertler et al., 2008). Similar to our findings in Som ${ }^{+}$ CeLC neurons, in the apical dendrite of layer $2 / 3$ pyramidal neurons, higher dendritic branching complexities have been reported to correlate with greater excitability (van der Velden et al., 2012). Moreover, in cortical pyramidal neurons, higher complexity of dendritic branching complexity was shown to increase excitability by reducing
ISI accommodation, which is consistent with the lack of ISI accommodation we see in Som ${ }^{+}$neurons (Fig. 5). Together, these results demonstrate that cell-type-specific morphology is an important determinant of neuronal excitability in $\mathrm{PKC} \delta^{+}$and $\mathrm{Som}^{+}$CeLC neurons and can be used as a predictor of function in the $\mathrm{CeA}$.

\section{Pain-related changes in excitability exemplify the ability of $\mathrm{PKC} \delta^{+}$and $\mathrm{Som}^{+}$CeLC to undergo robust plasticity \\ Our cell-type-specific characterization of $\mathrm{PKC} \delta^{+}$and} $\mathrm{Som}^{+}$cells in the CeLC demonstrated that the overall output of these two genetically distinct populations is different at baseline (Fig. 3). In the context of pain, however, we found that these differences were occluded (Fig. 11), highlighting the power of these cells to undergo plasticity. Our findings suggest that a disruption in the excitability equilibrium of $\mathrm{PKC} \delta^{+}$and $\mathrm{Som}^{+}$neurons, driven by an increase in $\mathrm{PKC} \delta^{+}$neuronal excitability, can lead to CeLC-mediated pathologic states. Similar to the properties at baseline, whether these cell-type-specific injury-induced changes are generalizable across species, development, sex or other types of pain (i.e., inflammatory, visceral, cancer) and timepoints after injury remains unknown. Similarly, it will be important to determine whether the relative excitability of these cells is differently affected in other behavioral contexts (i.e., food seeking behaviors, fear, drug reward and relapse, etc.).

\section{Biological and methodological considerations}

Multiple studies have previously described the intrinsic membrane and morphologic properties of unidentified CeA neurons (Martina et al., 1999; Schiess et al., 1999; Dumont et al., 2002; Lopez de Armentia and Sah, 2004; Chieng et al., 2006; Amano et al., 2012). While our results in genetically distinct $\mathrm{CeA}$ cells are mostly consistent with previous results in unidentified neurons, there are some notable differences. For example, while previous studies report low-threshold bursting neurons in the $\mathrm{CeA}$ (Dumont et al., 2002; Haubensak et al., 2010; Hunt et al., 2017; Li and Sheets, 2018), we did not encounter any low-threshold bursting cell in our recordings. A second important difference between our study and previous reports is that $\operatorname{PKC} \delta^{+}$neurons have been previously described as mostly late-firing neurons in mice (Haubensak et al., 2010), whereas we see clear heterogeneity in the firing types of these cells (Fig. 1), consistent with previous reports in rats (Amano et al., 2012).

These apparent discrepancies might stem from differences in the light/dark cycle stage used, as discussed in detail above. Previous studies have shown that an additional important source of between-studies variability in slice physiology experiments is the specific experimental conditions used, such as composition of solutions used while prepping the slices and during recordings as well as the temperature of recordings (Avegno et al., 2019). Biological variables, such as animal model species, sex and age have also been shown to strongly influence intrinsic membrane properties (Dumont et al., 2002). Biological and 
methodological differences between studies may, therefore, account for the between-studies differences. Whether the differences in the properties of $\mathrm{PKC} \delta \delta^{+}$and $\mathrm{Som}^{+} \mathrm{CeA}$ cells that we report here are translatable to other animal species, females, different developmental stage and light phase of the light/dark cycle remains to be determined. An additional methodological consideration to keep in mind when interpreting the results presented here is that neuronal output was measured in response to depolarizing current injected directly into the cells. Future studies evaluating the output of $\mathrm{PKC} \delta^{+}$and $\mathrm{Som}^{+} \mathrm{CeA}$ to synaptic stimulations will be needed to get a full picture of the distinguishing biological features of these cells.

Lateralization of function in the $\mathrm{CeA}$ in the context of pain has been previously described (Carrasquillo and Gereau, 2007; Ji and Neugebauer, 2009; Allen et al., 2020). Most CeA studies either indiscriminately use either side of the brain and pool the data or do not report the side of the brain used in the experiments. For this reason, whether the electrophysiological and morphologic properties of $\mathrm{CeA}$ neurons, as well as the anatomic distribution of genetically distinct cells within the $\mathrm{CeA}$ varies as a function of the side of the brain remains unknown. The experiments described here were all performed in the right amygdala and the nerve injuries in the contralateral (left) sciatic nerve.

A final important source of between-studies variability might be the mathematical definition (or lack of reported definition) of the electrophysiological parameters measured and the criteria used for firing type classification. One of the strengths in the present study is the development, use and report of mathematical definitions for all parameters measured and for the classification of firing types. Use and report of mathematical definitions in future studies will facilitate comparison of findings between reports and labs.

\section{Concluding remarks}

Together, the findings described here demonstrate that genetically distinct CeLC neurons display celltype-specific differences in firing output and dendritic morphology. These results support the distinct, and often opposite, contribution of $\mathrm{PKC} \delta{ }^{+}$and $\mathrm{Som}^{+} \mathrm{CeLC}$ neurons in the modulation of specific behavioral outputs and set the foundation for future studies aimed at identifying the cellular mechanisms driving heterogeneity of function in the CeA.

\section{References}

Aggleton JP (2000) The amygdala: a functional analysis. New York: Oxford University Press.

Allen H, Bobnar H, Kolber BK (2020) Left and right hemispheric lateralization of the amygdala in pain. Prog Neurobiol. Advance online publication. Retrieved July 28, 2020. doi: 10.1016/j. pneurobio.2020.101891.

Amano T, Amir A, Goswami S, Paré D (2012) Morphology, PKC $\delta$ expression, and synaptic responsiveness of different types of rat central lateral amygdala neurons. J Neurophysiol 108:3196-3205.

Avegno EM, Middleton JW, Gilpin NW (2019) Synaptic GABAergic transmission in the central amygdala $(\mathrm{CeA})$ of rats depends on slice preparation and recording conditions. Physiol Rep 7:e14245.
Bean BP (2007) The action potential in mammalian central neurons. Nat Rev Neurosci 8:451-465.

Benbouzid M, Pallage V, Rajalu M, Waltisperger E, Doridot S, Poisbeau P, Freund-Mercier MJ, Barrot M (2008) Sciatic nerve cuffing in mice: a model of sustained neuropathic pain. Eur $\mathrm{J}$ Pain 12:591-599.

Bernard JF, Besson JM (1990) The spino(trigemino)pontoamygdaloid pathway: electrophysiological evidence for an involvement in pain processes. J Neurophysiol 63:473-490.

Carrasquillo Y, Gereau RW IV (2007) Activation of the extracellular signal-regulated kinase in the amygdala modulates pain perception. J Neurosci 27:1543-1551.

Chieng BC, Christie MJ, Osborne PB (2006) Characterization of neurons in the rat central nucleus of the amygdala: cellular physiology, morphology, and opioid sensitivity. J Comp Neurol 497:910-927.

Choi Y, Yoon YW, Na HS, Kim SH, Chung JM (1994) Behavioral signs of ongoing pain and cold allodynia in a rat model of neuropathic pain. Pain 59:369-376.

Ciocchi S, Herry C, Grenier F, Wolff SB, Letzkus JJ, Vlachos I, Ehrlich I, Sprengel R, Deisseroth K, Stadler MB, Müller C, Lüthi A (2010) Encoding of conditioned fear in central amygdala inhibitory circuits. Nature 468:277-282.

Colburn RW, Lubin ML, Stone DJ Jr, Wang Y, Lawrence D, D'Andrea MR, Brandt MR, Liu Y, Flores CM, Qin N (2007) Attenuated cold sensitivity in TRPM8 null mice. Neuron 54:379-386.

Connors BW, Regehr WG (1996) Neuronal firing: does function follow form? Curr Biol 6:1560-1562.

Costantini I, Ghobril JP, Di Giovanna AP, Allegra Mascaro AL, Silvestri L, Müllenbroich MC, Onofri L, Conti V, Vanzi F, Sacconi L, Guerrini R, Markram H, lannello G, Pavone FS (2015) A versatile clearing agent for multi-modal brain imaging. Sci Rep 5:9808.

Davis M, Whalen PJ (2001) The amygdala: vigilance and emotion. Mol Psychiatry 6:13-34.

Dumont EC, Martina M, Samson RD, Drolet G, Paré D (2002) Physiological properties of central amygdala neurons: species differences. Eur J Neurosci 15:545-552.

Franklin KBJ, Paxinos G (2008) The mouse brain in stereotaxic coordinates. Boston: Elsevier/Academic Press.

Gertler TS, Chan CS, Surmeier DJ (2008) Dichotomous anatomical properties of adult striatal medium spiny neurons. J Neurosci 28:10814-10824.

Gilpin NW, Herman MA, Roberto M (2015) The central amygdala as an integrative hub for anxiety and alcohol use disorders. Biol Psychiatry 77:859-869.

Gong S, Zheng C, Doughty ML, Losos K, Didkovsky N, Schambra UB, Nowak NJ, Joyner A, Leblanc G, Hatten ME, Heintz N (2003) A gene expression atlas of the central nervous system based on bacterial artificial chromosomes. Nature 425:917-925.

Gong S, Doughty M, Harbaugh CR, Cummins A, Hatten ME, Heintz N, Gerfen CR (2007) Targeting Cre recombinase to specific neuron populations with bacterial artificial chromosome constructs. J Neurosci 27:9817-9823.

Han S, Soleiman MT, Soden ME, Zweifel LS, Palmiter RD (2015) Elucidating an affective pain circuit that creates a threat memory. Cell 162:363-374.

Hargreaves K, Dubner R, Brown F, Flores C, Joris J (1988) A new and sensitive method for measuring thermal nociception in cutaneous hyperalgesia. Pain 32:77-88.

Haubensak W, Kunwar PS, Cai H, Ciocchi S, Wall NR, Ponnusamy R, Biag J, Dong HW, Deisseroth K, Callaway EM, Fanselow MS, Luthi A, Anderson DJ (2010) Genetic dissection of an amygdala microcircuit that gates conditioned fear. Nature 468:270-276.

He M, Liu Y, Wang X, Zhang MQ, Hannon GJ, Huang ZJ (2012) Celltype-based analysis of microRNA profiles in the mouse brain. Neuron 73:35-48.

Hunt S, Sun Y, Kucukdereli H, Klein R, Sah P (2017) Intrinsic circuits in the lateral central amygdala. eNeuro 4.

Hurst JL, West RS (2010) Taming anxiety in laboratory mice. Nat Methods 7:825-826. 
Janak PH, Tye KM (2015) From circuits to behaviour in the amygdala. Nature 517:284-292.

Ji G, Neugebauer V (2009) Hemispheric lateralization of pain processing by amygdala neurons. J Neurophysiol 102:2253-2264.

Kim J, Zhang X, Muralidhar S, LeBlanc SA, Tonegawa S (2017) Basolateral to central amygdala neural circuits for appetitive behaviors. Neuron 93:1464-1479.e5.

Li H, Penzo MA, Taniguchi H, Kopec CD, Huang ZJ, Li B (2013) Experience-dependent modification of a central amygdala fear circuit. Nat Neurosci 16:332-339.

Li JN, Sheets PL (2018) The central amygdala to periaqueductal gray pathway comprises intrinsically distinct neurons differentially affected in a model of inflammatory pain. J Physiol 596:6289-6305.

Li JN, Sheets PL (2019) Spared nerve injury differentially alters parabrachial monosynaptic excitatory inputs to molecularly specific neurons in distinct subregions of the central amygdala. Pain 161:166-176.

Lopez de Armentia M, Sah P (2004) Firing properties and connectivity of neurons in the rat lateral central nucleus of the amygdala. $J$ Neurophysiol 92:1285-1294.

Ma C, Zhong P, Liu D, Barger ZK, Zhou L, Chang WC, Kim B, Dan Y (2019) Sleep regulation by neurotensinergic neurons in a thalamoamygdala circuit. Neuron 103:323-334.e7.

Mainen ZF, Sejnowski TJ (1996) Influence of dendritic structure on firing pattern in model neocortical neurons. Nature 382:363-366.

Martina M, Royer S, Paré D (1999) Physiological properties of central medial and central lateral amygdala neurons. J Neurophysiol 82:1843-1854.

McCullough KM, Morrison FG, Hartmann J, Carlezon WA Jr, Ressler KJ (2018) Quantified coexpression analysis of central amygdala subpopulations. eNeuro 5.

Neugebauer V, Li W, Bird GC, Han JS (2004) The amygdala and persistent pain. Neuroscientist 10:221-234.

Paxinos G, Franklin KBJ, Franklin KBJ (2001) The mouse brain in stereotaxic coordinates. San Diego: Academic Press.

Schiess MC, Callahan PM, Zheng H (1999) Characterization of the electrophysiological and morphological properties of rat central amygdala neurons in vitro. J Neurosci Res 58:663-673.
Stiefel KM, Sejnowski TJ (2007) Mapping function onto neuronal morphology. J Neurophysiol 98:513-526.

Swietek B, Gupta A, Proddutur A, Santhakumar V (2016) Immunostaining of biocytin-filled and processed sections for neurochemical markers. J Vis Exp (118):54880.

Taniguchi H, He M, Wu P, Kim S, Paik R, Sugino K, Kvitsiani D, Kvitsani D, Fu Y, Lu J, Lin Y, Miyoshi G, Shima Y, Fishell G, Nelson SB, Huang ZJ (2011) A resource of Cre driver lines for genetic targeting of GABAergic neurons in cerebral cortex. Neuron 71:9951013.

van der Velden L, van Hooft JA, Chameau P (2012) Altered dendritic complexity affects firing properties of cortical layer $2 / 3$ pyramidal neurons in mice lacking the 5-HT3A receptor. J Neurophysiol 108:1521-1528.

Veinante P, Yalcin I, Barrot M (2013) The amygdala between sensation and affect: a role in pain. $\mathrm{J}$ Mol Psychiatry 1:9.

Venniro M, Caprioli D, Zhang M, Whitaker LR, Zhang S, Warren BL, Cifani C, Marchant NJ, Yizhar O, Bossert JM, Chiamulera C, Morales M, Shaham Y (2017) The anterior insular cortex->central amygdala glutamatergic pathway is critical to relapse after contingency management. Neuron 96:414-427 e418.

Venniro M, Zhang M, Caprioli D, Hoots JK, Golden SA, Heins C, Morales M, Epstein DH, Shaham Y (2018) Volitional social interaction prevents drug addiction in rat models. Nat Neurosci 21:15201529.

Wilson TD, Valdivia S, Khan A, Ahn HS, Adke AP, Gonzalez SM, Sugimura YK, Carrasquillo Y (2019) Dual and opposing functions of the central amygdala in the modulation of pain. Cell Rep 29:332-346.e5.

Yu K, Garcia da Silva P, Albeanu DF, Li B (2016) Central amygdala somatostatin neurons gate passive and active defensive behaviors. J Neurosci 36:6488-6496.

Zald DH (2003) The human amygdala and the emotional evaluation of sensory stimuli. Brain Res Brain Res Rev 41:88-123.

Zhu W, Pan ZZ (2004) Synaptic properties and postsynaptic opioid effects in rat central amygdala neurons. Neuroscience 127:871879. 